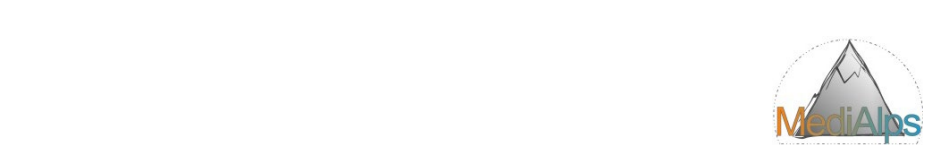

Final report

Disentangling anthropogenic drivers of climate change impacts on alpine plant species: Alps vs. Mediterranean mountains

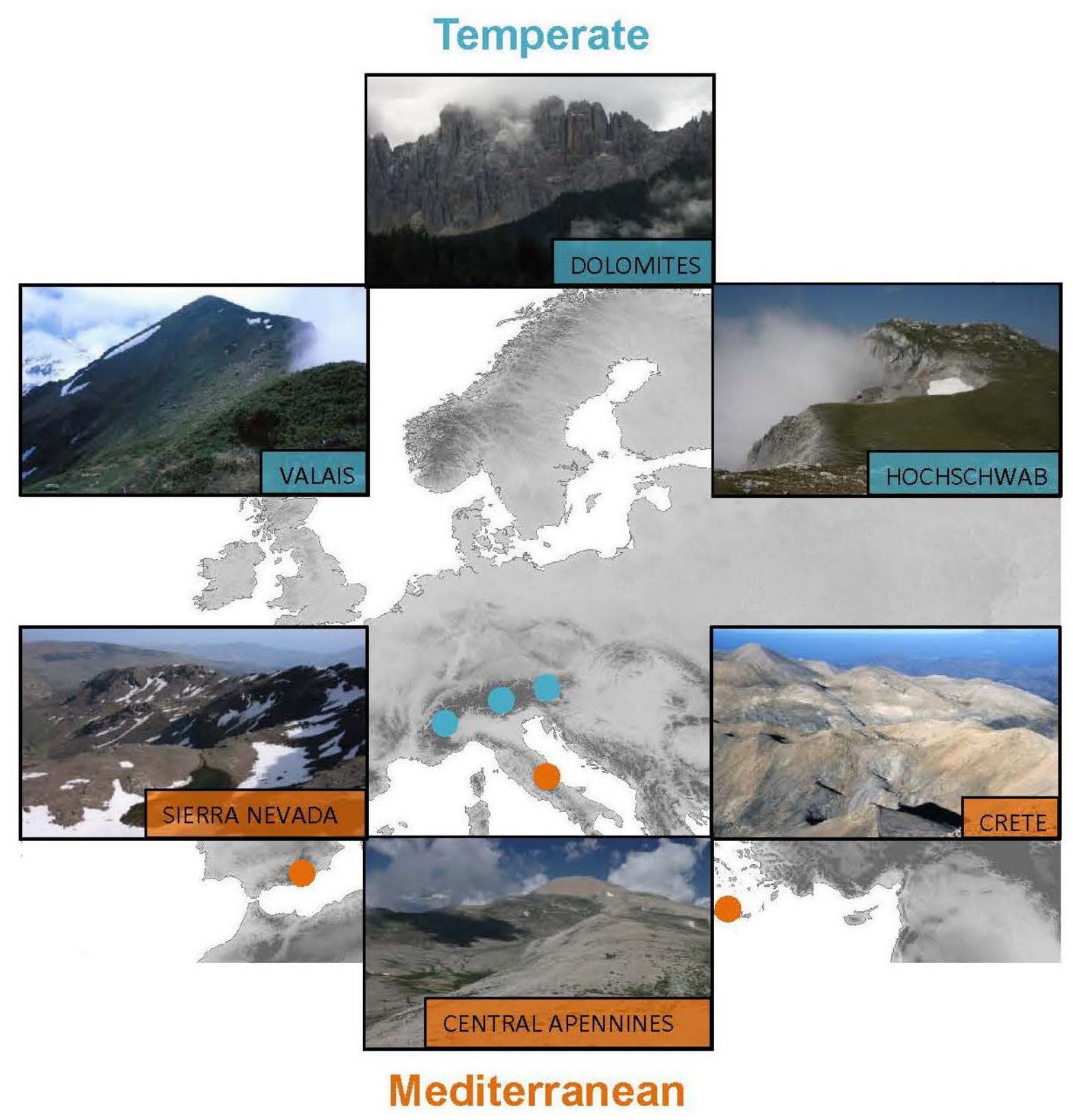

Vienna, February 2019

ISBN-Online: 978-3-7001-8469-0

DOI: 10.1553/ESS-MEDIALPS

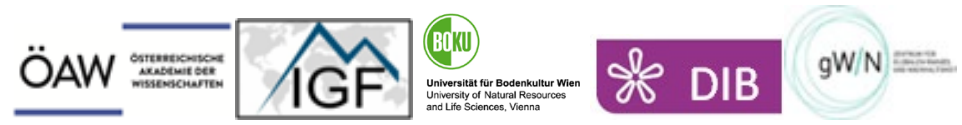


Andrea Lamprecht ${ }^{1}$, Martin Rutzinger ${ }^{2}$, Harald Pauli ${ }^{1}$, Manfred BardyDurchhalter ${ }^{1}$, Katrin Euller ${ }^{1}$, Robert Niederheiser ${ }^{2}$, Klaus Steinbauer ${ }^{1}$, Katrin Wilfing $^{1}$, Brigitta Erschbamer ${ }^{3}$, Rosa Fernández Calzado ${ }^{4}$, Valter Di Cecco ${ }^{5}$, Andreas Gattringer ${ }^{6}$, George Kazakis ${ }^{7}$, Martin Mallaun ${ }^{3}$, Joaquín Molero Mesa ${ }^{4}$, Dietmar Moser ${ }^{6}$, Hlektra Remoundou ${ }^{7}$, Angela Stanisci ${ }^{8}$, Jean-Paul Theurillat ${ }^{9,10}$, Pascal Vittoz ${ }^{11}$, Johannes Wessely ${ }^{6}$ \& Manuela Winkler ${ }^{1}$

1 GLORIA co-ordination, Austrian Academy of Sciences, Institute for Interdisciplinary Mountain Research \& University of Natural Resources and Life Sciences Vienna (BOKU), Department of Integrative Biology and Biodiversity Research; Vienna, Austria

${ }^{2}$ Austrian Academy of Sciences, Institute of Interdisciplinary Mountain Research; Innsbruck, Austria

${ }^{3}$ University of Innsbruck, Institute of Botany; Innsbruck, Austria

${ }^{4}$ University of Granada, Department of Botany; Granada, Spain

${ }^{5}$ Majella National Park, Majella Seed Bank; Lama dei Peligni, Italy

${ }^{6}$ University of Vienna, Division of Conservation Biology, Vegetation Ecology and Landscape Ecology (CVL); Vienna, Austria

${ }^{7}$ Mediterranean Agronomic Institute of Chania (MAICH), Department of Geo-information in Environmental Management, Chania, Greece

${ }^{8}$ University of Molise, Department of Bioscience and Territory; Termoli, Italy

${ }^{9}$ Centre alpien de Phytogéographie, Fondation J-M. Aubert; Champex-Lac, Switzerland

${ }^{10}$ University of Geneva, Section of Biology, Chambésy, Switzerland

${ }^{11}$ University of Lausanne, Institute of Earth Surface Dynamics; Lausanne, Switzerland

Funded by

Research Program "Earth System Sciences (ESS)"

Austrian Academy of Sciences

March 2015 - February 2019 
1.1 ObJeCtives OF THE OUtLINED PROJeCt 5

$\underline{2}$ STUDY REGIONS AND SAMPLING DESIGN

2.1 STUDY REgIONS

2.2 SAMPLING DESIGN

$\begin{array}{lll}2.2 .1 & \text { TERRESTRIAL PHOTOGRAMMETRY } & 10\end{array}$

$\underline{3}$ POTENTIAL DRIVERS OF CHANGES IN BIODIVERSITY AND PLANT SPECIES COMPOSITION 10

\begin{tabular}{lr}
3.1 & Climatic Factors \\
\hline
\end{tabular}

$\begin{array}{ll}3.1 .1 & 10\end{array}$

$\begin{array}{ll}\text { 3.1.2 WATER POTENTIAL AND PRECIPITATION } & 11\end{array}$

3.1.3 POLLUtion: NitRogen DEPOSITION 13

\begin{tabular}{ll}
3.2 & LAND-USE \\
\hline
\end{tabular}

3.2.1 GRAZING INDICES IN THE 1M² QUADRATS AND SUMMIT AREA SECTIONS 17

\begin{tabular}{ll}
3.2 .2 & SYSTEMATIC OBSERVATIONS \\
\hline
\end{tabular}

$\begin{array}{ll}\text { 3.2.3 HISTORICAL DIMENSIONS: QUALITATIVE INTERVIEWS } & 17\end{array}$

\begin{tabular}{ll}
3.2 .4 & LAND-USE IN THE MEDIALPS REGIONS \\
\hline
\end{tabular}

$\begin{array}{lll}3.2 .4 .1 & \text { ES-SNE } & 21\end{array}$

$\begin{array}{ll}3.2 .4 .2 & 23\end{array}$

$\begin{array}{ll}3.2 .4 .3 \text { GR-LEO } & 24\end{array}$

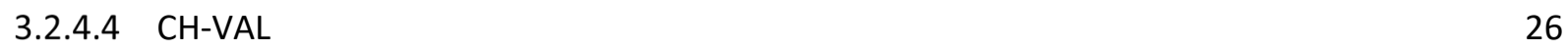

$\begin{array}{ll}3.2 .4 .5 & 28\end{array}$

$\begin{array}{llr}3.2 .4 .6 & \text { AT-HSW } & 29\end{array}$

$\begin{array}{lll}3.3 & \text { MiCROTOPOGRAPHY } & 30\end{array}$

3.3.1 MAPPING HIGH-RESOLUTION TOPOGRAPHY AND VEGETATION COVER 30

3.4 SOLAR IRRADIATION

4 SPATIOTEMPORAL DYNAMICS AND CHANGES IN BIODIVERSITY AND PLANT SPECIES COMPOSITION

4.1 REMOTE SENSING AND SPATIOTEMPORAL ANALYSIS

$\begin{array}{lll}4.2 & \text { PhenOLOGY } & 33\end{array}$

4.3 CHANGES IN PLANT BIODIVERSITY AND SPECIES COMPOSITION 34

4.3.1 CHANGES IN SPECIES RICHNESS

4.3.2 CHANGES IN VASCULAR PLANT COVER AND COMPOSITION

$\underline{\mathbf{5}}$ SYNTHESIS - INFLUENCE OF CLIMATE, LAND-USE, NITROGEN DEPOSITION, SOLAR IRRADIATION AND MICROTOPOGRAPHIC VARIABILITY ON CHANGES IN SPECIES RICHNESS AND COMPOSITION 37

5.1 SPECIES RICHNESS AND CHANGES IN SPECIES RICHNESS 


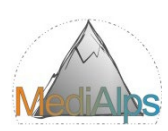

\section{Abstract}

Global warming has been strongly accelerating in the last decades. Climate models tell us that this trend will continue in the future, accompanied by a marked decline in precipitation in Southern Europe, whereas the Alps will likely receive more winter and less summer precipitation. Climate factors and additionally nitrogen deposition and land-use changes have been identified as global change factors posing threats on high-mountain biodiversity, ecosystem stability and services. On the other hand, the characteristic micro-topographic variability of high mountain ecosystems may buffer them against global change impacts. Monitoring data from European mountain peaks show that changes in biodiversity patterns are closely related to rising temperatures. However, the effects of climate change on plant biodiversity differ significantly between temperate and Mediterranean biomes with species richness increases synchronously with warming in the former and richness decreases in the latter.

The MediAlps project aimed at disentangling anthropogenic and natural factors underlying differential changes in plant species composition and richness observed on mountain summits in the European Alps and the Mediterranean biome at the local and regional spatial scale. Changes in plant species richness and composition and present land-use impact based on systematic field observations were recorded on long-term monitoring plots on 23 summits. Soil temperature, water potential and local dry nitrogen deposition were measured in situ. Topographic parameters were recorded with photogrammetric methods. At the regional level, climate data and regional nitrogen deposition data from online resources (CHELSA, EMEP) were used and past land-use impact was assessed via guideline-aided semi-structured interviews. (Generalized) linear mixed-effects models and structural equation models (SEM) were employed to assess the impact of these drivers on biodiversity changes. Furthermore, spatio-temporal analyses based on satellite images were conducted.

Climate change is and will probably continue to be the main driver of plant biodiversity, species composition and their changes on mountain summits in both biomes. However, there are biomespecific differences with precipitation playing an important role in the Mediterranean biome in addition to temperature, which clearly is the most important single factor in the temperate biome. These changes will likely lead to a further thermophilisation in both biomes. The upwards movement of species from lower elevations will likely also result in a biotic homogenization of the vegetation, exacerbated by the decline of high-elevation endemic species. Species richness will likely continue to increase in the temperate biome until the "pay-off" of extinction debts or threshold effects of population size on extinction risks set in. With decreasing precipitation species richness in the Mediterranean biome will probably decline in the long run, too.

Nevertheless, other anthropogenic drivers have to be considered as well, although their influence is arguably much smaller than that of climate variables, namely nitrogen deposition with a negative influence on species richness change in the temperate biome and present land-use with a positive one in the Mediterranean biome.

In addition to MediAlps' main focus on comparing multiple anthropogenic ecological drivers in the Alps with the Mediterranean mountains, the project substantially contributed to a spatially larger scaled long-term observation effort in the frame of the GLORIA (Global Observation Research Initiative in Alpine Environments) program. 


\section{Zusammenfassung}

Die globale Erwärmung hat sich in den letzten Jahrzehnten stark beschleunigt - ein Trend der laut Klimamodellen auch in Zukunft anhalten wird. Der Temperaturanstieg wird in Südeuropa von einem Rückgang der Niederschläge begleitet werden, während in den Alpen die Winterniederschläge zuund die Sommerniederschläge abnehmen werden. Neben dem Klimawandel stellen auch Stickstoffdeposition und Landnutzungsänderungen eine Bedrohung für Hochgebirgsökosysteme, deren Biodiversität und Ökosystemleistungen dar. Andererseits bietet die für Hochgebirge charakteristische mikrotopographische Variabilität eine gewisse Pufferfunktion gegenüber den Auswirkungen des globalen Wandels. Monitoringdaten von europäischen Gipfeln zeigen unterschiedliche Auswirkungen des Klimawandels auf die Diversität in temperaten und mediterranen Gebieten: während in ersteren die Artenzahlen auf den Gipfeln synchron mit der Temperatur zunehmen, war im Mediterranraum eine Abnahme der Pflanzendiversität zu verzeichnen.

Ziel des MediAlps Projekts ist die Abschätzung des relativen Effekts dieser Komponenten des globalen Wandels und deren Interaktionen auf die beobachteten Biodiversitätsveränderungen auf mediterranen und temperaten Gipfeln. Änderungen in Artenzahl und -zusammensetzung in Langzeitmonitoringuntersuchungsflächen sowie der derzeitige Landnutzungsdruck basierend auf systematischen Feldbeobachtungen wurden erhoben. In den Untersuchungsflächen wurden Bodentemperatur, Wasserpotential und Stickstoffdeposition gemessen. Mit Hilfe von photogrammetrischen Methoden wurden topographische Parameter erhoben. Regionale Temperatur-, Niederschlags- und N-Depositionsdaten aus Online-Ressourcen (CHELSA, EMEP) wurden für Analysen herangezogen. Die Landnutzungsintensität in der Vergangenheit wurde mittels semi-qualitativer Interviews erhoben. Mit gemischten Modellen (generalized linear mixed-effects models) und Strukturgleichungsmodellen (SEM) wurde der Einfluss der einzelnen Faktoren auf Biodiversitätsänderungen analysiert. Zusätzlich wurde die raumzeitliche Dynamik basierend auf Satellitenbilddaten analysiert.

Klimatische Faktoren und Klimawandel sind die wichtigsten Einflussfaktoren auf Diversität, Artenzusammensetzung und deren Änderungen in den untersuchten Hochgebirgsökosystemen beider Biome. Temperatur(änderung) ist der bestimmende Faktor im temperaten Biom, während auf mediterranen Gipfeln zusätzlich Niederschlagssummen eine Rolle spielen. Eine weitere Thermophilisierung der Vegetation ist in beiden Biomen zu erwarten, einhergehend mit einer Vereinheitlichung der Artenzusammensetzung bedingt durch das Höherwandern von Arten tieferer Lagen. Mittelfristig wird die Diversität auf den Alpengipfeln wahrscheinlich weiter zunehmen, bis die sogenannte „Aussterbeschuld“ (extinction debt) schlagend wird und langlebige, kälteliebende Arten lokal verschwinden. Mit abnehmenden Niederschlagssummen werden auch die Pflanzenartenzahlen auf mediterranen Gipfeln zurückgehen. Nichtsdestotrotz ist auch der - wenn auch vergleichsweise geringe - Einfluss anderer anthropogener Faktoren zu berücksichtigen: Stickstoffdeposition hat einen negativen Einfluss auf Änderungen der Artenzahl im temperaten Biom und die derzeitige Landnutzungsintensität einen positiven Einfluss auf mediterranen Gipfeln.

Darüber hinausgehend leistete das MediAlps Projekt einen substantiellen Beitrag zum weltweiten Langzeitmonitoring-Programm GLORIA (Global Observation Research Initiative in Alpine Environments). 


\section{INTRODUCTION}

Globally, ecosystems have been increasingly exposed directly and indirectly to anthropogenic influences during the last decades. Mountain ecosystems are especially prone to suffer from effects of increasing temperature and changes in the water balance (e.g. Broll and Keplin 2005, Körner and Spehn 2002, Steinbauer et al. 2018, Theurillat and Guisan 2001). In addition, nitrogen deposition and land-use changes have been identified as global change factors posing threats on high-mountain biodiversity, ecosystem stability and services (Körner 2000, Nagy and Grabherr 2009, Sala et al. 2000). Ecosystem services provided by high-mountain ecosystems include slope stability, clean water provision and flood prevention not only on the mountain regions themselves but also for huge areas of the surrounding lowlands. The stability of high-mountain soils is crucial for water retention (Becker et al. 2007). Soil and thus slope stability depend on the presence of a persistent vegetation cover with slow-growing, deeply-rooted and stress-resistant plants (Körner 2000) that can be drastically reduced or changed by increased human pressure, such as land-use change (e.g. infrastructure construction, deforestation, overgrazing or trampling; Rosenzweig 2007, Turalioglu et al. 2005).

High biodiversity buffers against functionality losses of ecosystems with respect to natural or anthropogenic disturbances, because high species diversity also implies a high diversity of functional response types (Isbell et al. 2015, Mace et al. 2012). However, the pace and extent of ongoing global change may even outstrip the resilience of well-buffered highly diverse ecosystems (Mooney et al. 2009). Assessments of biodiversity responses to each single global change driver and, even more important, their combined effects are thus crucial.

Global mean surface temperature has been strongly rising in the last decades, accelerating since 2001 when seventeen of the eighteen warmest years in the 136-year record have occurred (Earth Science Communications Team 2018). According to climate models projections, this trend will continue: a further increase in global average temperature between 1.0 and $3.7^{\circ} \mathrm{C}$ until 2100 compared to the period 1986-2005 is forecasted (Stocker et al. 2013). Climate warming is more pronounced at higher latitudes and higher elevations, e.g. the European Alps are experiencing a much stronger temperature increase than the global average (Mountain Research Initiative EDW Working Group 2015, Ohmura 2012, Wang et al. 2016b). Besides direct effects, increased temperature leads to drier conditions due to enhanced rates of evapotranspiration. In addition, reduced snowfall and earlier snowmelt can further diminish water availability, especially in regions where aridity during summer is already a restraining factor (e.g. in the Mediterranean biome of 
Europe). Moreover, climate change scenarios predict a marked decline in precipitation by the end of the $21^{\text {st }}$ century in Southern Europe, which is expected to strongly affect Mediterranean mountain vegetation, whereas the Alps will likely receive more winter and less summer precipitation (Fronzek et al. 2012, Nogues-Bravo et al. 2007). Generally, Europe's biomes are subjected to different climate change scenarios: The largest warming in northern Europe is predicted in winter, in the Mediterranean area in summer. Mean precipitation is projected to rise in northern Europe, especially in winter, whereas less precipitation is anticipated throughout the year in southern Europe and mostly in summer in central Europe (Christensen et al. 2007).

Monitoring data from European mountain peaks show that changes in biodiversity patterns are closely related to rising temperatures. However, the effects of climate change on local distribution patterns of plant species differ significantly between boreal/temperate and Mediterranean biomes. While in central and northern European mountain areas the number of species has increased synchronously with global warming (Pauli et al. 2012, Steinbauer et al. 2018), the Mediterranean mountains seem to follow a contrary trend, showing a decrease in species richness (Pauli et al. 2012). As probable reason a decrease in water availability was assumed, based on a decrease in precipitation in spring and early summer (Giménez-Benavides et al. 2018), and reinforced by effects of increasing temperature. Even if there is no significant change in precipitation, integrated effects of increasing soil temperature and decreasing soil moisture can cause declines in species richness (Niu et al. 2019). However, in both Mediterranean as well as temperate/boreal biomes, species with their center of distribution in lower areas (i.e. more thermophilic plants) have increased in frequency or abundance in relation to high-altitude species (i.e. more cold-adapted or more cryophilic species; Gottfried et al. 2012), which suggests that the net species loss on the Mediterranean summits resulted from losses of cryophilic species. Such an ongoing directional change of species composition (i.e. thermophilisation) was documented in the Mediterranean mountains of the central Apennines (Majella, Italy), resulting from both a significant increase of more thermophilic plants and a local decrease of several cryophilic species (Evangelista et al. 2016). In the Southern Alps (Dolomites, Italy), cryophilic species remained more or less stable so that observed thermophilisation effects were mostly due to colonization of montane species, which signaled an upward shift of the tree line within the first decade of the century (Erschbamer et al. 2011). In high elevations of the Central Alps (alpine-nival ecotone of Mount Schrankogel, Austria) thermophilisation between 1994 and 2004 was found to having been of similar magnitude as the European average for the timespan 2001-2008, but accelerated significantly between 2004 and 2014 (Lamprecht et al. 2018). This study also exemplified that even on a temperate mountain with no obvious water limitation and an ongoing net-increase of species richness, the composition change resulted not only from colonisations and cover increases of 
alpine pioneer species but also from decreases in vegetation cover of subnival species and increasing frequency of disappearance of species from the permanent plots, which occurred almost exclusively in the most recent decade. A study comparing old (before 1970) and recent vegetation relevés across the Eastern Alps showed that lower range limits of species are shifting upwards at least as rapidly as the upper boundaries and that the velocity is higher the lower the boundaries are situated (Rumpf et al. 2018). Consequently, this leads to a progressive areal reduction of species' distribution ranges due to the conical shape of mountains with limited available space at higher elevations. The risk of critical biodiversity losses is especially high for species with small distribution areas restricted to the uppermost elevation zones. This is the case for many of the endemics in Mediterranean mountains and for endemism hot spots in the Eastern Alps.

In addition to the thermal and moisture components, factors such as geomorphology, pollution and land-use change and their mutual interactions, potentially, can strongly influence the composition of plant communities. Geomorphology is an important determinant for vegetation patterns. This is especially true for high mountain ecosystems which are characterized by a fine-grained mosaic of habitat patches with steep environmental gradients over short distances (Nagy and Grabherr 2009) and thus offer potential retreat habitats for cold-adapted plants (Scherrer and Körner 2010). Atmospheric nitrogen deposition, which is mainly caused by combustion processes and application of fertilizers in intense agriculture, can lead to severe changes in species composition (Bobbink et al. 2010, Phoenix et al. 2006). By increasing the availability of nitrogen for plants, competitive relationships among plant species are altered, favoring more nitrophilous species over those adapted to nutrient-poor conditions. On soils with limited nutrient availability, as this is common at alpine habitats (Körner 2003, Powers 1990), species diversity may initially increase as a consequence of nitrogen enrichment because of the immigration or enrichment of more nitrophilous species (e.g. Bobbink et al. 1998, Bowman et al. 2006, Evangelista et al. 2016). In the further course, local extinctions of species adapted to poor conditions will be likely as a consequence of competitive replacement by more vigorous generalists benefitting from nitrogen enrichment, rather than by direct effects on atmospheric nitrogen on the resident species (Bobbink et al. 2010, Hautier et al. 2009, Stevens et al. 2004). How sensitive ecosystems, plant communities and individual species respond to inputs of atmospheric nitrogen is a complex matter. It depends on multiple environmental variables, such as phosphorus limitation, soil $\mathrm{pH}$, soil moisture, and the thermal conditions (Porter et al. 2013, Simkin et al. 2016, Wang et al. 2016a). Average estimates of critical loads, i.e. the effect thresholds for nitrogen deposition, for overall community changes in European alpine ecosystems have been reported on the basis of experimental approaches to be around $10 \mathrm{~kg} \mathrm{~N}$ ha-1 yr-1 (Bobbink et al. 2010, Bowman et al. 2006). Currently, many regions of the European Alps 
and Apennines receive atmospheric $\mathrm{N}$ deposition loads exceeding this threshold, whereas Mediterranean mountains in SW Europe and Greece remain below (Engardt and Langner 2013). Following the pathway of the IPCC RCP4.5 emission scenario, and additionally taking climate changes into account, $\mathrm{N}$ deposition is expected to decrease all over Europe until the year 2050, although critical loads will probably still be exceeded (Engardt and Langner 2013, MSC-W \& CCC \& CEIP 2018). In addition to nitrogen deposition, increasing soil nitrogen availability due to higher mineralization rates in a warming world as well as counteracting factors, such as summer drought which reduces the aerobic mineralization rates, must be considered (Porter et al. 2013, Powers 1990).

The disentanglement of different anthropogenic factors is further complicated when species' response to pollution and climate effects is masked or restricted by coincidental land-use changes, which can result in over-fertilization, fragmentation and habitat destruction (Honnay et al. 2002). Compared to lowlands, such direct human interferences are less pronounced in mountain ecosystems because human settlements are scarce above a certain altitude and intensive agriculture is not feasible (Bender et al. 2011). More than half of the world's mountains are categorized as not or only little influenced by direct human activities, and about one third of these are located within protected areas (Rodríguez-Rodríguez and Bomhard 2012). While alpine areas are recognized and even valued for their pristine landscapes, thus making them ideal "natural laboratories" for the study of climate effects on natural systems (Barry 1994, Pauli et al. 2015), it is also recognized that humans have inhabited and directly influenced alpine ecological systems for millennia all over the world (Bätzing 2005, Netting 1981, 1990). Different forms of pastoralism and alpine dairy farms are traditional and still common in mountain regions in many parts of the world (Bunce et al. 2004, Herzog and Seidl 2018, Liechti and Biber 2016, Manzano Baena and Casas 2010, Suttie and Reynolds 2003). Anthropogenic land-use influences are particularly high on the subalpine and lower alpine level, resulting in downwardly displaced forest and tree lines, for example being situated 150 to 300 vertical meters below the potential natural limits in the European Alps (Holtmeier and Broll 2005). Especially changes in grazing intensity, i.e., the intensification of grazing in accessible areas as well as the abandonment of mountain pastures in remote areas lead to changes in community structure of resident vegetation (MacDonald et al. 2000, Nagy and Grabherr 2009, Patty et al. 2010, Yager et al. 2008). Climate extremes and ongoing socioeconomic changes (from population growth to competition for land, water and other natural resources) may for instance provoke the migration of people and livestock to or from high-elevation habitats. In this context, the past and future changes of further provisioning ecosystem services (in addition to providing pasture land), like gathering and hunting activities, have to be considered for mountain regions (Byg et al. 2010, Salick et al. 1999, Salick et al. 2009, Salick and Ross 2009). Furthermore, changing demands on cultural services such as 
aesthetic, recreational and cultural values of mountain regions may have a marked influence on mountain ecosystems (Garcia-Llorente et al. 2018, Locatelli et al. 2017, Zhao et al. 2019).

Temporal changes on alpine ecosystems and their species compositions are influenced by complex interactions of all abovementioned factors. However, their relative impact has rarely been comprehensively assessed, due to the limited availability of field data, especially on changes in the vegetation composition across pronounced environmental gradients and across climatically differing biomes. This project was a first attempt to connect a unique dataset on changes in occurrence and abundance of alpine plants based on standardized monitoring on mountain summits provided by GLORIA (Global Observation Research Initiative in Alpine Environments, www.gloria.ac.at) with (1) climatic factors: temperature, water potential/precipitation and solar radiation (2) topographic information (3) deposition rates of nitrogen and (4) information about land-use changes in the alpine life zone.

\subsection{OBJECTIVES OF THE OUTLINED PROJECT}

This project aimed at disentangling anthropogenic and natural factors underlying differential changes in plant species composition and richness observed on mountain summits in the European Alps and the Mediterranean. We operated on two different spatial scales. First, the local level constituted individual mountains from the treeline ecotone to the upper elevation zones where plants still occur, where temperature, water potential and nitrogen deposition were measured, and changes in species composition of high-mountain vegetation and grazing pressure were recorded. Second, on the regional level, we compared topography, climate parameters, regional nitrogen deposition and landuse. For an overview of the thematic framework see Fig. 1.

Specifically, we focused on the

(1) Identification of potential microrefugia for cryophilic vegetation based on topographic and solar radiation analysis

A varied topography in alpine environments provides a range of different microclimates on small spatial scales which is expected to buffer alpine plant species biodiversity against climate change (Graae et al. 2018, Scherrer and Körner 2010). We compared the relative extent of microtopographic variability between the Alps and the Mediterranean biome. 


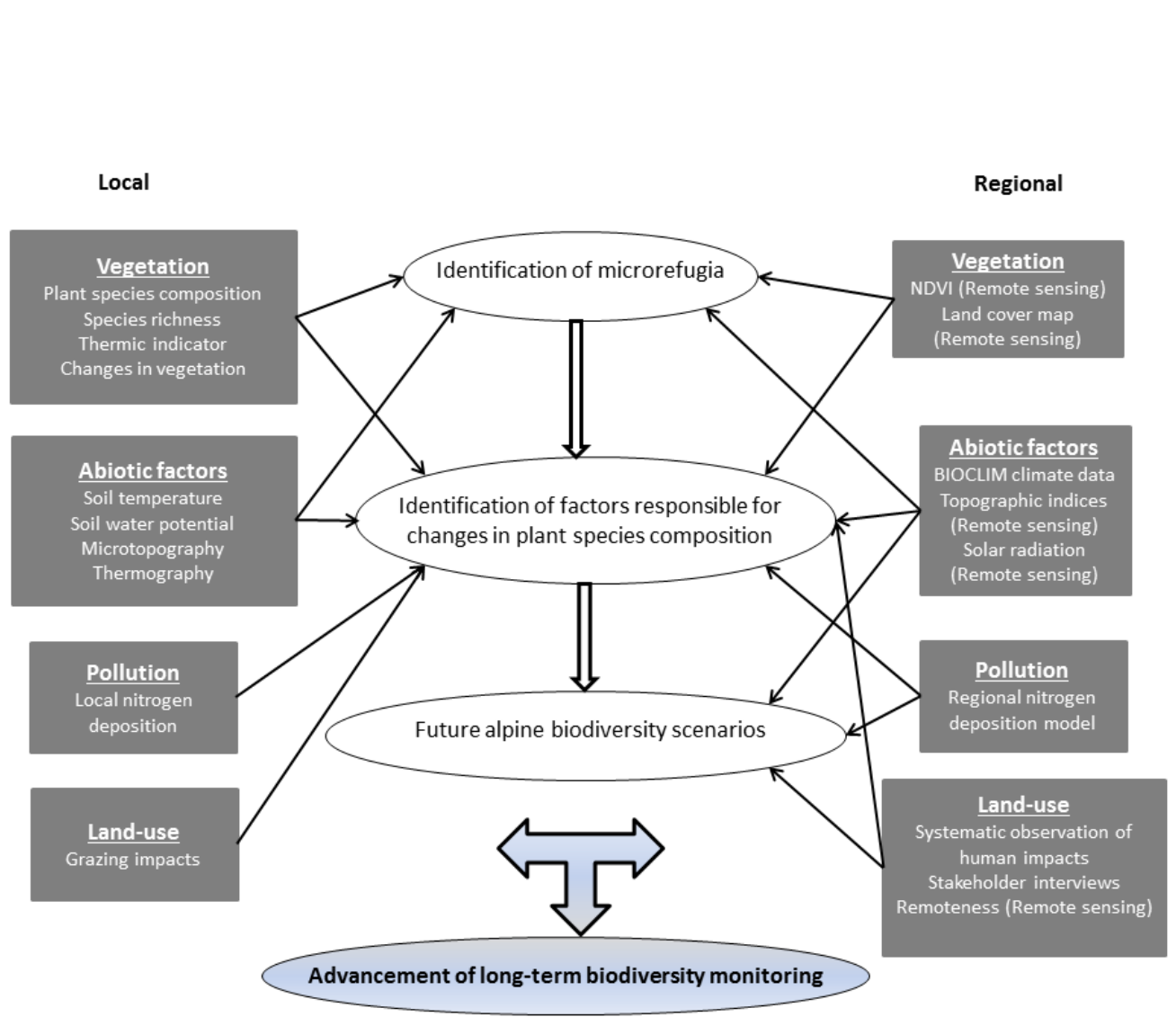

Figure 1. Flowchart illustrating the thematic framework of the MediAlps project.

(2) Identification of main factors responsible for observed changes in plant species richness and composition

Besides rising temperatures and changes in precipitation patterns, we expected nitrogen deposition to be an important factor driving changes in plant species composition in regions in relation to the distance to densely populated areas and industrial agglomerations. The influence from land-use, notably of livestock grazing, was expected to be higher in the Mediterranean regions than in the Alps.

(3) Identification of interactions between these factors relevant for changes in plant species composition

Interactions between temperature and soil water potential/precipitation were expected to play a crucial role in the Mediterranean region where the growing season does not coincide with precipitation maxima, in contrast to the Central and Eastern Alps. Furthermore, temperature and precipitation were expected to have an influence on nitrogen deposition (Engardt and Langner 2013). 
(4) Advancement of word-wide long-term monitoring in high-mountain environments

Being part of a large international monitoring program, the project yielded both new tested methods for additional and interdisciplinary monitoring approaches (i.e., structured land-use observations) to be applied at other existing GLORIA sites as well as much demanded information and insights on the relative regional importance of a range of human influences in alpine environments and their interdependencies with climatic key-drivers. Furthermore, MediAlps played a key role in the development and advancement of the GLORIA Europe network.

\section{STUDY REGIONS AND SAMPLING DESIGN}

\subsection{STUDY REGIONS}

For the MediAlps-project six representative GLORIA target regions (Global Observation Research Initiative in Alpine environments; see www.gloria.ac.at for a detailed description of the network) were chosen to compare the geographically and climatically strongly differing regions of the two biomes considered. Within each biome, also regions with different substrate types (calcareous/dolomitic versus siliceous) were involved. For the Alps, we included Entremont/Valais (CH-VAL) with siliceous bedrock, Latemar-Sella/Dolomites (Trentino, IT-ADO) and Hochschwab/NEAlps (Styria, AT-HSW) for dolomitic and calcareous mountains of the southern and northern Alps, respectively. For the Mediterranean biome Sierra Nevada (ES-SNE) represents a siliceous, Majella/Central Apennines (IT-CAM) and Lefka Ori/Crete (GR-LEO; Fig. 2) calcareous mountain regions. The selected sites cover a range of different protection statuses from no protection (Valais), protection through the European Union's Flora Fauna Habitat Directive (Crete, Dolomites), drinking water reserve (NE-Alps) and national park (Central Apennines, Sierra Nevada), the latter being also UNESCO Biosphere Reserves. In each of these GLORIA target regions, four summits representing an elevational gradient from the treeline ecotone to the region's uppermost vegetation zone (where vascular plant assemblages still occur) were selected in 2001. In IT-CAM one of the four summits was abandoned in 2008, therefore only three summits are part of this project. Thus, in total 23 summits are included in the MediAlps project. 


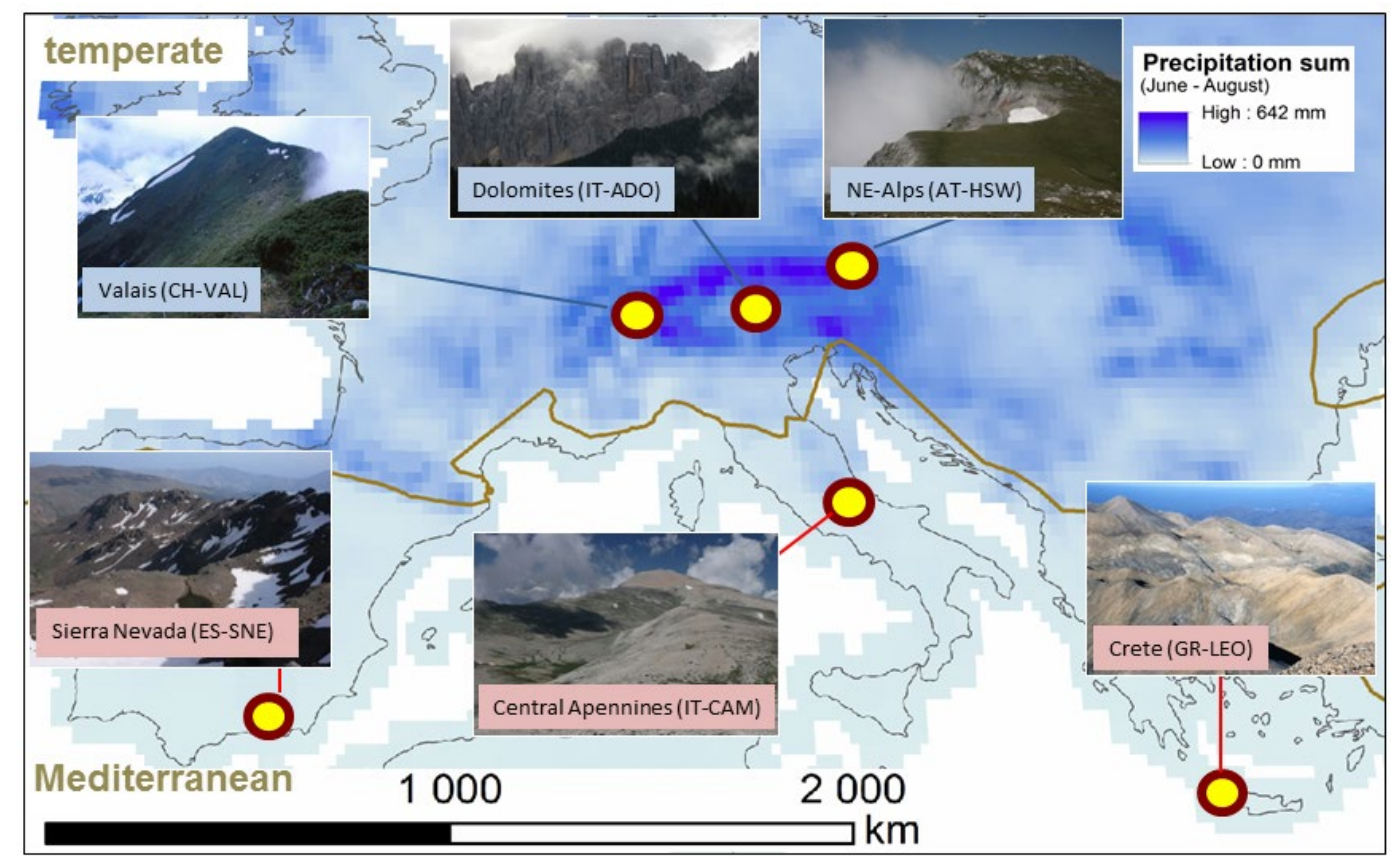

Figure 2. Location of the six target regions. Shown are positions of target regions, three located in the Alps (blue), three in the Mediterranean mountains (red). The background map shows June/July/August precipitation sums (obtained from doi: 10.5676/DWD_GPCC/CLIM_M_V2015_025). Projection: Eckert IV.

\subsection{SAMPLING DESIGN}

In 2001, each summit was divided into eight summit area sections (SASs), four in the top 5m, four between the $5 \mathrm{~m}$ and $10 \mathrm{~m}$ contour line (Fig. 3). At the $5 \mathrm{~m}$ contour line in each cardinal direction (north, east, south, west), $3 \mathrm{~m} \times 3 \mathrm{~m}$ quadrat clusters were established (a total of 92 in the six target regions; Fig. 3).

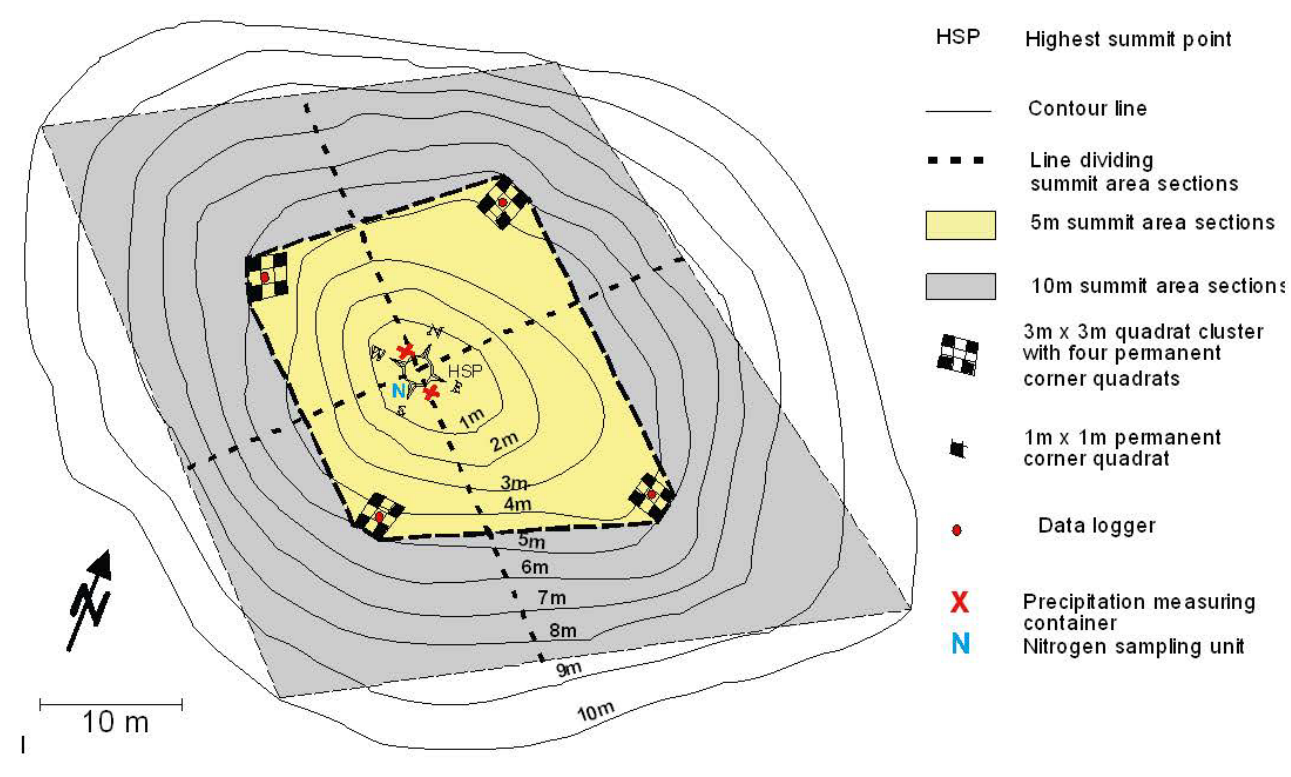

Figure 3. Sampling design with four $3 \mathrm{~m} \times 3 \mathrm{~m}$ quadrat clusters, and two precipitation and one nitrogen sampling units at each GLORIA summit. 
In the 2015 field campaign, twelve additional $3 \mathrm{~m} \times 3 \mathrm{~m}$ quadrat clusters were installed on the three highest summits in each region (at $25 \mathrm{~m}, 45 \mathrm{~m}$ and $65 \mathrm{~m}$ below the highest summit point in each cardinal direction; Fig. 4). As the lowest summits are located at the tree-line, they were excluded from setting additional plots, because these would have been located in forested areas. Where the terrain was inaccessible or working conditions were too dangerous, deviations from the exact cardinal directions were tolerated. In total, 308 quadrat clusters were installed and 1232 quadrats recorded in 2015.

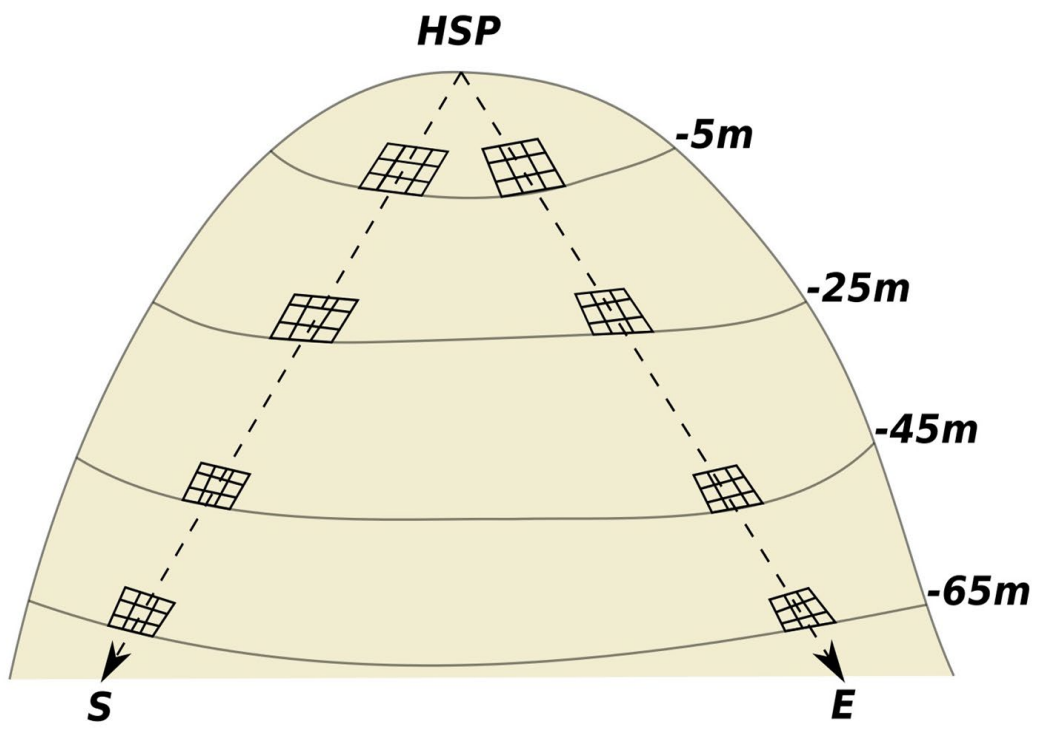

Figure 4. Distribution of the $3 \mathrm{~m} \times 3 \mathrm{~m}$ quadrat clusters on each summit at 5, 25, 45 and $65 \mathrm{~m}$ below the highest summit point (HSP). Quadrat clusters were established in all four cardinal directions, N, E, S, and W (Figure reproduced from Niederheiser et al. (2018) with permission from the authors).

In each of the eight SASs, a complete list plus estimation of the abundance (along an ordinal scale in five abundance categories) of all vascular plant species and a visual estimation of percentage top cover of surface types (vascular plants, solid rock, scree, lichens (excluding epilithic lichens), bryophytes, bare ground and litter) were recorded in every survey year, 2001, 2008 and 2015.

In the four corner quadrats of each of the $3 \mathrm{~m} \times 3 \mathrm{~m}$ quadrat clusters (QUAD), the top cover of surface types (the same as used in the SASs) was estimated visually, and a complete list of all vascular plants was recorded. In the standard quadrats at the $5 \mathrm{~m}$ line, additionally the percentage cover of each vascular plant species was estimated and subplot-frequency counts were conducted in 2001 and 2008, and pointing with a grid frame in 2015 for details see Pauli et al. (2015, Box 4.1). 


\subsubsection{TERRESTRIAL PHOTOGRAMMETRY}

On each $3 \mathrm{~m} \times 3 \mathrm{~m}$ cluster imagery was collected after a defined protocol in nadir and oblique view using a camera mounted on a pole (Niederheiser et al. 2018, Niederheiser et al. 2016; Fig. 5). The images were then used for photogrammetric processing and derivation of 3D point clouds and highresolution orthophotos.

In the CH-VAL and IT-ADO regions additionally to the photogrammetric processing near infrared imageries were taken for experiments on vegetation detection and identification (Kamphuis 2015). In the region ES-SNE thermal infrared time series where captured for experiments about time dependent temperature distribution with in the sites.

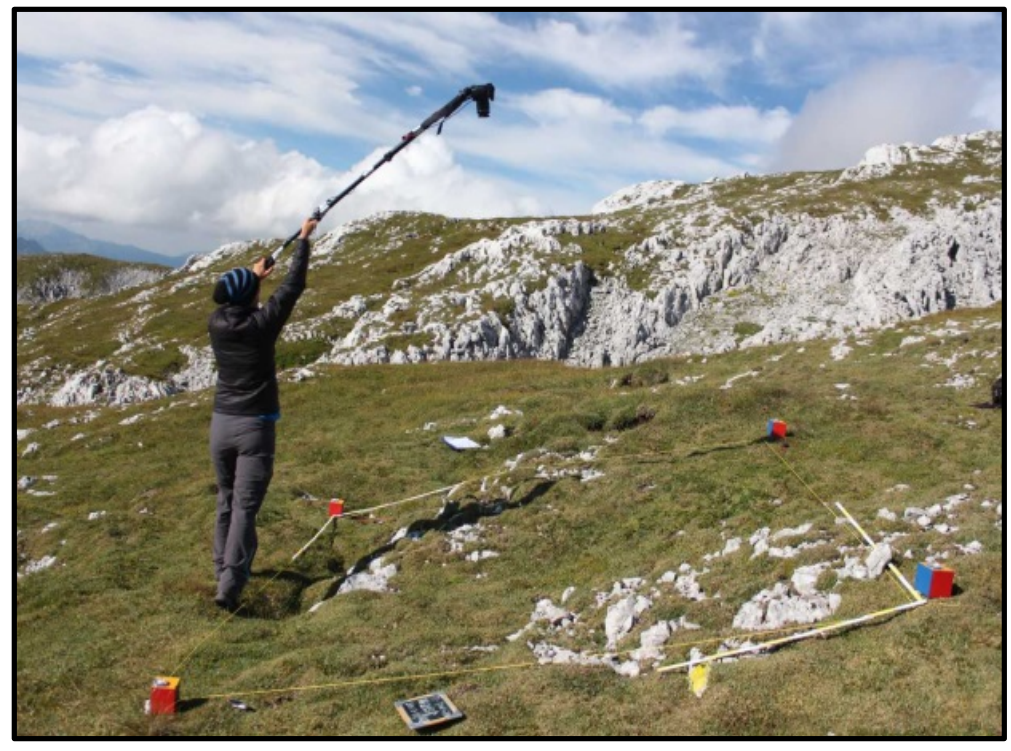

Figure 5. Terrestrial photogrammetry in GR-LEO, 2015.

\section{POTENTIAL DRIVERS OF CHANGES IN BIODIVERSITY AND PLANT SPECIES COMPOSITION}

\subsection{Climatic FACTORS}

\subsubsection{TEMPERATURE}

Temperature loggers, buried at a depth of $10 \mathrm{~cm}$ in the central quadrat of each $3 \mathrm{~m} \times 3 \mathrm{~m}$ quadrat cluster at the $5 \mathrm{~m}$ contour line (i.e., four loggers per summit, in total 92; Fig. 3), have been measuring soil temperatures hourly since summer 2001. In 2015, temperature loggers were read out and batteries were changed if necessary. Temperature data will be checked for consistency and outlier values and subsequently uploaded in the GLORIA temperature database which is currently being redesigned and re-structured. These in-situ temperature data will be used for analyses at small scale. 
As logger data are not available for periods prior to the first survey, CHELSA temperature data (https://www.wsl.ch/lud/chelsa/data/timeseries/prec/; Karger et al. 2017) for the years 1995-2013 (2013 is the latest year available so far) were downloaded and downscaled to $100 \mathrm{~m}$ spatial resolution using a statistical downscaling procedure called "delta method", which was frequently applied in studies of climate change effects (e.g. Dullinger et al. 2012, Ramirez-Villegas and Jarvis 2010, Tabor and Williams 2010, Zimmermann et al. 2009). For each summit, the mean summer temperature (June, July, August) was averaged over the seven years preceding each survey (i.e., 1995-2000 for the 2001 survey, 2001-2007 for the 2008 survey and 2008-2013 for the 2015 survey; Table 1).

\subsubsection{WATER POTENTIAL AND PRECIPITATION}

Soil water potential measures the energy a plant needs to retrieve water from the soil, thus it gives an estimate of soil water availability. Water potential is measured in pF:

$p F=\log _{10}\left|\frac{\psi_{m}}{h P a}\right|$, where $\psi_{m}$ is the matrix potential.

It ranges from 1 (which corresponds to $-10^{1} \mathrm{hPa}$; wet) to $7\left(-10^{5} \mathrm{hPa}\right.$; very dry). 92 loggers measuring both temperature and soil water potential (in Tensiomark, GeoPrecision, Ettlingen, Germany) at an interval of two hours were established in the $3 \mathrm{~m} \times 3 \mathrm{~m}$ cluster at $5 \mathrm{~m}$ below HSP in summer 2015 (Fig. 3, Fig. 6).

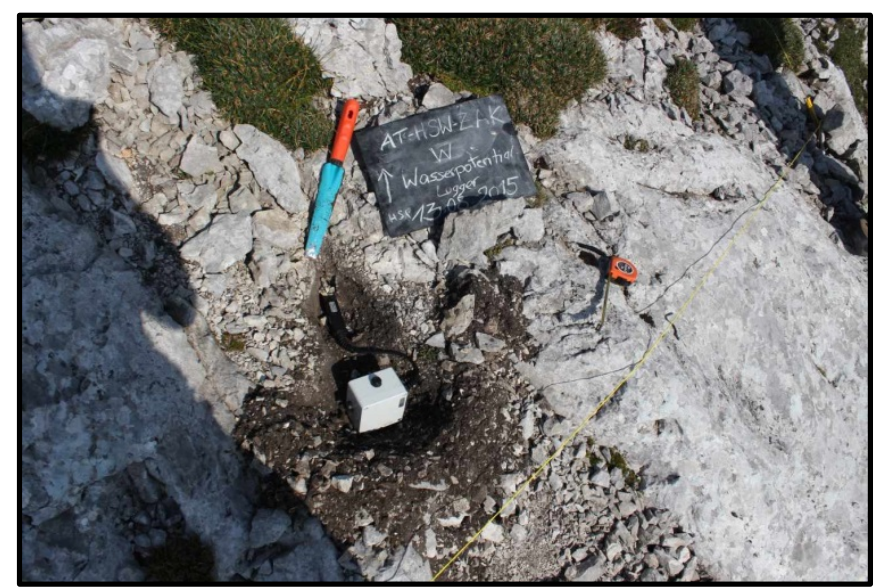

Figure 6. Water potential logger on Mt. Hochschwab.

The first data readout from these loggers took place in summer 2016. Unfortunately, many loggers failed due to faulty contacts and two loggers in ES-SNE disappeared. As a consequence, all loggers were excavated and repaired in 2016. Most of the loggers could be re-introduced in summer 2016 and were read out in summer 2017 . About $15 \%$ of these loggers again showed defects, mostly caused by water ingress which led to rapid battery discharge. Some of the loggers could be repaired and re-introduced only in summer 2017. At the end of summer 2018, all loggers (temperature and 
water potential loggers) were read out again (except for two summits in ES-SNE due to an unexpectedly early and sudden onset of winter). Water potential time series covering a year (01.07.2017 - 30.06.2018) are available for 72 loggers in total (ES-SNE: 6, IT-CAM: 11, GR-LEO: 12, CH-VAL: 15, IT-ADO: 15, AT-HSW: 13; Fig. 7). Mediterranean regions, especially ES-SNE and GR-LEO showed significantly higher pF-values in the summer months than the temperate regions (linear mixed effect models ${ }^{1}, p$-value $<0.001$ ) indicating profound summer drought in the former. The data for each logger will be used for future analyses at small scale.

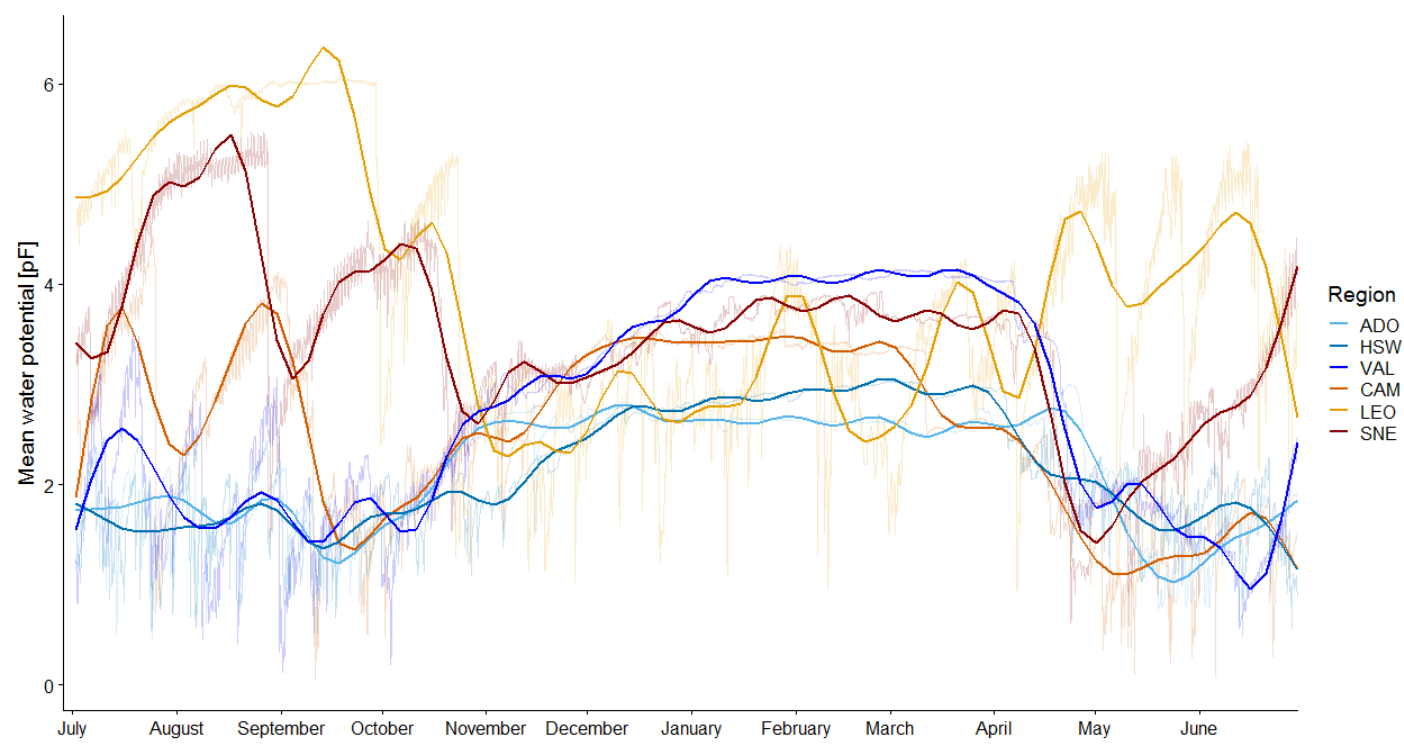

Figure 7. Mean soil water potential in the six study regions. Mediterranean regions are given in shades of yellow to red, and temperate regions in blue, respectively. Smoother lines based on generalized additive models with integrated smoothness estimation ${ }^{2}$.

To measure local precipitation, two gauges were installed in the uppermost part of the summit area (a few meters apart from each other) in 2015 (Fig. 8). The plastic gauges, each with a capacity of 5 liters and an opening diameter of 6-10 $\mathrm{cm}$, were filled with $50 \mathrm{ml}$ Paraffinum liquidum (vaseline), which floats on the water and prevents evaporation. The opening was covered with a $1 \mathrm{~cm} \times 1 \mathrm{~cm}$ grid to prevent small mammals or birds from falling into the container. After four weeks, each plastic

\footnotetext{
1 Linear mixed-effects models ( $\mathrm{Imms}$ ) with time and biome and their interaction as fixed effects and region as random intercept term, calculated using the function Imer from the R-library Ime4 (Bates et al. 2015). A significant interaction means that the water potential curves of the two biomes are deviating significantly from each other.

2 Generalized additive models calculated using the function gam from the R-library mgcv (Wood et al. 2016).
} 
container was emptied into a graduated cylinder and the amount, including vaseline was measured. As the amount of water in the two containers of a summit showed considerable deviations in some regions, the measurements were not considered reliable and not used in further analyses. This is a general problem at high elevations: difficult conditions also prevented the inclusion of precipitation data time series of high mountain meteorological stations in the HISTALP database (Auer et al. 2007).

Regional precipitation data for the years 1995-2013 were downloaded from CHELSA and processed as described for the temperature data above (Table 1).

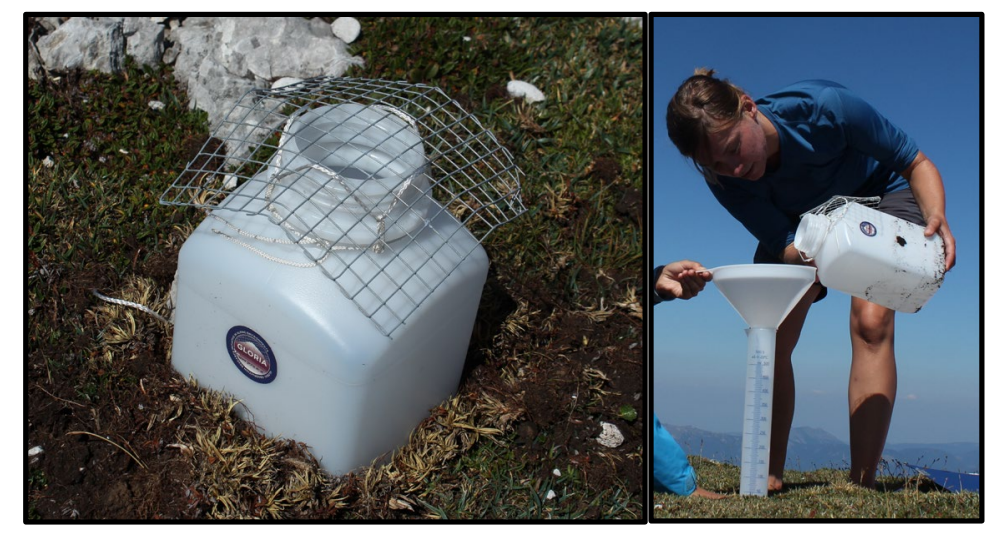

Figure 8. Measurement of local precipitation

\subsubsection{Pollution: Nitrogen deposition}

Atmospheric nitrogen concentrations were measured in-situ with passive collection tubes (www.passam.ch). $\mathrm{NO}_{2}$ and $\mathrm{NH}_{3}$ were collected by molecular diffusion along an inert polypropylene tube with triethanolamine and sulphuric acid as absorbent, respectively. Four measuring samplers each for $\mathrm{NO}_{2}$ and $\mathrm{NH}_{3}$ were placed in a special shelter to protect them from rain and minimize the wind influence, and mounted at ca. $2 \mathrm{~m}$ above ground level on a wooden pole near the highest summit point in summer 2015 (Fig. 9). In total, $92 \mathrm{NO}_{2}$ and $92 \mathrm{NH}_{3}$ passive samplers measured in the field and 16 blank samples of each kind stayed in the offices during the measuring period as controls. After an exposure of four weeks the tubes were recovered. Nitrogen concentration values retrieved from the nitrogen samplers were multiplied with a deposition velocity of 0.17 and $1.4 \mathrm{~cm} \mathrm{~s} \mathrm{~s}^{-1}$ for $\mathrm{NO}_{2}$ and NH3 (empirical values for extensively managed grassland, Kirchner et al. 2005), respectively, to obtain nitrogen dry deposition values. 


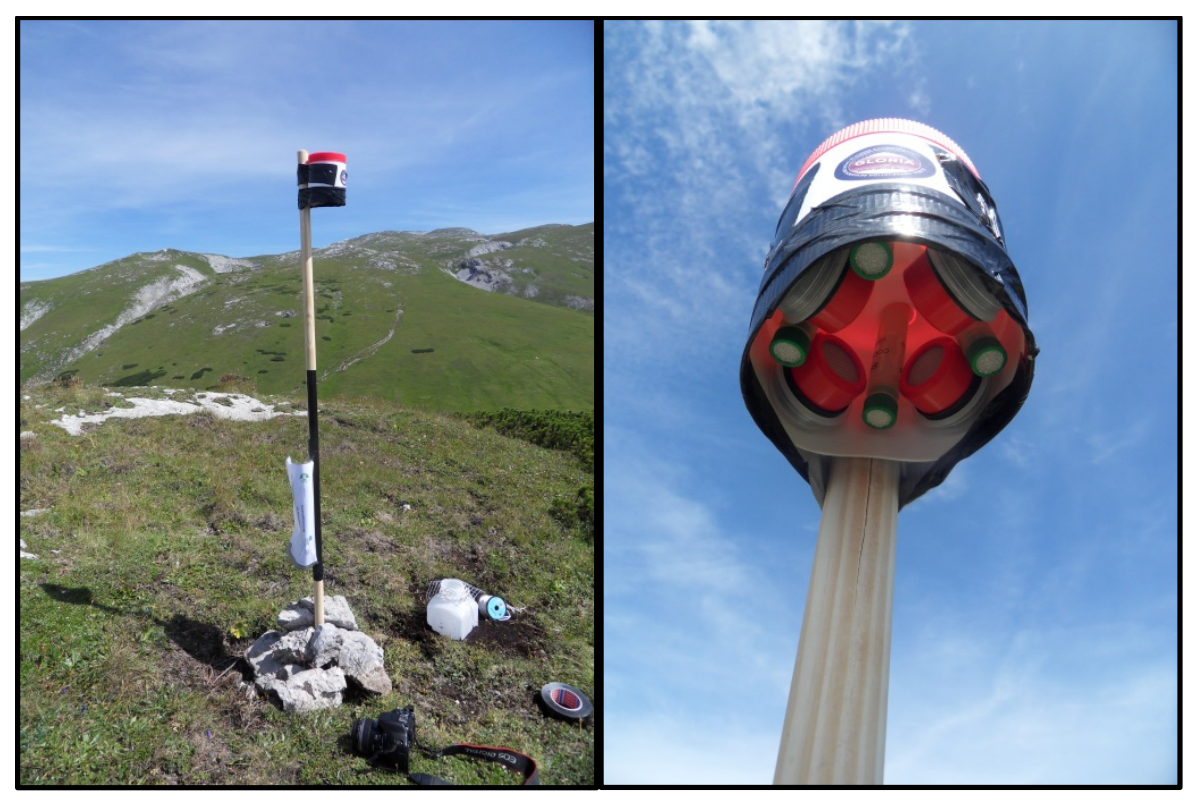

Figure 9. Nitrogen deposition sampler unit $\left(\mathrm{NH}_{3}\right.$ and $\left.\mathrm{NO}_{2}\right)$ on $\mathrm{Mt}$. Hochschwab

Modelled dry nitrogen deposition data for each month of the year 2015 were downloaded from the homepage of the European Monitoring and Evaluation Programme (EMEP, http://emep.int/mscw/mscw_moddata.html; based on data from the Norwegian Meteorological Institute). Currently, the annual EMEP MSC-W model results of nitrogen depositions are only available as $50 \mathrm{~km} \times 50 \mathrm{~km}$ gridded data (on the EMEP grid). Dry nitrogen deposition sums of $\mathrm{NO}_{2}$ and $\mathrm{NH}_{3}$ of the year 2015 were added for each summit (Table 1). Dry nitrogen deposition sums ranged from approximately $50 \mathrm{mg} / \mathrm{m}^{2} . \mathrm{yr}^{-1}$ to almost $300 \mathrm{mg} / \mathrm{m}^{2} . \mathrm{yr}^{-1}$, i.e., between 0.5 and $3 \mathrm{~kg} \cdot \mathrm{ha}^{-1} . \mathrm{yr}^{-1}$. They were highest in AT-HSW, followed by IT-CAM, IT-ADO and CH-VAL. GR-LEO and ES-SNE had the lowest values (Table 1). 


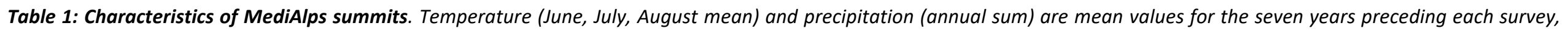

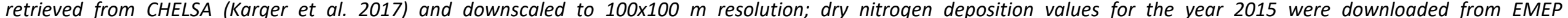

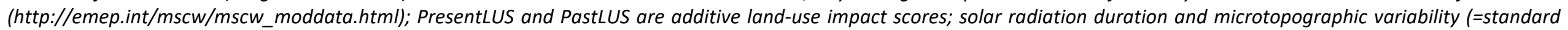
deviation of slope) were obtained through high-resolution microtopographic mapping.

\begin{tabular}{|c|c|c|c|c|c|c|c|c|c|c|c|c|c|}
\hline \multirow[t]{2}{*}{ Biome } & \multirow[t]{2}{*}{ Region } & \multirow{2}{*}{$\begin{array}{l}\text { Summit } \\
\text { altitude } \\
\text { [m.s.m.] }\end{array}$} & \multicolumn{3}{|c|}{ Temperature JJA $\left[{ }^{\circ} \mathrm{C}\right]$} & \multicolumn{3}{|c|}{ Precipitation [mm] } & \multirow{2}{*}{$\begin{array}{l}\text { Nitrogen } \\
\text { deposition } \\
{\left[\mathrm{mg}(\mathrm{N}) / \mathrm{m}^{2} \text {. }\right.} \\
\left.\mathrm{yr}^{-1}\right]\end{array}$} & \multirow{2}{*}{$\begin{array}{l}\text { Present } \\
\text { LUS }\end{array}$} & \multirow{2}{*}{$\begin{array}{l}\text { Past } \\
\text { LUS }\end{array}$} & \multirow{2}{*}{$\begin{array}{l}\text { Solar } \\
\text { radiation } \\
\text { duration }[\mathrm{h}]\end{array}$} & \multirow{2}{*}{$\begin{array}{l}\text { Microtopo- } \\
\text { graphic } \\
\text { variability }\end{array}$} \\
\hline & & & $1995-2000$ & 2001-2007 & 2008-2013 & $1995-2000$ & 2001-2007 & 2008-2013 & & & & & \\
\hline Mediterranean & IT-CAM & 2405 & 9.3 & 9.7 & 10.2 & 841 & 902 & 999 & 150.6 & 0 & 0 & 4.56 & 28.1 \\
\hline Mediterranean & IT-CAM & 2635 & 8.2 & 8.6 & 9.1 & 829 & 902 & 976 & 235.0 & 0 & 0 & 4.80 & 26.1 \\
\hline Mediterranean & IT-CAM & 2737 & 7.9 & 8.4 & 8.8 & 821 & 908 & 958 & 235.0 & 1 & 0 & 3.97 & 27.4 \\
\hline Mediterranean & GR-LEO & 1664 & 14.7 & 14.9 & 15.1 & 601 & 622 & 657 & 121.2 & 9 & 3 & 6.11 & 31.5 \\
\hline Mediterranean & GR-LEO & 1965 & 13.7 & 13.8 & 14.1 & 609 & 630 & 668 & 121.2 & 5 & 3 & 5.82 & 28.9 \\
\hline Mediterranean & GR-LEO & 2160 & 12.5 & 12.6 & 12.9 & 701 & 732 & 730 & 121.2 & 4 & 3 & 5.20 & 27.2 \\
\hline Mediterranean & GR-LEO & 2339 & 11.7 & 11.8 & 12.1 & 787 & 818 & 815 & 121.2 & 5 & 3 & 5.95 & 25.6 \\
\hline Mediterranean & ES-SNE & 2778 & 10.5 & 11.4 & 11.3 & 382 & 322 & 462 & 61.9 & 2 & 1 & 5.21 & 25.5 \\
\hline Mediterranean & ES-SNE & 2968 & 9.4 & 10.2 & 10.1 & 419 & 360 & 503 & 49.1 & 1 & 1 & 5.45 & 27.7 \\
\hline Mediterranean & ES-SNE & 3150 & 8.4 & 9.2 & 9.2 & 493 & 417 & 592 & 49.1 & 3 & 1 & 7.03 & 27.8 \\
\hline Mediterranean & ES-SNE & 3327 & 8.2 & 9.0 & 9.0 & 450 & 395 & 543 & 84.0 & 3 & 1 & 4.32 & 30.9 \\
\hline Temperate & IT-ADO & 2199 & 9.5 & 9.8 & 10.2 & 1185 & 1110 & 1340 & 177.7 & 4 & 2 & 5.24 & 24.0 \\
\hline Temperate & IT-ADO & 2463 & 8.8 & 9.1 & 9.4 & 1191 & 1149 & 1389 & 141.4 & 2 & 2 & 4.94 & 24.1 \\
\hline Temperate & IT-ADO & 2757 & 8.4 & 8.6 & 9.0 & 1285 & 1247 & 1507 & 141.4 & 2 & 2 & 3.97 & 25.7 \\
\hline Temperate & IT-ADO & 2893 & 5.7 & 6.0 & 6.4 & 1415 & 1360 & 1598 & 108.2 & 0 & 2 & 5.88 & 24.4 \\
\hline Temperate & AT-HSW & 1910 & 10.4 & 10.9 & 11.1 & 1173 & 1119 & 1256 & 214.9 & 2 & 0 & 5.12 & 25.0 \\
\hline Temperate & AT-HSW & 2065 & 8.8 & 9.3 & 9.5 & 1252 & 1232 & 1363 & 287.1 & 4 & 0 & 5.13 & 25.5 \\
\hline Temperate & AT-HSW & 2214 & 8.2 & 8.7 & 8.9 & 1263 & 1217 & 1367 & 214.9 & 3 & 0 & 5.25 & 25.6 \\
\hline Temperate & AT-HSW & 2255 & 7.8 & 8.4 & 8.6 & 1305 & 1269 & 1413 & 214.9 & 3 & 0 & 4.91 & 26.1 \\
\hline Temperate & $\mathrm{CH}-\mathrm{VAL}$ & 2360 & 9.4 & 9.6 & 9.4 & 1121 & 1077 & 1057 & 139.3 & 1.5 & 0 & 4.94 & 30.5 \\
\hline Temperate & CH-VAL & 2550 & 8.4 & 8.6 & 8.5 & 1296 & 1175 & 1163 & 139.3 & 0 & 0 & 2.82 & 29.6 \\
\hline Temperate & CH-VAL & 2989 & 6.8 & 7.0 & 6.9 & 1408 & 1280 & 1235 & 139.3 & 0 & 0 & 2.34 & 28.4 \\
\hline Temperate & $\mathrm{CH}-\mathrm{VAL}$ & 3212 & 5.0 & 5.2 & 5.0 & 1381 & 1265 & 1218 & 139.3 & 2 & 0 & 3.96 & 27.0 \\
\hline
\end{tabular}


Local nitrogen deposition values were regressed against regional nitrogen data from EMEP from the same period (July or August 2015) to evaluate whether coarse regional data which are retrieved from lowland measuring stations are transferrable to remote alpine locations. Local and regional data were positively correlated, with $\mathrm{NO}_{2}$ showing a better accordance between the two scales than $\mathrm{NH}_{3}$ (linear model, $\mathrm{NO}_{2}: \mathrm{p}=0.002, \mathrm{R}^{2}=0.4 ; \mathrm{NH}_{3}: \mathrm{p}=0.135, \mathrm{R}^{2}=0.11$; Fig. 10). However, $\mathrm{N}$-deposition values from the samplers were approximately an order of magnitude smaller than those from the regional EMEP-model indicating that $\mathrm{N}$ deposition may be much less in remote locations than in the lowlands near the emission sources. However, the limited observation time of only one month prevents us from drawing more definite conclusions.

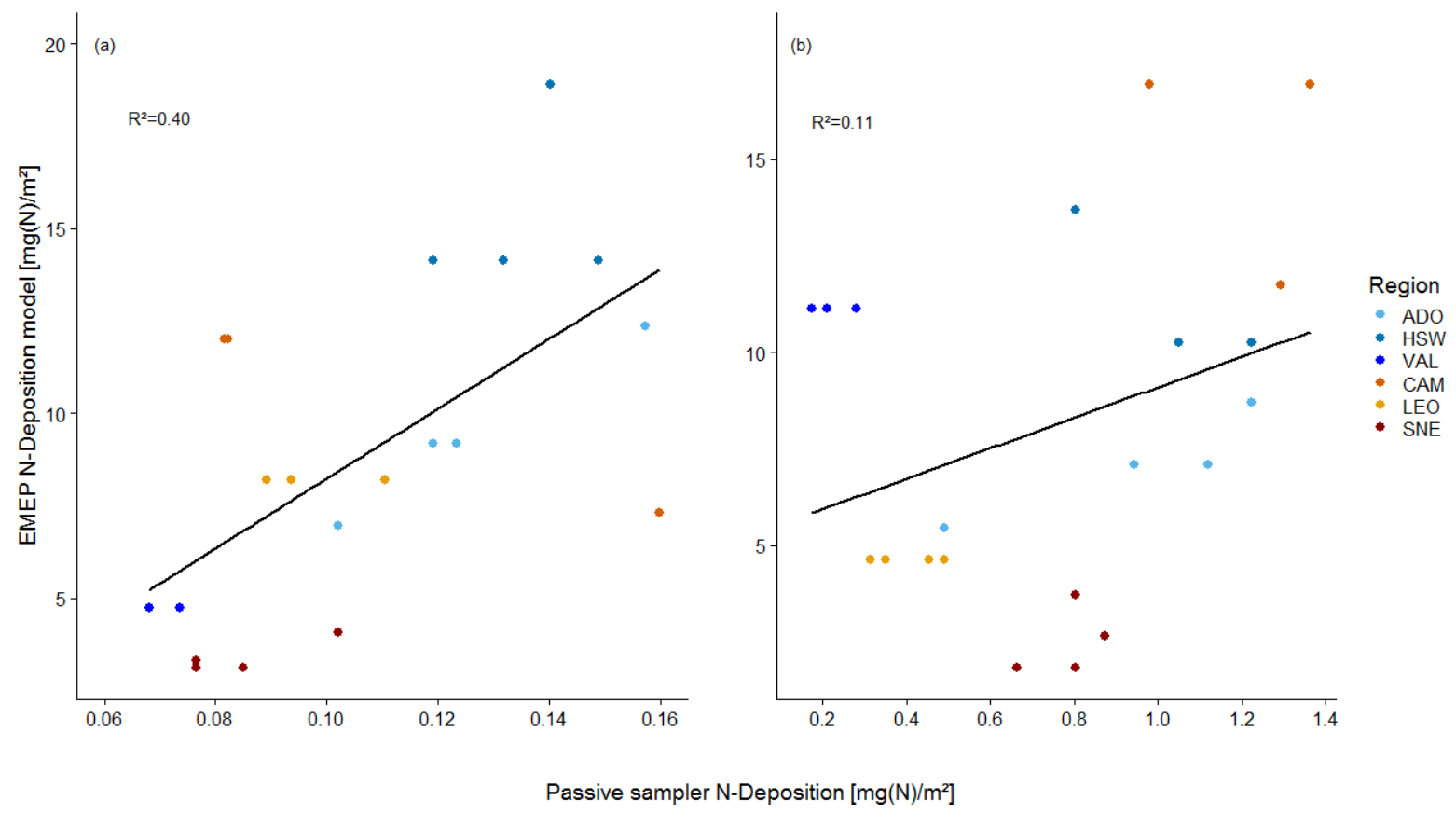

Figure 10. Comparison between monthly local nitrogen deposition values obtained from passive nitrogen samplers and regional nitrogen dry deposition values retrieved from EMEP${ }^{3}$ for (a) $\mathrm{NO}_{2}$ and (b) $\mathrm{NH}_{3}$ in July or August 2015.

\footnotetext{
3 (http://emep.int/mscw/mscw_moddata.html)
} 


\subsection{LAND-USE}

\subsubsection{GRAZING INDICES IN THE $1 M^{2}$ QUADRATS AND SUMMIT AREA SECTIONS}

The frequency of signs indicating the presence of grazing mammals (faeces/droppings, browsing damage, trampling) were recorded for each of the hundred $10 \mathrm{~cm} \times 10 \mathrm{~cm}$ subplot of the corner quadrats of the $3 \mathrm{~m} \times 3 \mathrm{~m}$ quadrat clusters at the summits in 2001 and 2008. In 2015, the frequency of each grazing impact category (faeces/droppings, browsing damage and trampling) was estimated as percentage cover in each $1 \mathrm{~m}^{2}$ plot. In the SASs, comments on grazing impact were noted in all three survey years.

\subsubsection{SYSTEMATIC OBSERVATIONS}

To identify and compare discernible anthropogenic influences, systematic observations were conducted in each of the six selected target region throughout the alpine life zone. Standardised field sheets were developed (Fig. 11), accompanied by a photo-documentation. Recorded key-indications of human impact were grouped in eight categories: pastoralism (e.g., browsing damage, faeces accumulation, eutrophication indicators), trampling damage, infrastructure (e.g., for summer and winter tourism), agriculture, plant gathering, fire, neobiota and other human land-use. Systematic observations were conducted by members of the GLORIA coordination team in each region and additionally by the local teams between June 2016 and August 2018. The added impact scores ( $0 \ldots$ no impact to $4 . .$. high impact) of the eight categories represent the "Present Land-Use Score" (Table $1)$.

\subsubsection{HISTORICAL DIMENSIONS: QUALITATIVE INTERVIEWS}

To assess types of anthropogenic activities as well as spatial and temporal dimension of land use and anthropogenic influences in our target sites we carried out qualitative semi-structured, guidelineaided interviews (Fig. 12). Depending on the specific influencing factors of a region, different interviewees, such as regional land-use experts or stakeholders, were interviewed (Table 2). Durations of interviews took between one to more than five hours. Used languages were English, German, French (with translation in English) and Spanish (with translation in English).

The information gathered in the interviews were grouped in three main categories (grazing, tourism, plant gathering) and their added impact scores ( 0 ... no impact to $4 . .$. high impact) represent the region-specific "Past Land-Use Score" (Table 1). 
Field protocol CC-TRC ${ }^{1}$ : AT-TES Date(s): 8.6.16:11.6.16 Time(s) from/to: 08:00-15:00: 11:00-19:00 Observers: F.Gerni, A.Bauer

Brief description of the inspection tour: $\quad 8.6:$ Bodenwirt $(880 \mathrm{~m})$ - through Blumental - Kraxelroa - via AT-TES-VKS - via Spitzstein (2377m) Weihkessel - via AT-TES-HAK - Speikboden - Schüsselhaus (2254m).

11.6: Schüsselhaus - Spitzstein plateau - passing AT-TES-AHS - via AT-HSW-ZAK - passing Hochwart - through Hundsböden - via AT-TES-HLW - Hüslealm (1526m) - Bodenwirt

General comments ${ }^{2}$ :

Below timber line a lot of grazing (cattle). Forest road (private) up to Hüslealm.

Hut keeper: Lot of tourism on the main routes and the highest peak Spitzstein. Cross-country skiing in winter.

\begin{tabular}{|c|c|c|c|}
\hline $\begin{array}{l}\text { Observations in } \\
\text { the region }{ }^{3}:\end{array}$ & 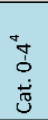 & $\begin{array}{l}\text { Description and comments } \\
\text { (If observation occurs only locally, please give detailed information about location, aspect etc. Describe } \\
\text { summit-specific impacts of the surrounding environment. For direct influences on particular summits } \\
\text { please use the back side of this form.) }\end{array}$ & $\begin{array}{l}\text { Picture } \\
\text { numbers: }\end{array}$ \\
\hline l) Pastoralism & 3 & $\begin{array}{c}\text { List of grazing livestock species } \\
\text { cattle and sheep }\end{array}$ & 22019,22031 \\
\hline $\begin{array}{l}\text { a) Accumulation of } \\
\text { faeces }\end{array}$ & 3 & From grazing livestock but also from wild animals (ibex, chamois) & 22013,22081 \\
\hline $\begin{array}{l}\text { b) Other indications } \\
\text { of grazing activity }\end{array}$ & 1 & Clustered occurrence of nitrophilous species, mostly Rumex alpinus & 22015 \\
\hline c) Browsing damage & 2 & Grazing livestock but probably also from wild animals (ibex, chamois) - not distinguishable & $\begin{array}{l}22027 \\
22035\end{array}$ \\
\hline d) Cattle trails & 2 & On the southern side of the plateau & 22034 \\
\hline $\begin{array}{l}\text { II) Trampling damage } \\
\text { off the trails } \\
\text { (animals or humans) }\end{array}$ & 3 & $\begin{array}{l}\text { Note whether through animals or humans, if possible } \\
\text { Mostly by animals (3). Only at the Spitzstein peak are signs of sleeping places and trampling } \\
\text { off the trail by humans (1). }\end{array}$ & 22051,22052 \\
\hline $\begin{array}{l}\text { III) Infrastructure for } \\
\text { tourism, agroforestry, } \\
\text { hunting, research or } \\
\text { mining }^{6}\end{array}$ & 2 & $\begin{array}{l}\text { Please specify } \\
\text { Well-developed trails, mountain hut (Schüsselhaus) next to the main peak. Some summit } \\
\text { crosses in the region. Stonewalls for sleeping places on the main peak. } \\
\text { Biwak cabin at the plateau }(2253 \mathrm{~m} \text { ). Weather station next to the Schüsselhaus. }\end{array}$ & $\begin{array}{l}22017 \\
22049 \\
22052- \\
22057 \\
22099\end{array}$ \\
\hline $\begin{array}{l}\text { IV) Agriculture } \\
\text { (crop fields, meadows) }\end{array}$ & 0 & & \\
\hline v) Plant gathering ${ }^{7}$ & 2 & $\begin{array}{l}\text { Gentiana clusii were topped (ornamental plants); Valeriana celtica (Speik): excavated } \\
\text { rootstocks }\end{array}$ & $\begin{array}{l}\text { 22068, } \\
22071,22075\end{array}$ \\
\hline $\begin{array}{l}\text { vl) Fire/burning } \\
\text { practices }\end{array}$ & 0 & & \\
\hline VII) Neobiota & 3 & $\begin{array}{l}\text { Species names (incl. specific frequency }{ }^{4} \text { if more than } 1 \text { species) } \\
\text { Ibex (Capra ibex) }\end{array}$ & 22021,22030 \\
\hline VIII) Other & 0 & & \\
\hline
\end{tabular}

Figure 11. Standardised field sheets for systematic observation of present land-use. 
Guideline for semi-structured interview about the past, current and potential future human influences in the selected GLORIA target regions

Location:

Date:

time: from

to

Interviewer(s):

Interviewee(s):

Comments:

To identify spatial and temporal dimension of land-use history and development (since around 1950), current situation and potential future influences of the following topics:

(1) Tourism

Number of tourists; summer- and winter tourism

(2) Pastoralism

List of grazing livestock species

Numbers of animals

Pastoralism type: with or without herdsman/ alpine dairymaid, reason of pastoralism (milk, wool, young cattle...)

(3) Agricultural activities.

Fertilization

(4) Mining

(5) Wildlife

Hunting

Numbers of wild animals

(6) Plant gathering e.g. for medicinal use or food plants, "Schnaps", ..,

(7) Ceremonial and sacred sites

(8) Fire/burning practices

(9) Natural reserve

what category, where and since when

strategies/management

(10) Properties

private, municipal, national, institutional

(11) Economic situation and changes

(12) Further informants

Figure 12. Guideline for land-use interviews. 
Table 2: Overview of land-use interviews.

\begin{tabular}{|c|c|c|c|c|c|c|}
\hline Region & Date & Position/Role & Interviewee ${ }^{a}$ & Interviewer & Language & Translator \\
\hline SNE & 26.07.2016 & $\begin{array}{l}\text { Staff of the Sierra Nevada } \\
\text { national park \& the Botanical } \\
\text { garden (Jardín Botánico Hoya de } \\
\text { Pedraza) }\end{array}$ & A & $A L, H P$ & Spanish & $\mathrm{RF}, \mathrm{HP},(\mathrm{JM})$ \\
\hline SNE & 26.07.2016 & Retired park ranger & B & $A L, H P$ & Spanish & $R F, H P,(J M)$ \\
\hline SNE & 01.08 .2016 & Forestry staff & C & $A L, H P$ & Spanish & $R F, H P,(J M)$ \\
\hline SNE & 01.08 .2016 & Expert for ibex & $\mathrm{D}$ & $A L, H P$ & Spanish & $R F, H P,(J M)$ \\
\hline CAM * & 13.01.2019 & Member of GLORIA IT-CAM & VC & AL & English & - \\
\hline CAM * & 13.01.2019 & Head of GLORIA IT-CAM & AS & AL & English & - \\
\hline LEO $* *$ & 12.12 .2018 & Head of GLORIA GR-LEO & GK & AL & English & - \\
\hline VAL & 29.08 .2018 & $\begin{array}{l}\text { Farmer, member of bourgeoisie }{ }^{b} \\
\text { of Bagnes }\end{array}$ & $\mathrm{E}$ & AL & French & JT \\
\hline VAL & 29.08 .2018 & $\begin{array}{l}\text { Farmer, member of bourgeoisie }{ }^{b} \\
\text { of Liddes }\end{array}$ & $\mathrm{F}$ & AL & French & JT \\
\hline VAL & 30.08 .2018 & $\begin{array}{l}\text { Farmer, member of bourgeoisie }{ }^{b} \\
\text { of Liddes }\end{array}$ & G & $A L$ & French & JT \\
\hline VAL & 30.08 .2018 & $\begin{array}{l}\text { Farmer, member of bourgeoisieb } \\
\text { of } d^{\prime} \text { Orsières }\end{array}$ & $\mathrm{H}$ & AL & French & JT \\
\hline ADO & 06.08.2017 & Functionary of fraction Eggen & 1 & AL & German & - \\
\hline HSW & 26.10 .2016 & Manager of a mountain hut & J & MW & German & - \\
\hline HSW & 20.08.2018 & Local herbalist & K & AL & German & - \\
\hline
\end{tabular}

a interviewees who are not co-authors of this report $(A-K)$ are anonymised

${ }^{\mathrm{b}}$ statutory corporation

AL ... Andrea Lamprecht, AS ... Angela Stanisci, GK ... George Kazakis, HP ... Harald Pauli, JM ... Joaquín Molero Mesa, JT ... Jean-Paul Theurillat, MW ... Manuela Winkler, RF ... Rosa M. Fernández Calzado, VC ...Valter Di Cecco

${ }^{*}$ written interview, ${ }^{* *}$ via Skype

In the study regions the two main forms of land-use are pastoralism and tourism. Where pastoralism is present, shepherds are increasingly rare and absent. The number of free ranging domestic animals tends to increase in some regions (see below). Tourism is increasing in most regions. 


\subsubsection{LAND-USE IN THE MEDIALPS REgIONS}

\subsubsection{ES-SNE}

Since 1989, the area of the Sierra Nevada in Spain is a natural park (IUCN cat. V) and parts of it were upgraded into a national park (IUCN cat. II) in 1999. Traditionally it was used as animal husbandry and agriculture (subsistence farming) was realized up to $1600 \mathrm{~m}$, but this changed, when it became a hunting reserve in 1960.

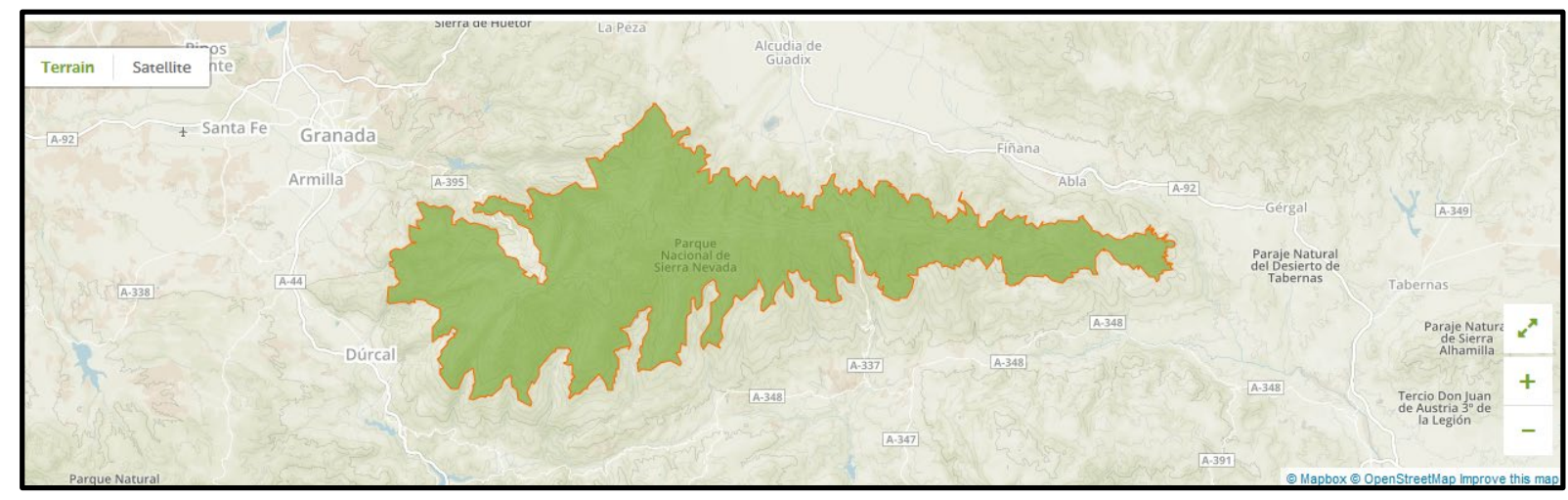

Figure13. Map of the area of the national park Sierra Nevada in Spain ${ }^{4}$.

Actually, there are still many cattle and other livestock inside the national park, also in the core zone. From April until around October, there are about 2000-3000 cattle in the park area, however, the real number is stated as certainly higher than the official number. Local politics, rather than the national park administration, is responsible for allocations of grazing areas on the public land, which differ every year. The animals are kept free and are checked only once or twice a week. While the number of cattle is increasing, sheep and goats are decreasing because shepherds or dogs are needed to protect them. In the lower regions there are still goat herds with shepherds, however, overall, there are rarely any shepherds. The main reason for the utilisation is meat. Instead, in the Alpujarras dairy products, including cheese are produced, but wool and leather are not used. Sheep have been found to climb up to the highest peak Mulhacén repeatedly. Cows could be sighted close to the lower GLORIA summits during systematic observations. However, even if the impact of pastoralism in the region was documented as moderate, mainly exemplified through faeces accumulation, the impact by livestock on the GLORIA summits was not observed. Observed resting places and faeces were most likely from ibex (Capra pyrenaica subsp. hispanica). At the same time, it is hard to distinguish between impact from livestock and wildlife. Further, neglected animals become wild repeatedly. According to ibex specialists, Capra pyrenaica subsp. hispanica (Iberian Ibex) is

\footnotetext{
${ }^{4}$ Source: https://www.protectedplanet.net/sierra-nevada-nacional-park
} 
immigrating from neighbouring areas, after the population was reduced to 200 to 400 individuals during Spanish Civil War (1936 - 1939). Hunting was allowed until the 1950s. Since the 1960s the area above $3000 \mathrm{~m}$ in the Sierra Nevada is a hunting reserve (Reserva Nacional de Caza). Currently, there are between 14,000 and 15,000 individuals in the national park area, resulting in discussions about changes of management strategies. Additionally, animals like horses and mules are more and more used for touristic purposes. Agencies offer horse trips into the national park, which leads not only to increased trampling but also to droppings on the highest peaks of the Sierra Nevada. During systematic observations Urtica dioica could be determined as one of the highest growing plants of Spain, found on the summit zone on $3474 \mathrm{~m}$ (Fig. 14).

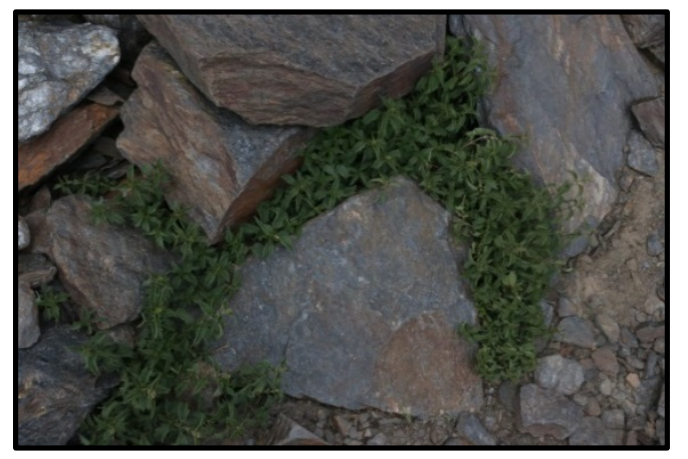

Figure 14. Urtica dioica on the Mulhacén at 3480m, July 2016.

As a whole, tourism in the Sierra Nevada is strongly increasing since the designation as national park. Road infrastructure up to $3100 \mathrm{~m}$ and numerous hiking trails make accessibility to the area easy, even of the highest peaks Mulhacén and Veleta. Since 2010, a ski lift is operating also during summer as it is suggested a more ecological transport system. Another reason for rising popularity of hiking in the Sierra Nevada the financial crisis has been stated, as it forced local people (which are most of the visitors) to search for cheaper holiday alternatives in the region. The introduction of the camino integral is a famous trekking tour over all $3000 \mathrm{~m}$ peaks of the Sierra Nevada and was followed by an invasion of active sports fans. During the systematic observations, touristic infrastructure was documented as moderate in the region and as low impact on the highest GLORIA summit, although camino integral is passing through. As a further identifiable influence, the use of Artemisia granatensis was specified, which is used as tea. Considering the low numbers of individuals ( 5000$)$ of this local endemic, gathering is problematic. However, controls and fines are not executed, due to a low number of national park rangers. Because only little examples of $A$. granatensis were found during the systematic observation, with no signs of disturbance, impact by plant gathering was documented as not observed. 


\subsubsection{IT-CAM}

The National Park of Majella was established in 1991 with the aim to strictly protect high elevation areas.

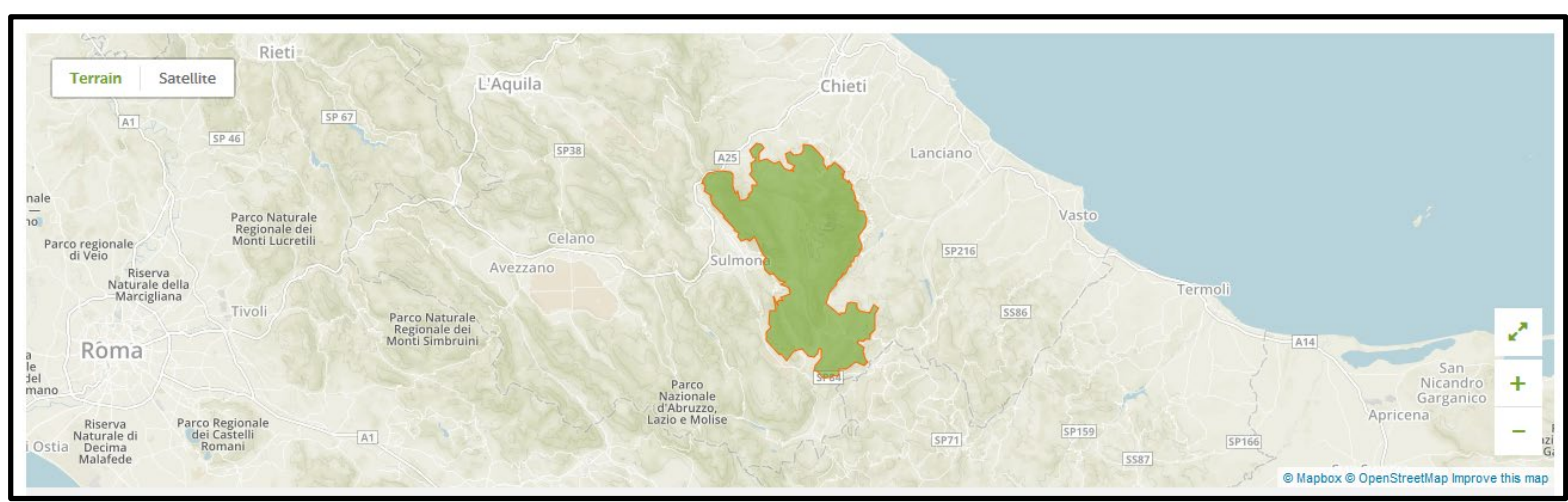

Figure 15. Map of the area of the national park Majella (Parco nazionale della Majella) ${ }^{5}$.

Nature-related and hiking tourism in summer has recently increased in the national park. However, the number of tourists is low. According to our informants it is no mass tourism but "niche tourism". The GLORIA summits are far-off from indicated pathways so they are not visited by hikers. Just a "hardly noticeable" trail was documented during the systematic observation for one summit (MAM).

More direct impact seems to come from pastoralism. Between $500-1000$ grazing livestock are reported by the GLORIA partners to graze in the national park area. Among them are sheep, goats, cows, horses and mules. Sheep and goats are mainly used for milk and are guided by shepherds at altitudes that rarely exceed $2200 \mathrm{~m}$ a.s.l. during summer. According to our partners fewer and fewer shepherds are available, which results in a decreasing number of sheep and goats. Cows and horses are used for meat and are kept without shepherds from July to September, leading to an increase in numbers. Only the lowest GLORIA summit, Femmina Morta, is near to the grazing area. According to the observation protocol, there is no impact observed directly on Femmina Morta but approximately $40 \mathrm{~m}$ below the summit. In the region, pastoralism was only observed in the southern parts of the national park up to $2300 \mathrm{~m}$. Wild animals are increasing as a result of protection activities and reintroduction actions of endangered species (e.g. chamois). Around 3000-5000 ungulates live perennially or occasionally at the high altitudes of the national park, most of them are chamois. Hunting and gathering is forbidden in the national park, yet, historical records for the usage of some species (Gentiana lutea, Chenopodium bonus-henricus and Artemisia umbelliformis subsp. eriantha) by the local population exist.

\footnotetext{
5 Source: https://www.protectedplanet.net/parco-nazionale-della-maiella-national-park
} 


\subsubsection{GR-LEO}

The area of Lefka Ori belongs to the Natura 2000 network. Since 2000 it was declared as "Site of Community Importance" (SCl) and since 2011 it is characterized as "Special Area of Conservation" (SAC). The area is managed by the Management Body of Samaria National Park. A Special Environmental Study and a Management Plan were developed, but the necessary presidential degrees for their ratification, are still missing. Thus, an actual management plan doesn't exist (see also Natura 2000, 2019, 6. site management).

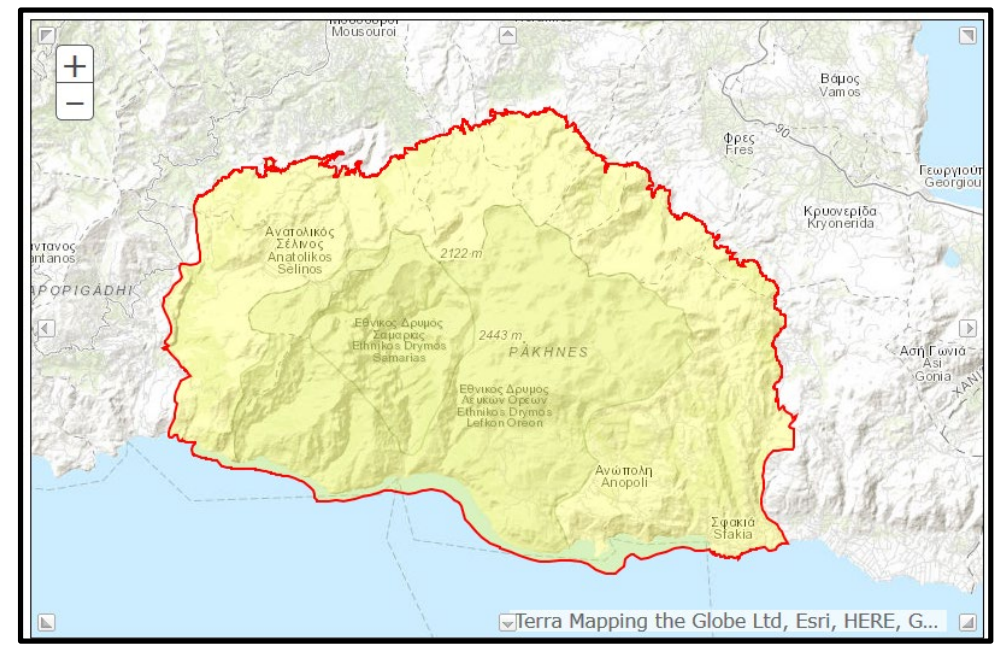

Figure 16. Map of the Special Area of Conservation Lefka Ori Kai Paraktia Zoni ( $\triangle$ EYKA OPH KAI ПAPAKTIA Z $\Omega N H)^{6}$.

Pastoralism and apiculture is an old tradition in the region. According to the interviewee pastoralism is traditional for thousands of years in the region, which assumes a preadaptation of the vegetation to grazing. Sheep are the most important livestock with the latest official number of 13.250 animals in 2010 in the whole area of Anopoli. The number of sheep increased from 6.000 to 12.000 to 18.000 in 1970, 1990 and 2000 respectively and is associated with European subsidies. Also important are goats which numbers increased from 3.000 in 1970 to 8.250 in 2010.

Livestock is utilised for milk and meat, sheep are sheared once a year without using the wool. Nowadays there are two to three dairy maids/dairyman in the region making cheese. The number of shepherds was higher in former times, but since a road was built up to $2000 \mathrm{~m}$, a permanent residence at higher elevations became redundant. Livestock is more or less free grazing, in higher areas mainly between June and August. In the last 20 years the grazing pressure has been decreasing on the summits and will further decrease in the future, because trade-off between money raised

6 Source: http://natura2000.eea.europa.eu/Natura2000/SDF.aspx?site=GR4340008 
from pastoring and the low efforts ("Not so many young people want to do that."). However, during systematic observations, a high impact of pastoralism for the region was observed. For the summits (in average), a moderate impact was documented which was visible through browsing damage and a low frequency of faeces accumulation.

Above $600 \mathrm{~m}$ apiculture has always been the main agricultural activity. It is a very old tradition which is still popular and even increasing. Nowadays, there are around 1,000 bee hives in the region of Anopoli. Some of them are close to the lowest GLORIA summit. Since 20 years also a soft tourism is increasing. In summer, between May and September, around 1,000 people are hiking from Anopoli to the highest peak Pachnes $(2454 \mathrm{~m})$. Locals try to establish agrotourism in the area. The GLORIA summits are not affected by visitors at present. During observation days in the region, three to five visitors were documented per day. All of them stayed on the paths.

Additionally, worth mentioning for the Lefka Ori region is plant gathering of Sideritis syriaca, which is endemic for Crete and very famous for the region. It is used as the Greek mountain tea, also available in Austria. Special collection rules for the gatherers are respected, e.g. they just cut the branches. Allowed areas and quantity are under the control of the Forest Directorate of Chania. According to the interviewee, the type of collection is traditional and there's no danger for the species because of gathering. According to Natura 2000 (2019), Sideritis syriaca subsp. syriaca is listed as important species of the flora but common in abundance. Origanum microphyllum, is gathered in high elevations as well. Origanum vulgare and Salvia fruticosa are only gathered at low elevations in the area around the village of Anopoli. Origanum vulgare is cultivated as well. Directly on the GLORIA summits no impact was apparent through plant gathering.

Further anthropogenic impact, such as hunting of rabbits and partridges, are negligible for the region. 


\subsubsection{CH-VAL}

The region around the GLORIA summits of CH-VAL is a traditional grazing area. According to a farmer of the region, the oldest written record about grazing dates back to 1287. The GLORIA summits are located in three different communes (municipalities; are the lowest level of administrative division in Switzerland): commune de Bagne, c. de Liddes and c. d'Orsières. The Bourgeoisie is a parallel system within a commune, which combines property of land as well as easement of wood. These rights can also be leased by non-bourgeoisie members. The infrastructure (streets, huts, ...) on this land, however, belongs to the commune. Membership in a bourgeoisie is inheritable and more or less patrilineal. All farmers close to GLORIA summits are hired by the bourgeoisies, although the size of their farms, technical development and management strategies are very different. One thing they have in common is the possession of Hérens (Fig. 17), a special cattle breed from the Val d'Hérens, a region in the Valais, which are aggressive and prone to fight between themselves (to define the hierarchy of the females in the herd). The Herrens fights are very popular and famous for the region, as can be seen on many mural paintings on houses in the Valais.

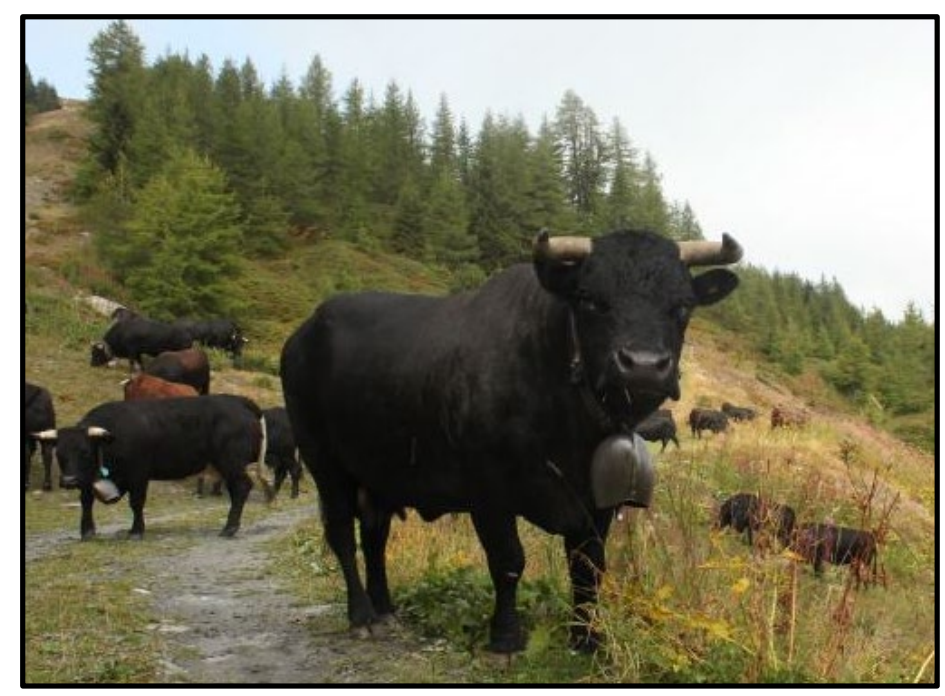

Figure 17. Hérens on a mountain pasture in the Valais, August 2018.

All four interviewed farmers predominantly have cows. Three of them are producing cheese, especially raclette. One farmer is using his livestock only for meat because of low quality of the grazing area. The livestock density, which should be kept per area, was calculated by the government in the 80 's. For a full subvention by the state, farmers have to fulfil the requirements, which include a mixture of landscape quality (inclusive biodiversity), combined with a predefined livestock density $( \pm 20 \%)$ and diversity of animals (different species and breeds). Some of the farmers use fences and confirmed that they never included the GLORIA summits by showing the exact grazing areas on a map. They couldn't exclude, however, that young cows or sheep go up to the two lower summits occasionally when they are free. During the systematic observations of the area, on one of the 
summits a low frequency of faeces from cows could be documented. The other summits seemed unaffected.

An unpaid duty of the bourgeoisie is called corvée and includes cleaning and clearing of the grazing area. The most important species they cut to prevent from spreading are Alnus viridis, Larix decidua,

Juniperus nana and sometimes Veratrum album, which is invading since ten to 15 years because of warmer climate. At the lower parts of the grazing areas they spread the liquid manure which is collected in the stable at the Alp.

Plant gathering is popular among people of elder generations but younger people are not interested anymore. Two plant species were mentioned for production of schnapps. While Artemisia genipi is used for the famous Génépy, a distilled alcoholic drink, a schnapps of Arnica montana is used externally for smaller injuries like sprains. Further, the use of Euphrasia s.l. was mentioned for problems with the eyes and Vaccinium myrillus as well as Vaccinium vitis-idea are collected for making jam. One of the interviewees is the founder of Valplantes (http://www.valplantes.ch/), a company cultivating medicinal plants for cosmetics, pharmacy and drinks in the lower region, instead of gathering wild plants. They also have a very small culture of Artemisia genipi.

Wild animals are very rare in the area, e.g. chamois diminished quite a lot over the last decades. Ibex (Capra ibex) can only be found in the higher regions. Marmots almost disappeared because of overhunting. Only eagles recolonized the whole area since hunting is forbidden.

The study region in Switzerland is located in one of the less touristic regions of the Valais. During the last 15 years, an increase of "easy" hiking with good paths for families was noticed. The hikers stay mostly on the paths and are more sensitive to nature and leave much less litter in environment compared to earlier times. Some of the farmers try to introduce ecotourism by organising some trips and selling their products. 


\subsubsection{IT-ADO}

Since 1996, both parts of the study site in the Dolomites, the Latemar and the Sella massif, are Sites of Community Importance (Nodo del Latemar) and as part of the Dolomites also a World Heritage Site since 2009.

As most parts of the Dolomites the study sites are touristy. The Latemar round trip is very popular among hikers and mountain bikers. Mainly limited to the western and southwestern parts, winter tourism is as important as summer tourism. First ski lifts were built in 1973. Currently, there are 14 lifts up to $2300 \mathrm{~m}$ (at Mount Zanggen) and $2150 \mathrm{~m}$ at the Latemar and tourism is the number one source of income of the valley. The skiing area belongs to the provinces Trento and Bolzano/Bozen. Two of four GLORIA summits are at the north-eastern part of the Latemar massif in a surprisingly little touristy area without infrastructure, neither for summer nor winter tourism. One summit is close to the ski area at the south-eastern part. The fourth one is in a remote part on the Sella plateau, which is really touristic in most parts, due to a powerful cable car and easy tracks. All four summits seem to be unaffected from tourism (proved by interview and systematic observation), which is not easy to find in the Dolomites.

This does not apply for pastoralism. The area around the Latemar has been used for grazing at least since the Second World War, when Karakul sheep were kept for their fell. According to our informant this led to massive overgrazing and was quitted immediately after the end of the war. Since then, the area has been used as commonage grazing for cows and sheep. Number of animals and management differ between the provinces Trento and Bolzano/Bozen. The impact by grazing is moderate on the summits in the Latemar area, noticeable by faeces, browsing and trampling damages. The impact is caused mainly by cows on the lowest summit and by sheep on the higher ones, but also goats occur. There is no information about pastoralism at the high plateau of the Sella massif. Even through the systematic observation no signs of pastoralism could be observed there.

Moreover, meadows up to $2000 \mathrm{~m}$ are mown once a year at the end of July, and are used for grazing in autumn.

Wild ungulates are rare in the area. Ibex could not be found and chamois have been decimated by scabies. Red deer is common in lower areas and sometimes mouflons are appearing. Hunting is allowed and managed by an annual shooting plan. Plant gathering is forbidden, nevertheless, you can find regional "Zirbenschnaps" from Pinus cembra and Artemisia spp. (one of the species known as "Edelraute") were historically used for tea. During the systematic observations no signs of collecting activities were noticed. 


\subsubsection{AT-HSW}

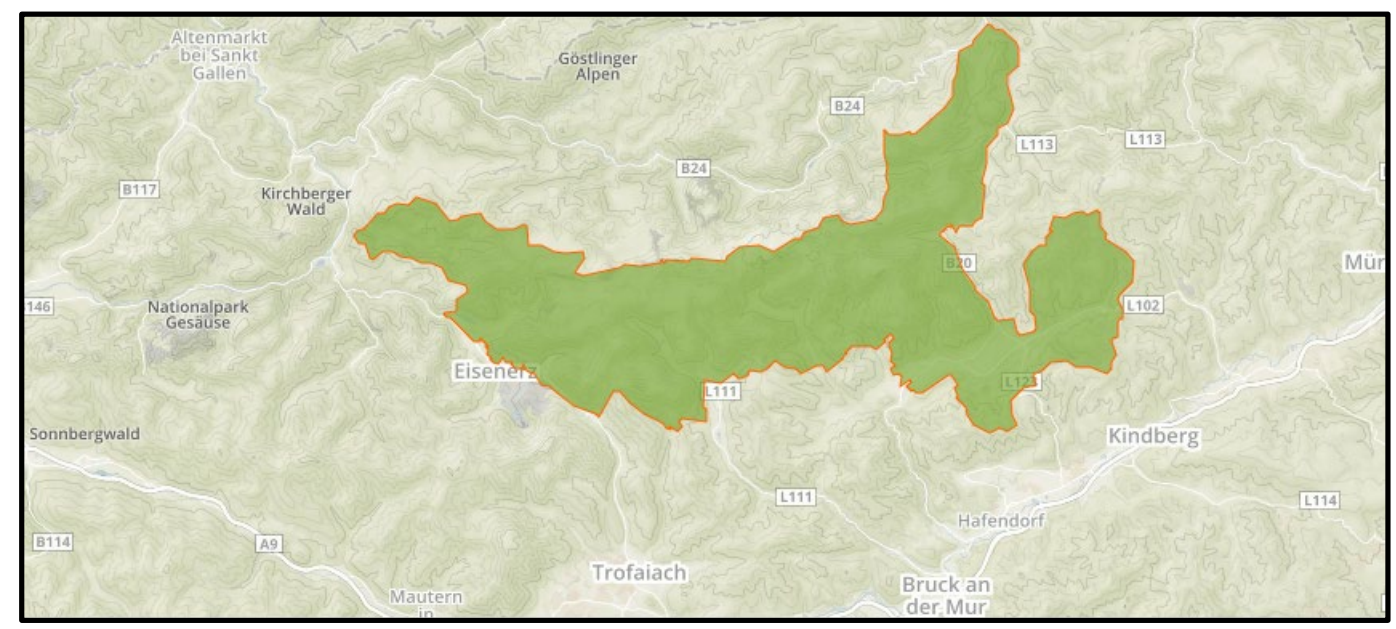

Figure 18. Map of the area of the landscape protection area Hochschwab - Staritzen?.

Since 1981, the area of the Hochschwab massif is a Landscape Protection Area (IUCN cat. V).

Mountaineering has a long tradition in this easily accessible and well developed region and popularity is still rising. Since 2005 the number of overnight stays at the highest hut has doubled and would be even higher, if more beds would be available, commented the hut keeper. Nevertheless, according to the interviewees hikers are disciplined and do not leave the paths. During the systematic observations, impact through tourism was designated as hardly noticeable, just small cairns on the highest points were documented.

Grazing concentrates on areas below the timberline. Especially in the western and eastern parts there are distributed mountain pastures. The high plateau has always been unsuitable for grazing due to the absence of water. All four GLORIA summits were found to be unaffected by pasturing. Faeces on the summits originate from wild ungulates, mainly from the re-introduced ibex, whose population seems to be fairly stable (or even increasing) on Mt. Hochschwab (Fig. 19). Hunting has played a very important role already since the second half of the $19^{\text {th }}$ century when hunting grounds were massively extended at the expense of alpine grazing grounds (Nevole 1908 in Dirnböck et al. 1999)

\footnotetext{
${ }^{7}$ Source: https://www.protectedplanet.net/hochschwab-staritzen-landscape-protection-area
} 


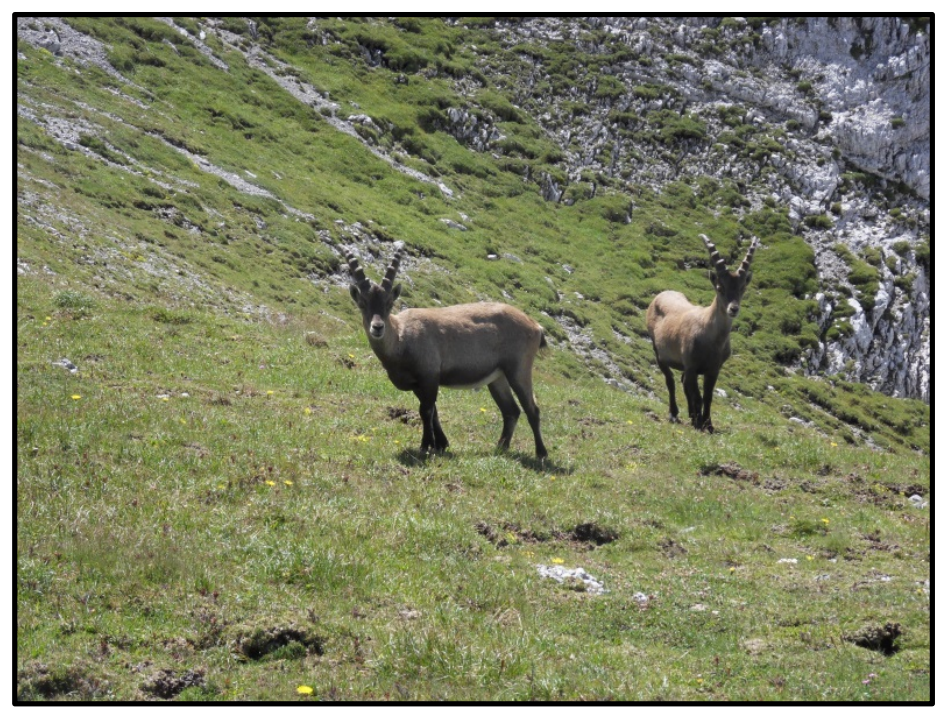

Figure 19. Ibex on Mt. Hochschwab, August 2015.

\subsection{MICROTOPOGRAPHY}

\subsubsection{MAPPING HIGH-RESOLUTION TOPOGRAPHY AND VEGETATION COVER}

Collected imagery were processed using the open source photogrammetric software MicMac (Rupnik et al. 2017) for producing 3D photogrammetric point clouds. These processing tasks were conducted on the high performance computer cluster (HPC) of the University of Innsbruck. We developed a semi-automated workflow for point cloud processing generating dense point clouds and orthophotos for 249 plots. Then, topographic parameters were derived by self-programmed scripts using Python programming language (Python Software Foundation, 2016). These access functions available from other software such as CloudCompare (Girardeau-Montaut 2016), SAGA GIS (Conrad et al. 2015) and SAGA GIS LiS-Tools (Rieg et al. 2014). Advanced statistical analysis for the comparison of vegetation location properties were implemented using Python programming language (Python Software Foundation, 2016) and R-statistics (R Core Team 2015).

249 3D photogrammetric point clouds were derived from 34,376 nadir images and 19,141 oblique images. For all point clouds 146 features, i.e. attributes, are available for selected scales. The 3D point cloud data set is unique by providing information for analysing 3D roughness and overhangs in very high detail. Multi-scale information allows comprehensive analysis of topographic parameters and thus of vegetation location properties. For example, roughness parameters are strongly changing with scale, which allows interpretation on micro-topography as well as at the local plot level. As a measure of microtopographic variability or roughness, the standard deviation of slope was averaged for each summit (Table 1). For the lowest summits, for which no photogrammetric point clouds are 
available, missing SD slope values were interpolated by regressing SD slope of the remaining summits in a region with altitude.

Vegetated points were separated from non-vegetation points by applying a conservative threshold which only separates points belonging to classes with high probability. The rule was applied on features derived from RGB-colour information. These are vegetation indices such as Excess Green (ExG), Excess Green Minus Excess Red (ExGR) and Vegetativen Index (VEG). All classified points were then used as training data for defining a Random Forest classifier classifying all unlabelled points. Then the actual vegetation cover was derived by meshing the 3D point cloud and then assigning border points between classes according to a neighbouring rule.

The importance of vegetation indices and topographic parameters for distinguishing vegetation from non-vegetation and the influence of topographic attributes on vegetation cover was evaluated using linear mixed-effect models ${ }^{8}$ and the Akaike information criterion (AIC). The most important attributes for automated vegetation classification were vegetation indices derived from RGB-colour information (e.g. EXG, VEG and ExGR), while topographic parameters and roughness were less relevant for separating vegetation from non-vegetation in both biomes.

The topographic parameters with the highest influence on vegetation cover in both biomes analysed together were SD of slope, elevation, aspect und mean direct solar irradiation. For the temperate biome elevation, mean direct solar irradiation, aspect and the topographic variability parameter $\lambda 0$ had the highest influence, while for Mediterranean model $\lambda 0$ was not important (linear mixed-effects models; Niederheiser in prep.).

Manual mappings of surface cover types were conducted by drawing polygons on orthoimages of $2073 \times 3$ m clusters using the GIS software ArcGIS 10.3 (ESRI 2015). These orthoimages were derived from the same input images which were also used for the photogrammetric point clouds. After rectifying the orthoimages and fitting them to $3 \times 3 \mathrm{~m}$ grids, the areas of the surface cover types in each $1 \mathrm{~m}^{2}$ corner quadrat of each cluster were polygonized in the application ArcMap (Esri 2015, Hofbauer 2018, Klingraber 2018). Using linear mixed-effects models ${ }^{9}$, we compared automatically derived, in-situ and manually GIS-mapped vegetation cover estimates, which were positively

\footnotetext{
8 Linear mixed-effects models (Imms) with vegetation indices and topographic parameters as fixed effects and summit nested in region as random intercept term, calculated using the function Imer from the R-library Ime4 (Bates et al. 2015).

${ }^{9}$ Linear mixed-effects models (Imms) with summit nested in region as random intercept term, calculated using the function Imer from the R-library Ime4 (Bates et al. 2015).
} 
correlated ( $R^{2}$ from 0.695 to 0.9 ), with higher $R^{2}$ in the temperate than the Mediterranean biome (Hofbauer 2018, Klingraber 2018, Niederheiser in prep.).

\subsection{SOLAR IRRADIATION}

One important parameter for the characterisation of vegetation locations is the potential solar irradiation, which was computed at different scales. Solar irradiation was simulated using the 3D photogrammetric point clouds by considering the geographic position of plots and shadow effects from surrounding mountains applying the approach after (Bremer et al. 2016). The georeferenced 3D photogrammetric point clouds allow topographic analysis even in very steep and overhang situations. A comparison between low resolution 2.5D digital elevation models and the photogrammetric models showed that low resolution input elevation data tend to overestimate solar irradiation neglecting micro structures, local topography and object shadows (Niederheiser et al. 2018). The mean daily solar irradiation duration in the vegetation period was calculated for each summit (Table 1). For the lowest summits, for which no photogrammetry was conducted, missing solar radiation values were replaced with the respective region mean.

\section{SPATIOTEMPORAL DYNAMICS AND CHANGES IN BIODIVERSITY AND PLANT SPECIES COMPOSITION}

\subsection{REMOTE SENSING AND SPATIOTEMPORAL ANALYSIS}

For all regions land cover classification and changed detection analysis were conducted at the regional scale. Satellite scenes acquired around the year 2000 and 2015 by Landsat- 8 and Landsat- 7 were classified and analysed for changes. Since 2015 Sentinel-2 scenes with higher spatial and temporal resolution were analysed as well (Fig. 20). After radiometric and topographic correction a supervised machine learning classification by random forest was conducted. The classification used single bands, vegetation indices and elevation as classification features. Ten land cover classes (artificial land, water, rock, alpine tundra, stunted trees, forest, agriculture/pastures, natural grassland/shrubs, open land, glaciers/snow) were defined achieving a classification accuracy better than 95\% (Mayr 2017). 


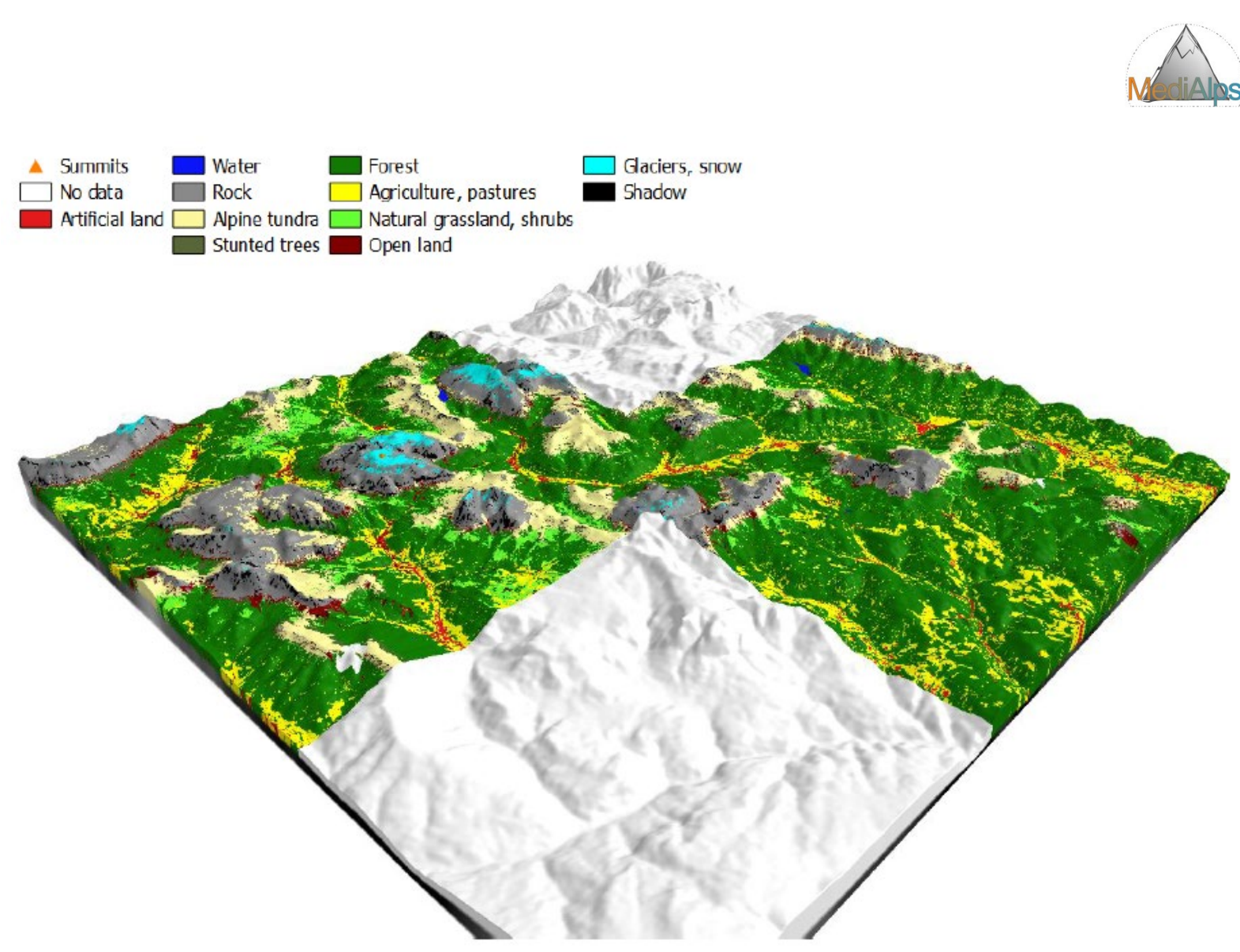

Figure 20. Land cover classification for IT-ADO.

Analysed land cover changes in the study regions indicate an expansion of alpine vegetation, most notably in more elevated and previously rock-dominated areas (Mayr 2017). This is in accordance with observations of a general upward-shift of plant species under a warming climate (Pauli et al. 2012).

\subsection{Phenology}

For each plot in the MEDIALPS test site framework phenological time series were derived from Landsat-5, Landsat-8 and Sentinel-2 data analysing vegetation indices normalized difference vegetation index (NDVI) and soil-adjusted vegetation index (SAVI). This was done for two time periods (1985 to 1995 and 2013 to 2018). Within these periods changes in phenological dates (e.g. start of season) and their spatial distribution are investigated. In order to compensate the scarcity of clear-sky data that is typical for optical remote sensing in high mountain regions, a combination of different techniques proposed by (Beck et al. 2006, Jonsson et al. 2018) was adapted and utilized. For each site a double logistic function is fitted to each full time series, which is then used to fill data gaps in the single year curves (results will be published as a master thesis: (Stackelberg in prep.). 


\subsection{CHANGES IN PLANT BIODIVERSITY AND SPECIES COMPOSITION}

\subsubsection{CHANGES IN SPECIES RICHNESS}

Changes in species richness in the uppermost $10 \mathrm{~m}$ of each summit were calculated using the species presence data from the eight summit area sections. Although the Mediterranean summits are located in three regions very far from each other they showed an almost uniform decrease in species richness between 2001-2008 (on average -3 species/summit; generalized linear mixed-effects model ${ }^{10}$; cf. (Pauli et al. 2012) followed by a significant increase between 2008-2015 (on average +6 species/summit; generalized linear mixed-effects model ${ }^{10}$, Fig. 21). Only the second highest summit in IT-CAM and the lowest summit in GR-LEO showed a deviating pattern (Fig. 21). Owing to the intermittent decrease in species richness, the richness change per year between 2001 and 2015 in ES-SNE was not significant, whereas the number of colonisations per summit area section increased and the number of disappearances decreased significantly over the same period (Table 3; Lamprecht et al. in prep.).

Table 3: Mean changes per year in the Sierra Nevada between 2001 and 2015.Changes in species richness, number of colonisation, and disappearances per summit area section, and total plant species cover and the thermic vegetation indicator per $1 m^{2}$-plot.

\begin{tabular}{lll}
\hline & Change per year & p-value \\
\hline Richness & +0.003 & $>0.1$ \\
Cover $\left[\mathrm{dm}^{2}\right]$ & +0.26 & $<0.001^{* * *}$ \\
Colonisations & +0.14 & $<0.001^{* * *}$ \\
Disappearances & -0.08 & $<0.001^{* * *}$ \\
Thermic vegetation indicator & +0.007 & $<0.05^{*}$ \\
\hline
\end{tabular}

a (Generalized) linear mixed-effects models with year as fixed effect and cardinal direction nested in summit as random intercept term.

In contrast, the prevailing pattern on temperate summits was a significant increase 2001-2008 (on average +8 species/summit; generalized linear mixed-effects model ${ }^{10}$; cf. (Pauli et al. 2012) followed by a weaker but not significant increase 2008-2015 (on average +4 species/summit; generalized linear mixed-effects model ${ }^{10}$; Fig. 21). Although summits showed idiosyncratic patterns all but one AT-HSW summit still had a net increase in species richness over the entire observation period (Fig. 21). In IT-ADO species richness increase was higher the higher the summit (Unterluggauer et al. 2016). While species richness increase is accelerating in temperate and boreal Europe over the last

\footnotetext{
10 Generalized linear mixed-effects models (glmms) using Penalized Quasi-Likelihood and a Poisson error distribution, with year as fixed effect and summit nested in region as random intercept term, calculated using the function g/mmPQL from the R-library MASS (Venables et al. 2002).
} 
1.5 centuries (Steinbauer et al. 2018) a deceleration of species richness increase was also observed on a long-term monitoring site in the central Alps during the past two decades (Lamprecht et al. 2018) which may be an indication that populations of more cold-tolerant species are starting to decline (Dullinger et al. 2012, Lamprecht et al. 2018).

\subsubsection{CHANGES IN VASCULAR PLANT COVER AND COMPOSITION}

Between 2001 and 2015, total plant cover increased significantly in ES-SNE (Table 3; Lamprecht et al. in prep.), GR-LEO (linear mixed-effects model ${ }^{11,12}$, p-value<0.001), IT-CAM and IT-ADO (Rogora et al. 2018), whereas the increase in CH-VAL and AT-HSW was not significant (Rogora et al. 2018). These increases were linked with precipitation in ES-SNE (Lamprecht et al. in prep.) and with increasing temperatures in the other regions (Rogora et al. 2018).

The "thermic vegetation indicator" was calculated as the mean of the altitudinal ranks (vertical distribution preference of a species retrieved from the literature) of all species present in a $1 \mathrm{~m}^{2}$-plot, weighted with their respective cover. An increase of this thermic vegetation indicator over time indicates a thermophilisation of the vegetation (Gottfried et al. 2012). While on temperate summits the thermic vegetation indicator increased significantly in both periods, on Mediterranean summits a thermophilisation between 2001 and 2008 was followed by a stagnating thermic vegetation indicator between 2008 and 2015 (linear mixed-effects models ${ }^{12}$; Figure 21; cf. (Gottfried et al. 2012). This indicates a development of the species composition towards more warmth-demanding species, resulting from a combined decline of cold-adapted species and augmented establishment and increasing abundance of species from lower elevations. For instance, in IT-ADO newcoming species had on average higher altitudinal ranks (i.e., originated from lower elevations) than the mean of the residents (Unterluggauer et al. 2016), and a reforestation of the lowest peaks in the study area is expected in the next few decades (Erschbamer et al. 2017). In IT-CAM, an ongoing filling process by warm-adapted species was observed (Frate et al. 2018).

\footnotetext{
11 The dependent variable (plant cover) was transformed $(\wedge 1 / 3)$ to achieve variance homogeneity of residulas.

12 Linear mixed-effects models (Imms) with year as fixed effect and summit nested in region as random intercept term, calculated using the function Imer from the R-library Ime4 (Bates et al. 2015). Contrasts for pairwise comparisons of the levels of the fixed effect were calculated with the functions $c l d$ and Ismeans of the R-package (Lenth 2016).
} 


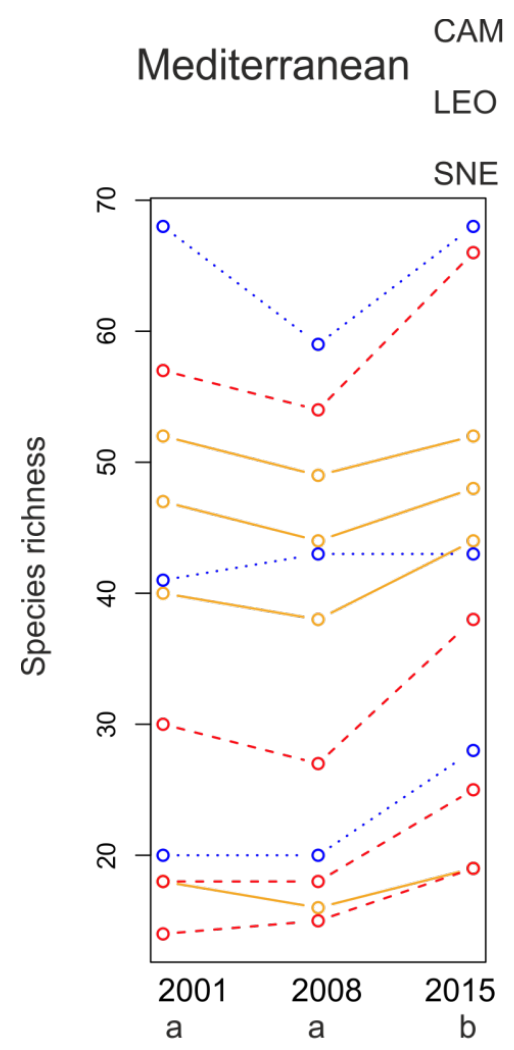

- - HSW

\section{Temperate}

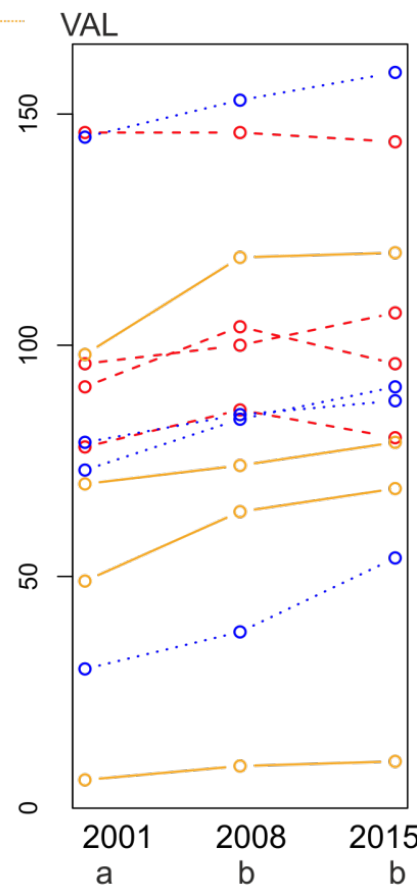

Figure 21. Species richness of the uppermost $10 \mathrm{~m}$ (upper panel) and thermic vegetation indicator (mean over $161 \mathrm{~m}^{2}$ plots, lower panel) on eleven summits in the Mediterranean (left) and twelve summits in the temperate (right) biome in the years 2001, 2008 and 2015. Each line represents a summit, regions are colour-coded. Different lower-case letters indicate significant differences between years (generalized linear mixed-effects models $^{13}$ for species richness, linear mixed-effects models for thermic vegetation indicator ${ }^{14}$ ).
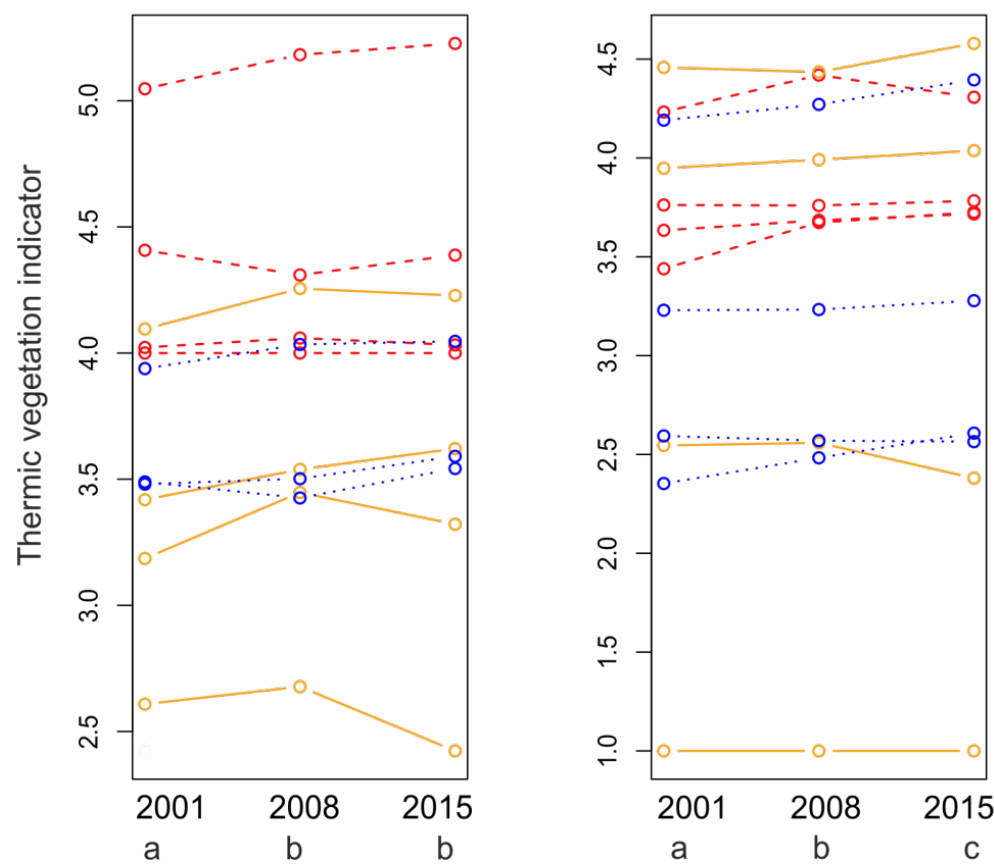

13 Generalized linear mixed-effects models (glmms) using Penalized Quasi-Likelihood and a Poisson error distribution, with year as fixed effect and summit nested in region as random intercept term, calculated using the function $\mathrm{g} / \mathrm{mm} P Q L$ from the R-library MASS (Venables et al. 2002). Contrasts for pairwise comparisons of the levels of the fixed effect were calculated with the functions cld and Ismeans of the R-package Ismeans (Lenth 2016).

14 Linear mixed-effects models (Imms)with year as fixed effect and summit nested in region as random intercept term, calculated using the function Imer from the R-library Ime4 (Bates et al. 2015). Contrasts for pairwise comparisons of the levels of the fixed effect were calculated with the functions cld and Ismeans of the R-package Ismeans (Lenth 2016). 


\section{SYNTHESIS - INFLUENCE OF CLIMATE, LAND-USE, NITROGEN DEPOSITION, SOLAR IRRADIATION AND MICROTOPOGRAPHIC VARIABILITY ON CHANGES IN SPECIES RICHNESS AND COMPOSITION}

In this chapter, we disentangle the influence of the drivers described above on plant species richness and composition and their changes using (generalized) linear mixed-effects models (GLMMs and LMMs) and structural equation modeling (SEM; Grace et al. 2015). SEM is a modeling framework for building and evaluating causal relationships in systems which involves the graphical representation of causal assumptions and network implications (Grace et al. 2015, Grace et al. 2012). In the future, we plan to complement the analyses at summit scale presented here with small-scale analyses at the level of individual plots (Winkler et al in prep.).

\subsection{SPECIES RICHNESS AND CHANGES IN SPECIES RICHNESS}

Species richness on summits was highly significantly influenced by temperature in the temperate biome, in the Mediterranean biome only precipitation had a small (borderline not significant) effect (Table 4, Fig. 22).

Table 4: Potential drivers of species richness on summits in the a) Mediterranean and b) temperate biome. Coefficient estimates and standard errors, degrees of freedom, $t$-values and $p$-values of fixed effects of generalized linear-mixed effects models with Penalized Quasi-Likelihood, a Poisson error distribution and summit nested in region as random intercept term are given. To avoid overfitting, models were fitted with a single fixed effect. Intercepts are not shown to enhance clarity.

\begin{tabular}{llllll}
\hline & Estimate & Std.Error & DF & t-value & p-value \\
\hline a) Mediterranean & & & & & \\
Precipitation & $6.21 \mathrm{E}-04$ & 0.00 & 21 & 2.05 & $\mathbf{0 . 0 5 3}$ \\
Temperature & 0.05 & 0.04 & 21 & 1.13 & 0.269 \\
Solar radiation duration & 0.11 & 0.17 & 7 & 0.66 & 0.528 \\
Past land-use & -0.12 & 0.11 & 1 & -1.04 & 0.487 \\
Nitrogen deposition & 0.00 & 0.00 & 7 & -0.38 & 0.712 \\
Microtopographic variability & 0.03 & 0.08 & 7 & 0.36 & 0.732 \\
& & & & & \\
b) Temperate & & & & & 0.49 \\
Precipitation & 0.00 & 0.00 & 23 & 6.54 & $<0.001$ \\
Temperature & 0.30 & 0.05 & 23 & 0.93 & 0.381 \\
Solar radiation duration & 0.19 & 0.20 & 8 & 0.34 & 0.789 \\
Past land-use & 0.08 & 0.22 & 1 & 1.52 & 0.166 \\
Nitrogen deposition & 0.01 & 0.00 & 8 & -0.43 & 0.675 \\
Microtopographic variability & -0.04 & 0.10 & 8 & & \\
\hline
\end{tabular}




\section{Mediterranean}
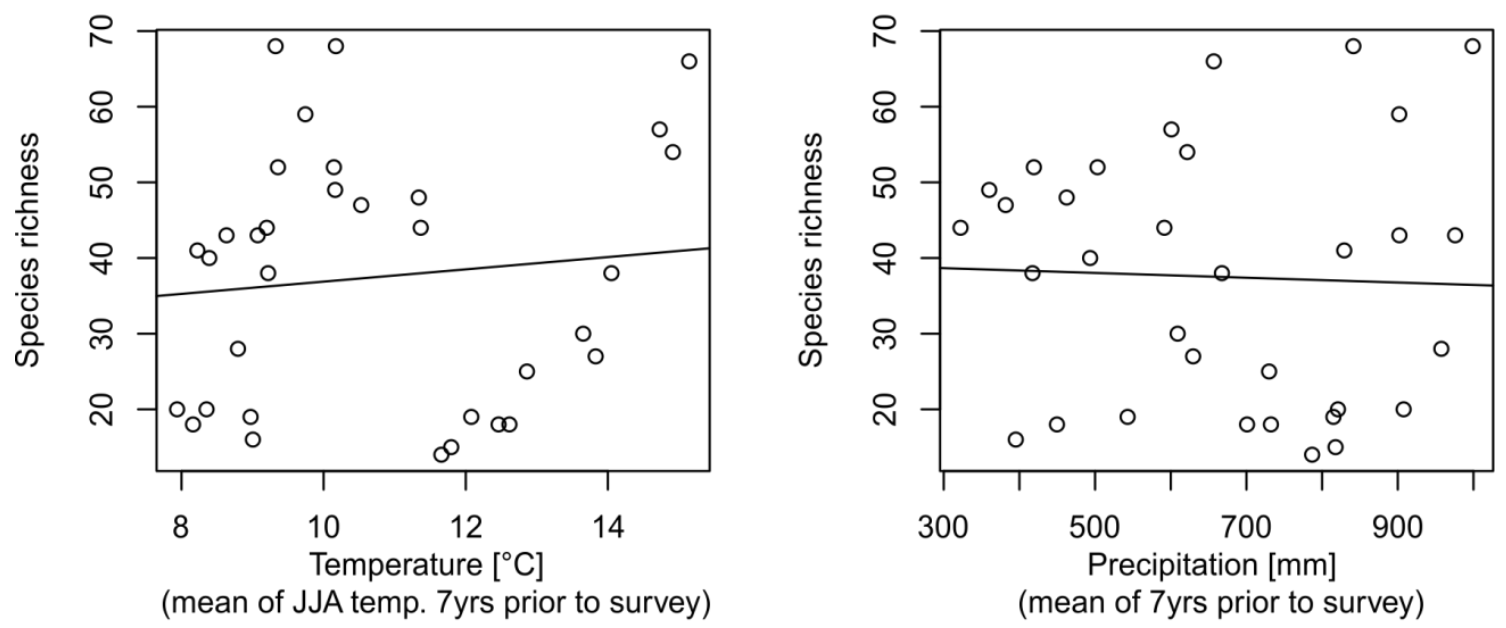

\section{Temperate}
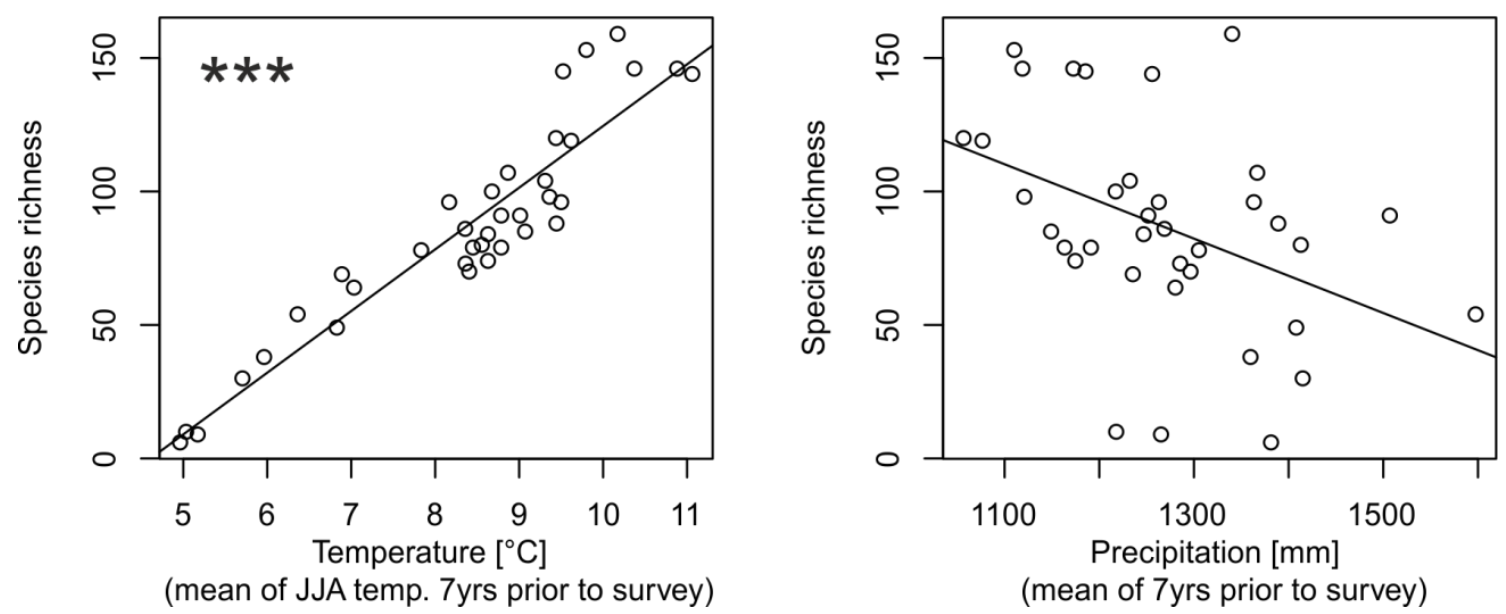

Figure 22. Scatterplots of climatic factors potentially affecting species richness on mountain summits in the Mediterranean (upper panel) and temperate (lower panel) biomes. Significance of fixed effects in linear-mixed effects models with each driver as single fixed effect and summit nested in region as random intercept term is indicated: $*$... p<0.05, ** ... p<0.01, *** ...<0.001.

To evaluate cause-effect relationships for changes in species richness, SEMs were implemented using the R-package lavaan 0.6-3 (Rosseel 2012). Two graphical networks were built, one for each biome, guided by the scatterplots of relationships between changes and drivers (Figs. 23, 24) and, most importantly, the theoretical knowledge about causal relationships in alpine ecosystems in the two biomes. 


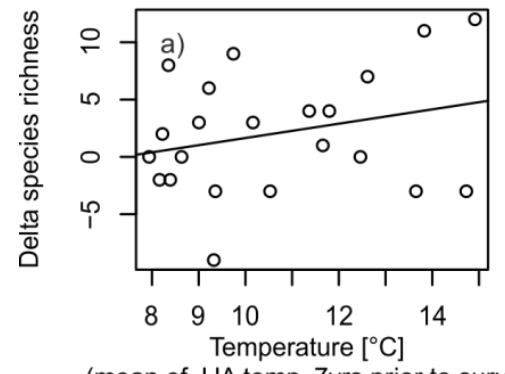

(mean of JJA temp. 7yrs prior to survey)

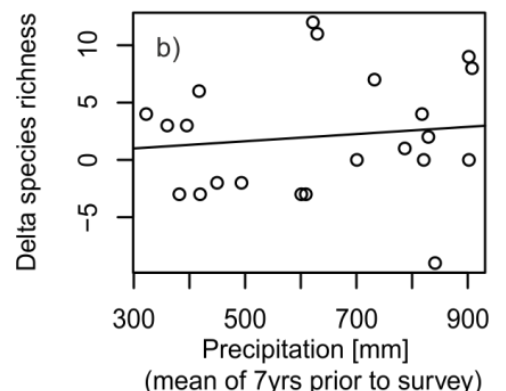

(mean of 7yrs prior to survey)
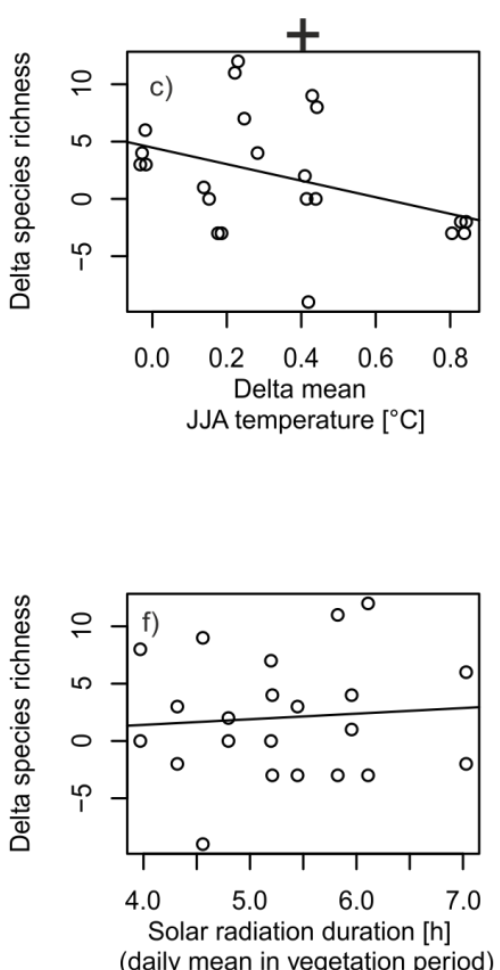

Nitrogen deposition $\left[\mathrm{mg} / \mathrm{m}^{2}\right.$.a]

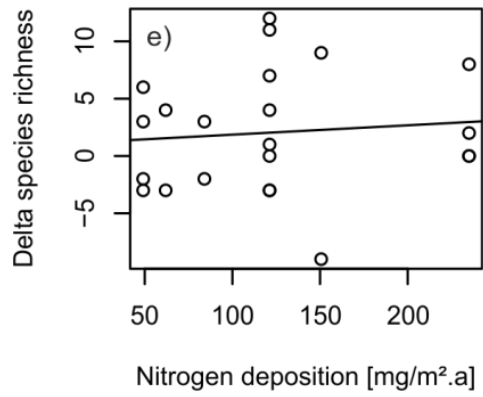

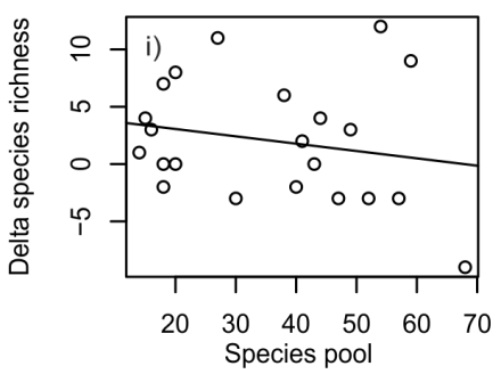

Present Land-use Score

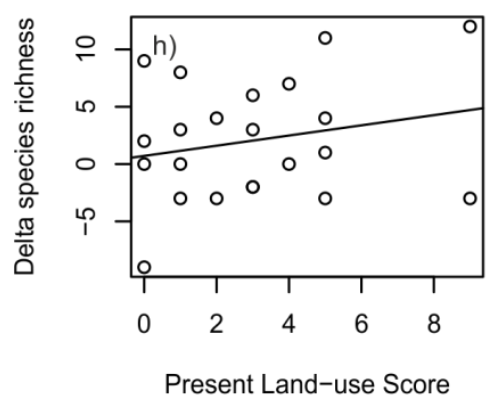

(total species richness on summit)

Figure 23. Scatterplots of factors potentially affecting changes in species richness on mountain summits in the Mediterranean biome. Significance of fixed effects in linear-mixed effects models with each driver as single fixed effect and summit nested in region as random intercept term is indicated: $+\ldots p<0.1,{ }^{*} \ldots p<0.05, * * \ldots$ $\mathrm{p}<0.01, * * * \ldots<0.001$. 


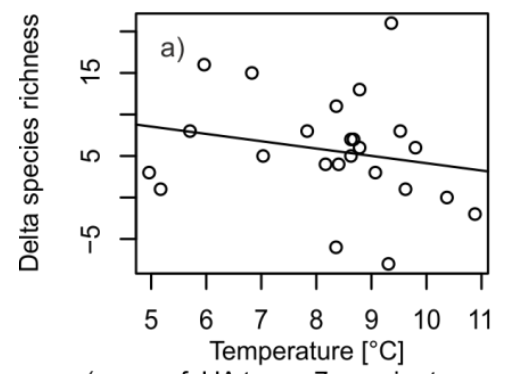

(mean of JJA temp. 7yrs prior to survey)

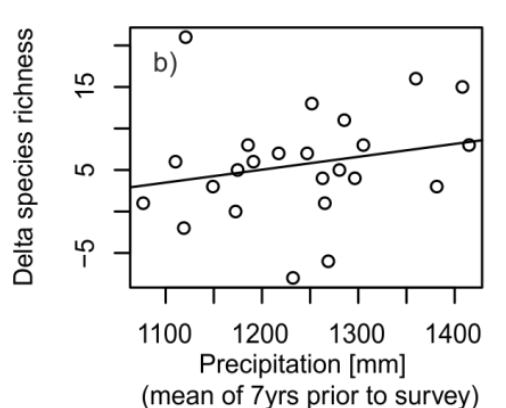

(mean of $7 y$ rs prior to survey)

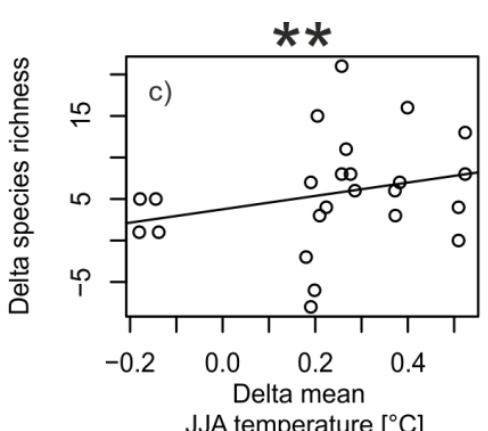

JJA temperature $\left[{ }^{\circ} \mathrm{C}\right]$
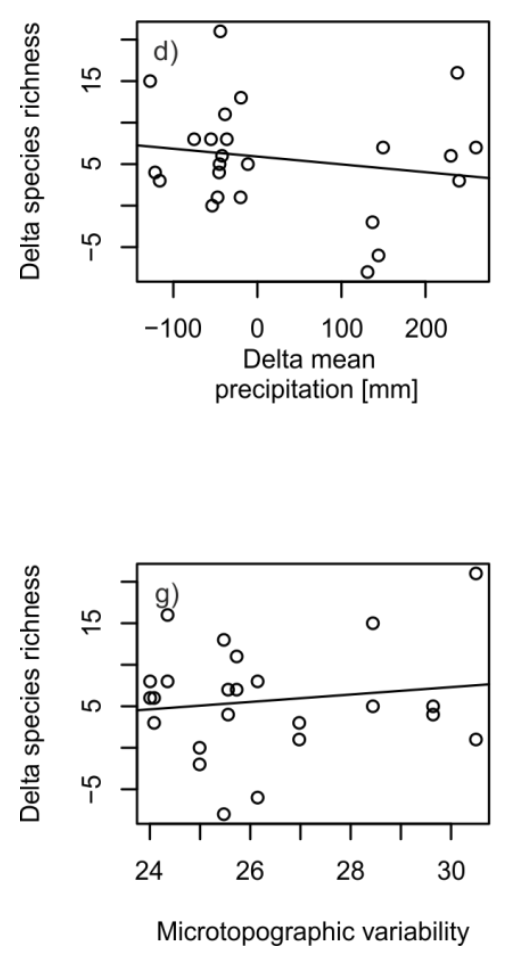
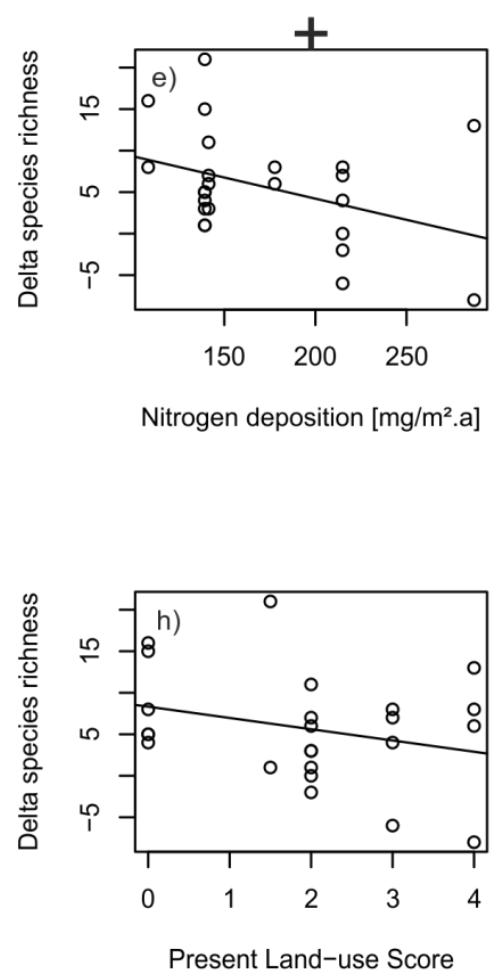
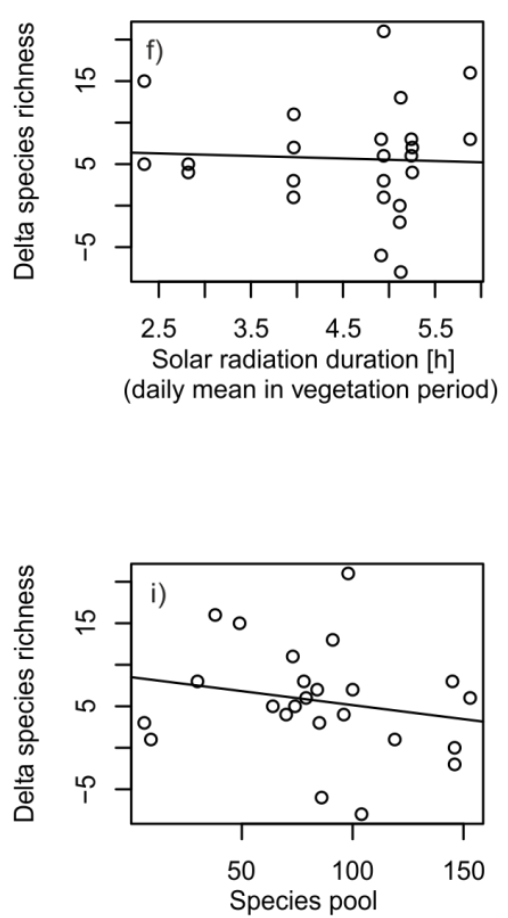

(total species richness on summit)

Figure 24. Scatterplots of factors potentially affecting changes in species richness on mountain summits in the temperate biome. Significance of fixed effects in linear-mixed effects models with each driver as single fixed effect and summit nested in region as random intercept term is indicated: $+\ldots p<0.1,{ }^{*} \ldots p<0.05, * * \ldots p<0.01$, *** ... < 0.001 . 


\section{a) Mediterranean Biome}

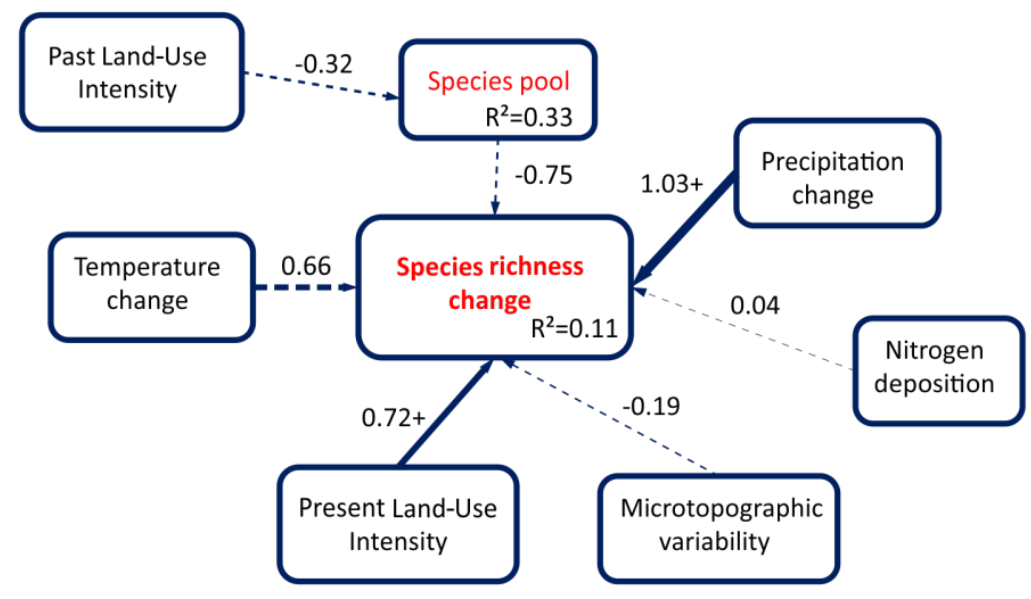

Iterations: 23

Optimization method: NLMINB

$\mathrm{N}$ free parameters: 9

N observations: 22

Estimator: ML

Model Fit Test Statistic: 7.299

Df: 6

P-value: 0.294

b) Temperate Biome

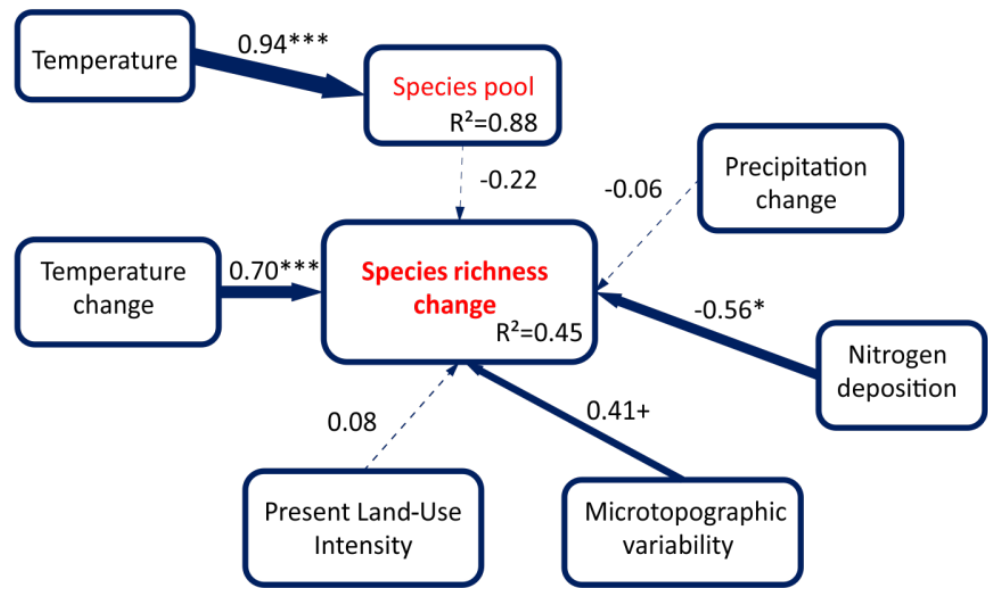

Iterations: 26

Optimization method: NLMINB

$\mathrm{N}$ free parameters: 9

N observations: 24

Estimator: ML

Model Fit Test Statistic: 6.435

Df: 6

P-value: 0.376

Figure 25. Results for the structural equation model (SEM) for the a) Mediterranean and $b$ ) the temperate biome. Boxes represent observed variables, arrow widths are proportional to the standardized path coefficients whose precise values are indicated by accompanying numbers. Significance of path coefficients is indicated with $+(p<0.1), *(p<0.05), * *(p<0.01)$ and $* * *(p<0.001)$. Paths with non-significant coefficients are dashed, those with significant ones are solid. Species pool is the total species richness on a summit in 2001. 
The SEM results suggest that biodiversity changes are caused by different drivers in the two biomes (Fig. 25), nevertheless, in both biomes changes in climatic variables had the highest influence. In the temperate biome temperature change was clearly the main factor, followed by nitrogen deposition and microtopographic variability. In contrast, in the Mediterranean biome precipitation changes were most important, followed by present land-use intensity. With the exception of nitrogen deposition, the path coefficients were positive, that is for instance an increase in temperature leads to an increase in species richness in the temperate biome. However, the models explained only $11 \%$ of the variation in species richness changes in the Mediterranean, probably indicating missing factors or paths. In the temperate biome, $45 \%$ of the variation in species richness change was explained by the SEM.

\subsection{THERMIC VEGETATION INDICATOR AND THERMOPHILISATION}

The thermic vegetation indicator on summits was highly significantly influenced by temperature in both biomes, in the temperate biome additionally by species richness (linear mixed-effects models; Table 5, Fig. 26).

Table 5: Potential drivers of the thermic vegetation indicator on summits in the a) Mediterranean and b) temperate biome. Coefficient estimates and standard errors, degrees of freedom, $t$-values and $p$-values of fixed effects of linear-mixed effects models with summit nested in region as random intercept term are given. To avoid overfitting, models were fitted with a single fixed effect. Intercepts are not shown to enhance clarity.

\begin{tabular}{|c|c|c|c|c|c|}
\hline & Estimate & Std.Error & DF & t-value & p-value \\
\hline \multicolumn{6}{|l|}{ a) Mediterranean } \\
\hline Precipitation & 0.00 & 0.00 & 22 & -0.05 & 0.960 \\
\hline Temperature & 0.16 & 0.03 & 21 & 4.88 & $<0.001$ \\
\hline Solar radiation duration & -0.13 & 0.24 & 9 & -0.55 & 0.599 \\
\hline Past land-use & 0.28 & 0.19 & 1 & 1.50 & 0.372 \\
\hline Nitrogen deposition & 0.00 & 0.00 & 4 & -0.17 & 0.877 \\
\hline Species richness & 0.00 & 0.00 & 28 & 0.64 & 0.525 \\
\hline Microtopographic variability & 0.07 & 0.09 & 7 & 0.76 & 0.473 \\
\hline \multicolumn{6}{|l|}{ b) Temperate } \\
\hline Precipitation & 0.00 & 0.00 & 23 & 1.59 & 0.126 \\
\hline Temperature & 0.21 & 0.04 & 27 & 4.69 & $<0.001$ \\
\hline Solar radiation duration & 0.31 & 0.29 & 10 & 1.06 & 0.315 \\
\hline Past land-use & -0.14 & 0.37 & 1 & -0.37 & 0.775 \\
\hline Nitrogen deposition & 0.01 & 0.01 & 10 & 1.49 & 0.168 \\
\hline Species richness & 0.01 & 0.00 & 27 & 2.75 & 0.011 \\
\hline Microtopographic variability & 0.23 & 0.22 & 2 & 1.07 & 0.392 \\
\hline
\end{tabular}




\section{Mediterranean}
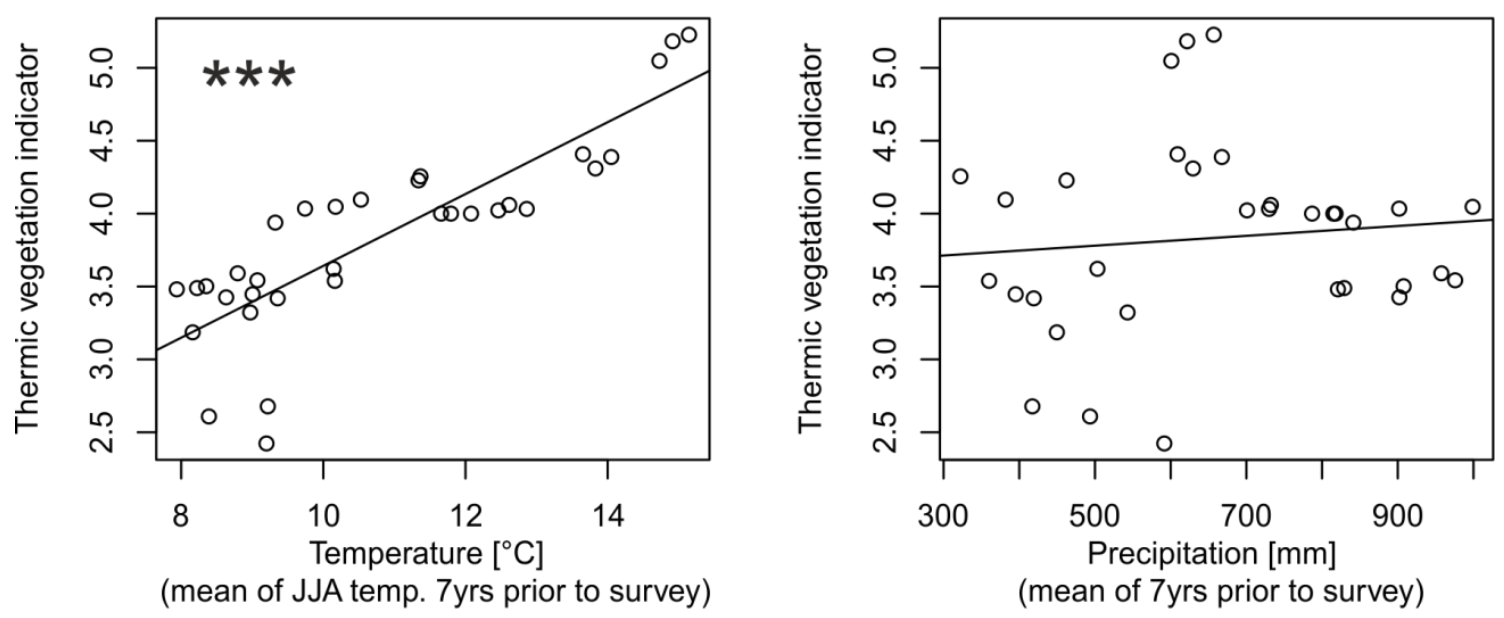

\section{Temperate}
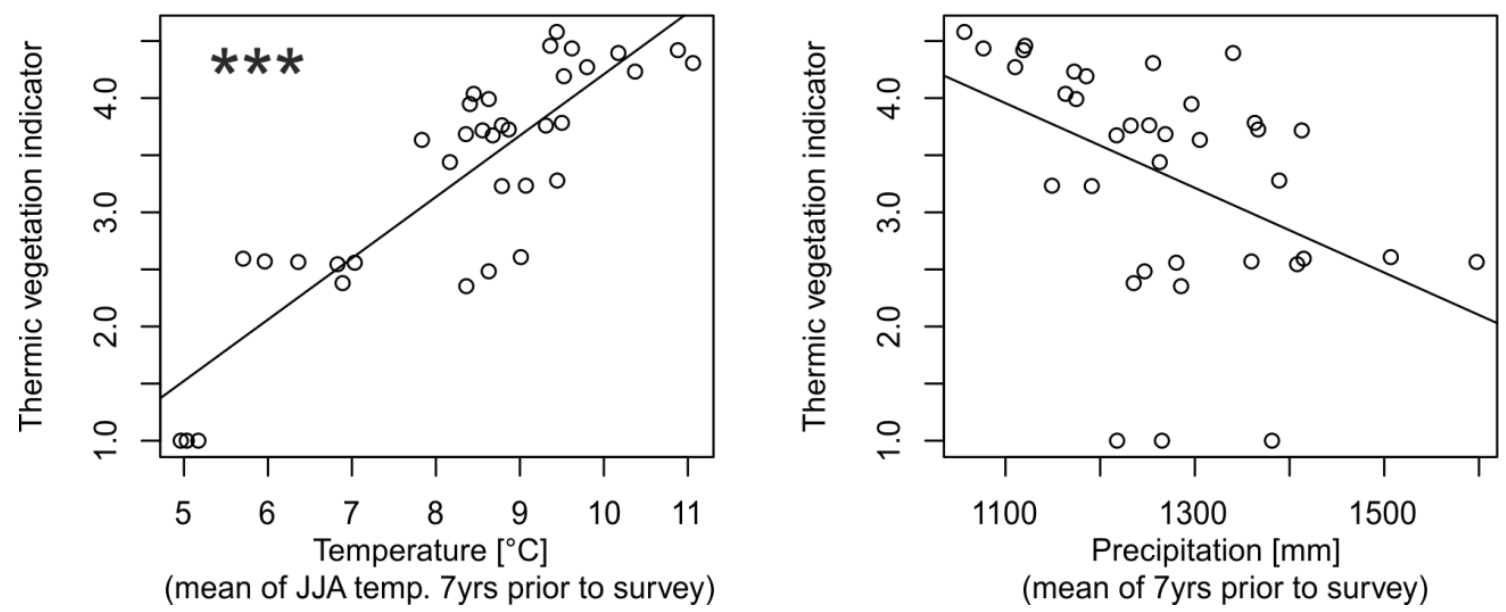

Figure 26. Scatterplots of climatic factors potentially affecting the thermic vegetation indicator on mountain summits in the Mediterranean (upper panel) and temperate (lower panel) biomes. Significance of fixed effects in linear-mixed effects models with each driver as single fixed effect and summit nested in region as random intercept term is indicated: * ... p<0.05, ** ... p<0.01, *** ... $<0.001$.

Thermophilisation was influenced by temperature change in both biomes (in the temperate biome only significant at the $p<0.1$ level), and additionally by precipitation change in the Mediterranean biome and present land-use in the temperate biome (the latter only significant at the $p<0.1$ level; Figs 27, 28) 


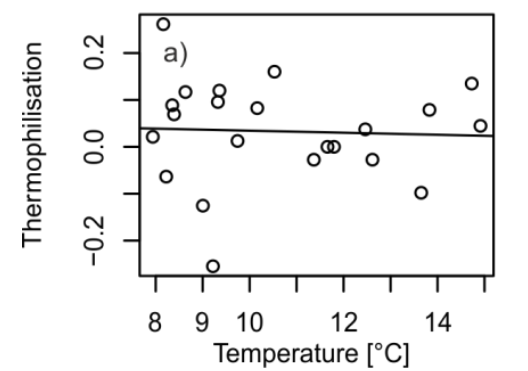

(mean of JJA temp. 7yrs prior to survey)
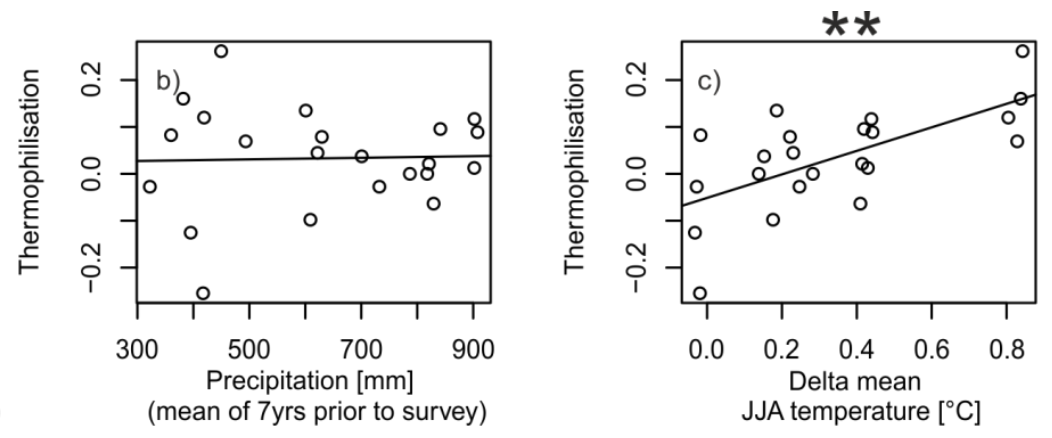

JJA temperature $\left[{ }^{\circ} \mathrm{C}\right]$
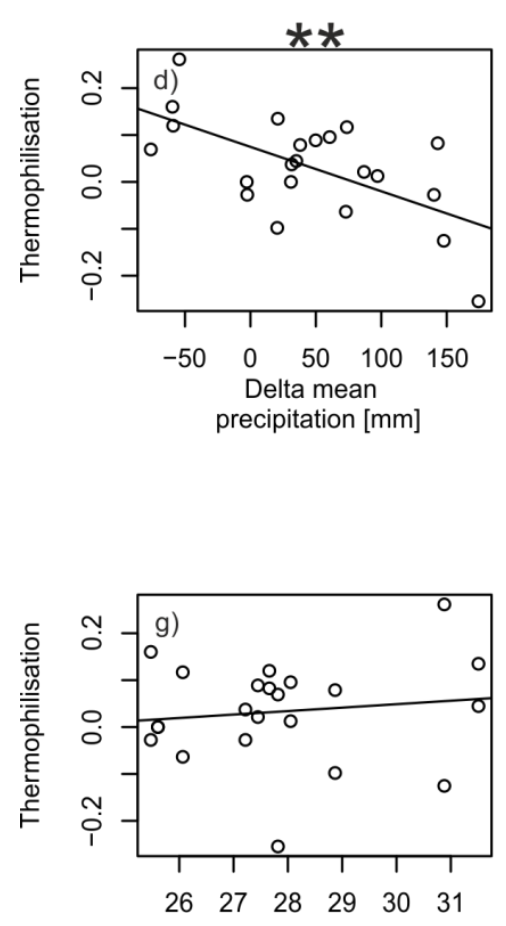

Microtopographic variability
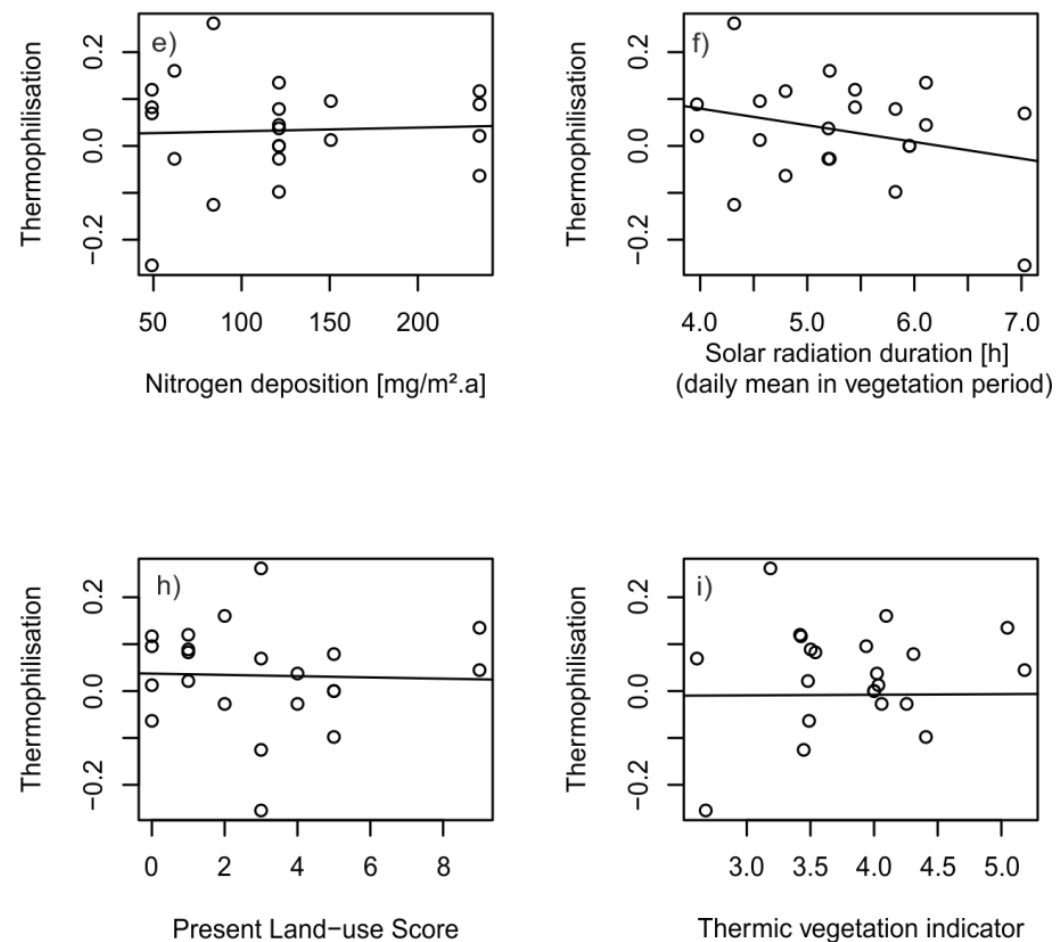

Figure 27. Scatterplots of factors potentially affecting changes in the thermic vegetation indicator (i.e., thermophilisation) on mountain summits in the Mediterranean biome. Significance of fixed effects in linearmixed effects models with each driver as single fixed effect and summit nested in region as random intercept term is indicated: $+\ldots \mathrm{p}<0.1, * \ldots \mathrm{p}<0.05,{ }^{* *} \ldots \mathrm{p}<0.01, * * * \ldots<0.001$. 


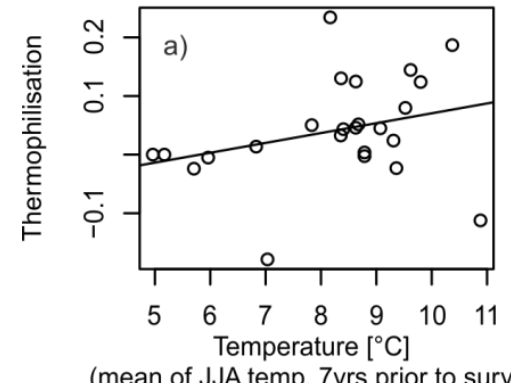

(mean of JJA temp. 7yrs prior to survey)

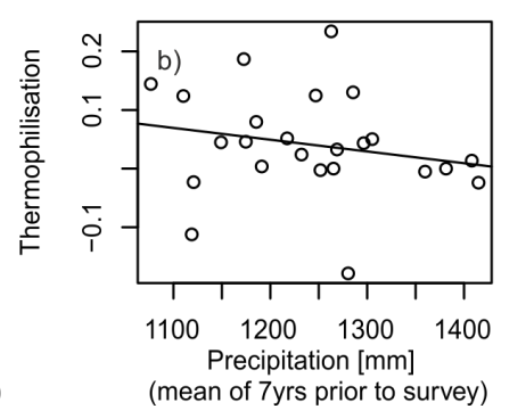

(mean of 7yrs prior to survey)
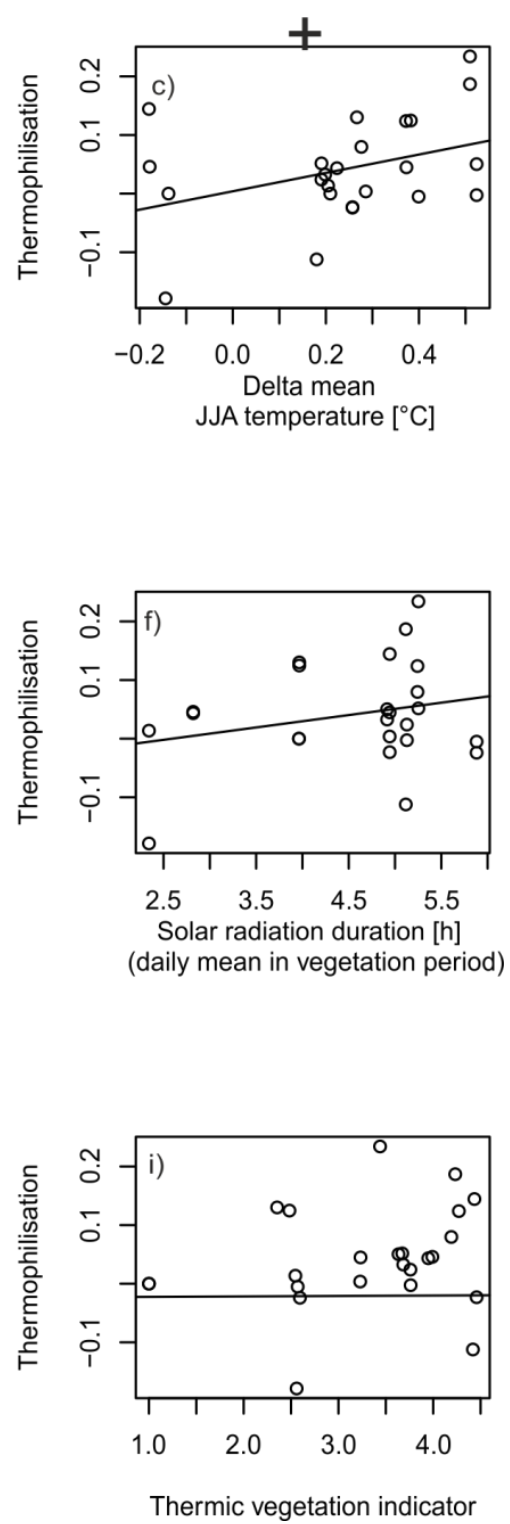
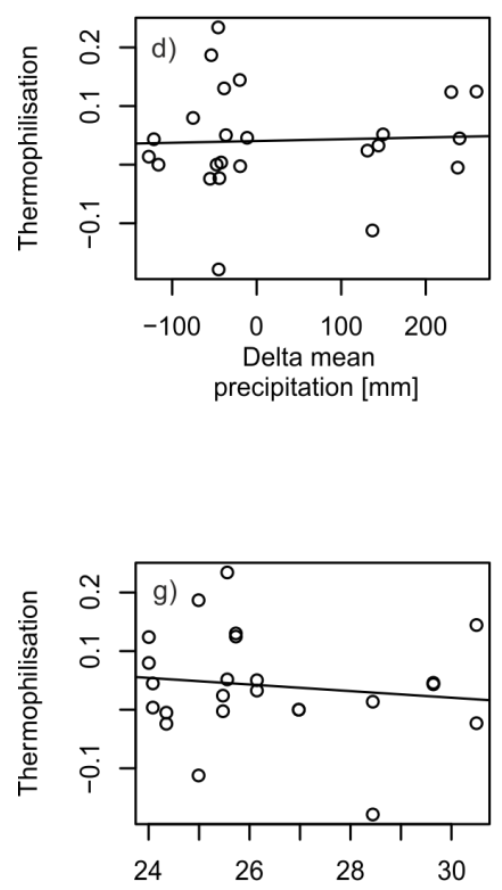

Microtopographic variability
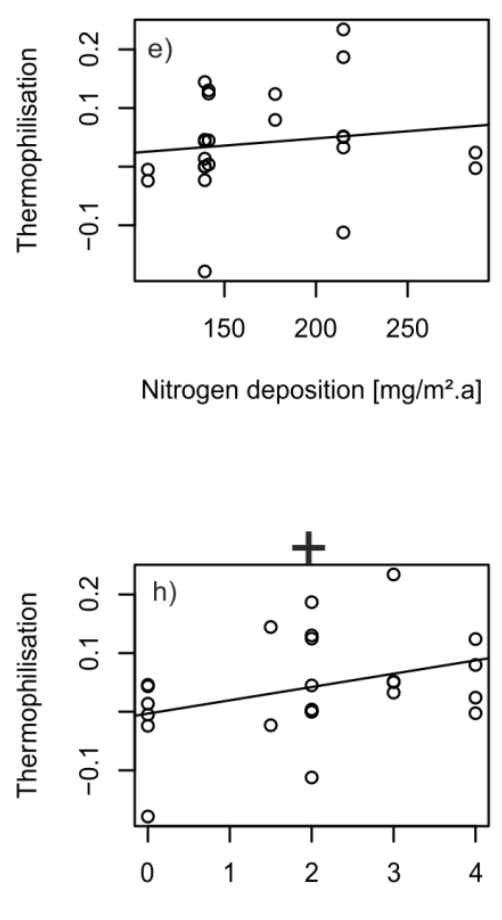

Present Land-use Score

Figure 28. Scatterplots of factors potentially affecting changes in the thermic vegetation indicator (i.e., thermophilisation) on mountain summits in the temperate biome. Significance of fixed effects in linear-mixed effects models with each driver as single fixed effect and summit nested in region as random intercept term is indicated: $+\ldots p<0.1, * \ldots p<0.05, * * \ldots p<0.01, * * * \ldots<0.001$. 


\section{CONCLUSIONS}

Climate change is and will probably continue to be the main driver of plant biodiversity, species composition and their changes on mountain summits in both biomes. However, there are biomespecific differences with precipitation playing an important role in the Mediterranean biome in addition to temperature, which clearly is the most important single factor in the temperate biome. Compared to the period 1971-2000 mean annual temperature is projected to increase by 1.9-3.4 K (IPCC scenario RCP4.5) or even 3.9-6.0 K (IPCC scenario RCP8.5) in the Alpine region, and 1.9-2.7 K (IPCC scenario RCP4.5) or even 3.9-5.4K (IPCC scenario RCP8.5) in southern Europe by the end of this century (Jacob et al. 2014). Concurrently, annual precipitation is projected to increase in the Alps (+4$8 \%$ RCP4.5, +7-16\% RCP8.5; albeit with regional variation, e.g. a decrease in summer precipitation is projected for the Swiss Alps, (CH2018 2018)) and decrease in southern Europe (-10 - 0\% RCP4.5, -2 to $-20 \%$ RCP8.5; Jacob et al. (2014)). These changes will likely lead to a further thermophilisation (Gottfried et al. 2012) in both biomes. The upwards movement of species from lower elevations will likely also result in a biotic homogenization of the vegetation (Boutin et al. 2017, Buhler and Roth 2011, Olden 2006, Ross et al. 2012), exacerbated by the decline of high-elevation endemic species (e.g., Theurillat 2016). Species richness will likely continue to increase in the temperate biome (cf. Steinbauer et al. 2018) until the "pay-off" of extinction debts (Dullinger et al. 2012) or threshold effects of population size on extinction risks (Oliver and Morecroft 2014) set in. With decreasing precipitation species richness in the Mediterranean biome will probably decline in the long run, too.

Nevertheless, other anthropogenic drivers have to be considered as well, although their influence is arguably much smaller than that of climate variables, namely nitrogen deposition with a negative influence on species richness change in the temperate biome and present land-use with a positive one in the Mediterranean biome. Nitrogen deposition alters species composition through competitive interactions and/or by making conditions unfavourable for some species (Bobbink et al. 2010). Under the IPCC scenario RCP4.5 the total (dry and wet) N deposition in Europe is predicted to decline by ca. $40 \%$ for $\mathrm{NO}_{2}$ and by ca. $1 \%$ for $\mathrm{NH}_{3}$ until 2050 compared to year 2000 . $\mathrm{NO}_{2}$ reductions will be proportionally higher in regions with higher present N-deposition (ca. 15\% in GR-LEO and ESSNE, $45 \%$ in AT-HSW, CH-VAL and IT-CAM; 50\% in IT-ADO). Thus, the moderating effect of nitrogen deposition on species richness increase in the temperate biome will likely decrease although the eutrophication effects from accumulated past depositions will take an unknown time to wear off.

Predicting land-use changes is challenging and projections focus mostly on (lowland) agriculture and forests (e.g., Holman et al. 2017) making forecasts for remote high-elevation locations extremely difficult. However, based on the expert judgement of the interviewees tourism and certain forms of 
pastoralism are increasing in the Mediterranean regions, which may lead to disturbance related changes in biodiversity and species compositions.

In addition to MediAlps' main focus on comparing multiple anthropogenic ecological drivers in the Alps with the Mediterranean mountains, the project substantially contributed to a spatially larger scaled long-term observation effort. MediAlps was the strongest 'individual' supporter of the third pan-European survey cycle of the GLORIA network so that it was possible to conduct the continentwide monitoring campaign at almost all European sites. Especially, it covered the majority of Mediterranean sites, where the risk of biodiversity losses is expected to be highest among Europe's mountains, owing to their limited and fragmented alpine areas and the large proportions of very locally distributed endemic species.

Climate warming strongly amplified during recent decades and increasingly leads to a pervasive reshuffling of species distributions. This rapid development, however, is not reflected in adequate support actions for long-term monitoring activities designed for detecting impacts of climate change on mountain biodiversity. At the turn of the Millennium, the GLORIA-Europe baseline was laid through an EU FP5 project. In 2008, the second survey circle was substantially supported by the private MAVA Foundation for Nature Conservation. In 2015, fund raising for conducting the third survey became more difficult, since the MAVA and other foundations went into a thematic restructuring and EU funding options did not offer suitable research topics.

In this critical phase, the contribution through the Earth System Sciences programme of the Austrian Academy of Sciences was invaluable. It enabled the uninterrupted continuation of the GLORIA monitoring in Europe, the continent's only alpine vegetation monitoring programme for climate change effects, based on a common permanent plot design. To illustrate the overall scarcity of Europe-wide biodiversity/climate change monitoring programmes, we give an example from about a decade ago: An effort on halting the loss of biodiversity in Europe by 2010 (SEBI), the European Environment Agency, together the European Topic Center on Biological Diversity, were looking for suitable 'indicators' for different organism groups. For the climate change context across Europe, they were successful for breeding birds and butterflies, where much of the data were collected through voluntary work. For the remaining part of the terrestrial biosphere only data for alpine vascular plant diversity was available thanks to the GLORIA network. The GLORIA network owns the largest bio-ecological database of mountain summit habitats at global scale and may become the research infrastructure of reference at least for monitoring of global change effects on biodiversity at the European level. 


\section{Publications in scientific journals}

Evangelista A, Frate L, Carranza ML, Attorre F, Pelino G, Stanisci A. 2016. Changes in composition, ecology and structure of high-mountain vegetation: a re-visitation study over 42 years. Aob Plants 8 : 11.

Niederheiser R., Rutzinger M., Lamprecht A., Steinbauer K., Winkler M. \& Pauli H. (2016): Mapping alpine vegetation location properties by dense matching. In: The International Archives of the Photogrammetry, Remote Sensing and Spatial Information Sciences. Prague, Czech Republic Vol. XLIB5, pp. 881-886.

Unterluggauer P., Mallaun M., Erschbamer B. (2016): The higher the summit, the higher the diversity changes - Results of a long-term monitoring project in the Dolomites. Gredleriana 16: 5-34.

Di Musciano M, Carranza ML, Frate L, Di Cecco V, Di Martino L, Frattaroli AR, Stanisci A. 2018. Distribution of Plant Species and Dispersal Traits along Environmental Gradients in Central Mediterranean Summits. Diversity-Basel 10/58(3): 1-17.

Frate L., Carranza M. L., Evangelista A., Stinca A., Schaminée J. H., \& Stanisci A. (2018). Climate and land use change impacts on Mediterranean high-mountain vegetation in the Apennines since the 1950s. Plant Ecology \& Diversity, 11(1), 85-96.

Niederheiser R., Rutzinger M., Bremer M. \& Wichmann V. (2018): Dense image matching of terrestrial imagery for deriving high-resolution topographic properties of vegetation locations in alpine terrain. International Journal of Applied Earth Observation and Geoinformation 66: 146-158.

Rogora M., L. Frate, M.L. Carranza, M. Freppaz, A. Stanisci, I. Bertani, R. Bottarin, A. Brambilla, R. Canullo, M. Carbognani, C. Cerrato, S. Chelli, E. Cremonese, M. Cutini, M. Di Musciano, B. Erschbamer, D. Godone, M. locchi, M. Isabellon, A. Magnani, L. Mazzola, U. Morra di Cella, H. Pauli, M. Petey, B. Petriccione, F. Porro, R. Psenner, G. Rossetti, A. Scotti, R. Sommaruga, U. Tappeiner, J.-P. Theurillat, M. Tomaselli, D. Viglietti, R. Viterbi, P. Vittoz, M. Winkler, G. Matteucci, 2018. Assessment of climate change effects on mountain ecosystems through a cross-site analysis in the Alps and Apennines. Sci Total Environ, 624: 1429-1442.

\section{Manuscripts in preparation}

Lamprecht A., H. Pauli, M.R. Fernández Calzado, J. Molero-Mesa, M. Bardy-Durchhalter, A. Gattringer, D. Moser, K. Steinbauer, M. Winkler: Climate driven changes of high mountain plant communities at the cold edge of southern Europe. In prep.

Niederheiser R., M. Winkler, C. Geitner, H. Pauli, B. Erschbamer, R. Fernández Calzado, D. Ghosn, H. Hofbauer B., G. Kazakis, Klingraber, A. Lamprecht, J. Molero Mesa, A. Stanisci, K. Steinbauer, J.-P. Theurillat, P. Vittoz, M. Rutzinger: Automated vegetation cover estimation from close-range photogrammetric point clouds in alpine terrain for interpretation of micro topographic conditions in summit areas of the alps and mediterranean mountains. In prep. 
Winkler M. et al. Climate change effects on species richness and composition of European mountain summits revisited. In prep.

\section{Theses}

Kamphuis J. (2015): Vegetation detection in Structure-from-Motion derived 3D-models. BSc Thesis. Applied Earth Sciences. Delft University of Technology.

Evangelista A. (2016): Resilience and turnover in high-altitude ecosystems in Central Apennines. PhD thesis in "Science, Technology and Biotechnology for Sustainability", $29^{\circ}$ Cycle, University of Tuscia University of Molise.

Di Musciano M. 2016: Vegetation analysis in the permanent plots of GLORIA project in Majella National Park: a synchronic approach to identify the key species for monitoring climate change. MSc Thesis. University of L'Aquila-University of Molise.

Den Outer J. (2016): Analyse von Vegetationsstandorten im Hochgebirge mithilfe des Verfahrens des dense matchings von terrestrischen Schrägbildaufnahmen. MSc Thesis. Institute of Geography, University of Innsbruck.

Mayr S. (2017): Analyse des Landbedeckungswandels von Vegetationsstandorten im Hochgebirge mittels Satellitenfernerkundung. Master Thesis, Institute of Geography, University of Innsbruck, 169 pp.

Hofbauer H. (2018): Mapping surface types in high moun-tain environments of the Alps. Bachelor Thesis, University of Natural Resources and Life Sciences Vienna (BOKU), Vienna, Austria, 29 pp.

Klingraber B. (2018): Comparing two methods of recording the top cover of surface types in permanent plots on GLORIA summits in Mediterranean regions. Bachelor Thesis, University of Natural Resources and Life Sciences Vienna (BOKU), Vienna, Austria, 24 pp.

Stackelberg, M. (in prep.): Modellierung und Analyse phänologischer Zeitreihen im Gebirge mit Landsat und Sentinel-2. MSc Thesis. School: Institute of Geography, University of Innsbruck. Innsbruck, Austria.

Di Musciano M. (in prep.) : Floristic diversity along elevation gradients in central Apennines: diversity pattern and global change. PhD School in "Sciences of health and environment" $32^{\circ}$ Cycle, L'Aquila University.

Lamprecht A. (in prep.) Disentangling anthropogenic drivers of global change impacts on alpine plant species. PhD Thesis, University of Natural Resources and Life Sciences Vienna (BOKU), Vienna, Austria

Niederheiser R. (in prep.) Mapping alpine vegetation location properties. PhD Thesis, Institute of Geography, University of Innsbruck. 


\section{Presentations at conferences}

Niederheiser R., Rutzinger M., den Outer J. \& Winkler M. (2015): Mapping vegetation location properties using a structure from motion approach. In: Perth III: Mountains of Our Future Earth. Perth, United Kingdom.

Evangelista A, Frate L, Carranza ML, Petriccione B, Pelino P, Attorre F, De Sanctis M \& Stanisci A. (2015) Long-term ecological research in Italian summit vegetation: observations at central Apennines. 58th IAVS Symposium, Brno, Czech Republic, $19-24$ July 2015, Book of Abstract, pp 62

Di Musciano M., Stanisci A., Frate L., Di Cecco V., Di Martino L., Frattaroli A.R. (2016). The Times they are a Changin': A Synchronic Approach for identifying the Key Plant Species to Monitor Climate Change: effects at high elevation in Majella National Park. $111^{\circ}$ Congresso della Società Botanica Italiana, Roma 21-23 settembre 2016.

Frate L, Evangelista A, Stinca A, Schamineé JHJ, Hennekens SM, Carranza ML, Stanisci A. (2016) Vegetation databases and long-term analysis of high mountain EU habitats: detecting ecological and structural changes in central Apennines. Book of Abstract Poster. $25^{\circ}$ Meeting of European Vegetation Survey, Rome 6-9 April 2016. Pag. 42. ISBN 9788890409155.

Di Musciano M., Stanisci A., Frate L., Carranza M.L., Di Cecco V., Di Martino L., Frattaroli A.R. 2017. Nurse plant effect along mountain vertical gradients. An insight in central Apennine. $112^{\circ}$ Congress of Italian Botanical Society, Parma 20-23/9/2017.

Di Musciano M., Stanisci A., Frate L., Di Cecco V., Di Martino L., Frattaroli A.R. - The importance of dispersal traits in mountain environment to predict changes in plant species distribution under climate warming, the case study on central Apennines GLORIA summits. Communication at Plant Traits 2.0 congress, Bologna 9/02/2017.

Erschbamer B.: Hochgebirge als Hotspots der Diversität - durch den Klimawandel in Gefahr? Jahrestagung der Reinhold-Tüxen-Gesellschaft in Hannover. 10.-12.03.2017.

Erschbamer B.: Habitat monitoring - an essential tool to assess changes and predict consequences. Experiences from the Alpine region. Keynote IAVS 2017, Palermo 20.-24.06.2017 In: Guarino, R., Bazan, G. \& Barbera G. (eds.) IAVS - Vegetation patterns in natural and cultural landscapes. Atti e Convegni 3: Abstract books, Palermo University Press: 18-19.

Evangelista A., Frate L., Stinca A., Carranza M.L., Stanisci A. (2017). Evoluzione floristica delle mughete appenniniche nel Parco Nazionale della Majella dagli anni 60 ad oggi. Atti delle giornata della ricerca scientifica Dipartimento di Bioscienze e Territorio. Volume degli atti pp: 29-30. ISBN: 9788896394205.http://www.unimol.it/wp-content/uploads/2017/02/ATTI_GRS_DIBT_2017.pdf

Frate L., Di Febbraro M., Evangelista A., Di Cecco V., Carranza M.L., Cutini M., Theurillat J.-P., Stanisci A. (2017). Using a model based fourth-corner analysis to explain plant traits pattern in high mountain ecosystems. Atti delle giornata della ricerca scientifica Dipartimento di Bioscienze e Territorio. Volume degli atti pp: 33-34. ISBN: 9788896394205. http://www.unimol.it/wpcontent/uploads/2017/02/ATTI_GRS_DIBT_2017.pdf

Freppaz. M., Rogora M., Stanisci A., 2017. Le montagne italiane, sentinelle europee del cambiamento climatico. Workshop 10 $10^{\text {th }}$ years of LTER Italy, Mantova 10 nov 2017. 
Lamprecht A; Pauli H; Steinbauer K; Bardy-Durchhalter M; Winkler M. 2017: Do alpine plant communities respond differently to climate change impacts? - The Alps versus Mediterranean mountains. 10th Annual Meeting of the Specialist Group on Macroecology of the Ecological Society of Germany Austria and Switzerland. Macroecology in Space and Time. , APR 19-21, 2017, Wien

Niederheiser R. (6.11.2017): Mapping Alpine Vegetation Location Properties by Dense Matching. PhD Seminar Doctoral Programm Alpine Biology and Global Change, University of Innsbruck.

Niederheiser R., Rutzinger M., Lamprecht A., Bardy-Durchhalter M., Pauli H. \& Winkler M. (2017): Mapping topographic plant location properties using a dense matching approach. In: Geophysical Abstracts.(EGU2017-15617-3).

Winkler M. 2017: MediAlps: Disentangling anthropogenic drivers of global change impacts on alpine plant species composition: Alps versus Mediterranean mountains. Botanisches Kolloquium, Institute of Botany, University of Innsbruck, MAI 31, 2017, Innsbruck, AUSTRIA

Lamprecht A; Pauli H; Fernández Calzado M R; Steinbauer K; Winkler, M. 2018: Vascular plants at the cold edge of southern Europe. Jahrestagung des AK Hochgebirge, FEB 2-4, 2018, Innsbruck

Lamprecht A; Pauli H; Fernández Calzado M.R; Bardy-Durchhalter M; Gattringer A; Moser D; Steinbauer K; Wilfing K; Winkler M; (2018): Climate driven changes of high mountain plant communities at the cold edge of southern Europe. [Poster] 48th Annual Meeting of the Ecological Society of Germany, Austria and Switzerland (GfÖ) "Ecology - meeting the scientific challenges of a complex world", SEP 10-14, 2018, Vienna, Austria

Mayr S., Rutzinger M., Geitner C., Niederheiser R. \& Winkler M. (2018): Land cover classification and change detection in European high-altitude regions. In: eo4alps. Innsbruck, Austria (https://www.dropbox.com/s/jx04b8nq7fixq5b/Abstract\%20Book\%20v.4.pdf?dl=1)

Niederheiser R. (7.2.2018): Charakterisierung alpiner Vegetationsstandorte mittels Dense Matching, Treffen der Arbeitsgruppe Boden und Landschaftsökologie, Institut für Geographie, Universität Innsbruck

Winkler M; Lamprecht A; Steinbauer K; Andrews C; Fernández Calzado MR; Carranza ML; Dick J; Goshn D; Kazakis G; Mallaun M; Moiseev D; Moiseev P; Molero Mesa J; Stanisci A; Theurillat J P; Unterluggauer P; Vittoz P; Pauli H; (2018): Different biomes, different responses of alpine plant communities to climate change impacts - Mediterranean vs. temperate and boreal mountains. IAVS 61st Annual Symposium "Natural Ecosystems as Benchmarks for Vegetation Science", JUL 22-27, 2018, Bozeman, Montana, USA

\section{Public relations}

Stanisci A. II valore della biodiversità. SUMMER SCHOOL "Turismo, Biodiversità, Heritage: dall'integrazione delle risorse alla progettazione territoriale"Caramanico Terme, Majella National Park 23-27 september 2015

BioBlitz - The story-telling of biodiversity in Apennines. Majella National Park, 23-07- 2016.

BioBlitz - The story-telling of biodiversity in Apennines. Majella National Park, 23-07-2017. http://www.Iteritalia.it/cammini2017/biodiversita 
Erschbamer B.: Der Klimawandel im Hochgebirge. Webforum 50 plus, Kolpinghaus Innsbruck; 07.03.2017

Erschbamer B.: Global Observation Research Initiative in Alpine Environments. Ausstellung Überlebenskunst, Botanischer Garten Innsbruck. 08.06.-15.10.2017

Erschbamer B.: Alpine Artenvielfalt in Gefahr? Die Vegetation der Berggipfel in Zeiten des Klimawandels - Untersuchungen in den Südtiroler Dolomiten. Berg, BergWissen, Alpenvereinsjahrbuch 2018: 212-217.

Stanisci A. The Mediterranean sentinels of global warming: GLORIA summits in Majella National Park. Forum degli Appennini. Caramanico (AQ). 20/12/2018.

\section{Project documentation}

Project-Homepage and project documentation at the homepage of IGF, ÖAW: http://www.mountainresearch.at/index.php/en/projects/49-remote-sensing-and-geomatics/404MediAlps-2.

Blog-entry at the homepage of IGF, ÖAW: http://www.mountainresearch.at/index.php/en/blogen/518-the-project-MediAlps.

Project documentation at ResearchGate: https://www.researchgate.net/project/MediAlps.

The ITCAM target site is described in the website of LTER Italy http://www.Iteritalia.it/?q=siti/appennino-centro-meridionale-majella-matese

Video „Project MediAlps Disentangling anthropogenic drivers of global change impacts on alpine plant species: Alps versus Mediterranean mountains, Target site Majella National Park". Available on request (Fig. 29).

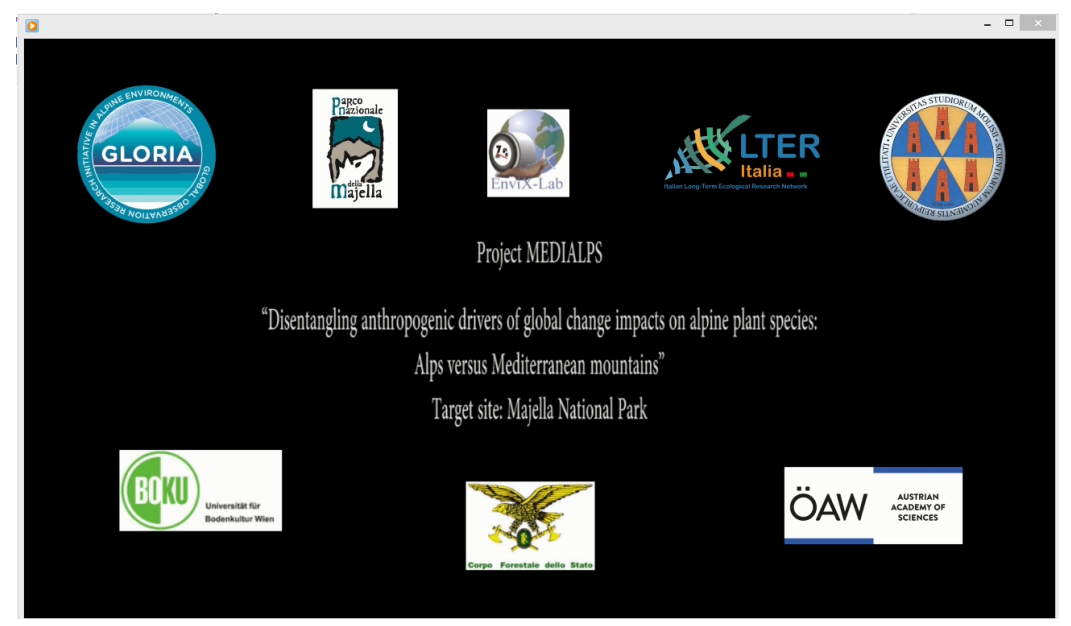

Figure 29. Screenshot MediAlps-Video. 


\section{ABSTRACTS OF PUBLISHED MANUSCRIPTS AND THESES}

Papers

The higher the summit, the higher the diversity changes - Results of a long-term monitoring project in the Dolomites

Unterluggauer P., Mallaun M., Erschbamer B.

Climate warming provokes changes in species diversity, abundance and community composition with time, especially at high altitudes. Long-term observations are indispensable to record these changes and to predict the consequences. Within a long-term monitoring project in the western Dolomites, plant species diversity and frequency were investigated after 5, 7, and 14 years along an elevation gradient, including four summits from the treeline ecotone ( $2199 \mathrm{~m}$ a.s.l.) to the lower alpine - (2463 $\mathrm{m}$ a.s.I.), upper alpine - (2757 $\mathrm{m}$ a.s.l.) and subnival zone (2893 $\mathrm{m}$ a.s.l.). Summit areas and permanent plots of $1 \mathrm{~m}^{2}$ were analysed. After 14 years, the highest increases in species numbers were detected at the highest summit. Frequency of most species increased in the $\mathrm{m}^{2}$ plots at the lower and upper alpine summits. At the treeline ecotone most species showed a decreasing frequency while competitive graminoids and species with a montane-centred distribution increased. Interestingly, mean frequency decreased also at the highest summit when comparing the first and the last census, but cushion plants were able to considerably enhance their occurrence during this period. At all summits, the newcomers were found to be of more thermophilic character compared to the resident species.

\section{Assessment of climate change effects on mountain ecosystems through a cross-site analysis in the Alps and Apennines}

Rogora M., Frate L., Carranza M.L., Freppaz M., Stanisci A., Bertani I., Bottarin R., Brambilla A.,

Canullo R., Carbognani M., Cerrato C., Chelli S., Cremonese E., Cutini M., DiMusciano M., Erschbamer B., Godone D., locchiM., Isabellon M., Magnani A., Mazzola L., Morra di Cella U., Pauli H., Petey M., Petriccione B., Porro F., Psenner R., Rossetti G., Scotti A., Sommaruga R., Tappeiner U., Theurillat J.-P.,Tomaselli M., Viglietti D., Viterbi R., Vittoz P., Winkler M., Matteucci G.

Mountain ecosystems are sensitive and reliable indicators of climate change. Long-termstudies may be extremely useful in assessing the responses of high-elevation ecosystems to climate change and other anthropogenic drivers from a broad ecological perspective. Mountain research sites within the LTER (Long-Term Ecological Research) network are representative of various types of ecosystems and span a wide bioclimatic and elevational range. Here, we present a synthesis and a review of themain results fromecological studies inmountain ecosystems at 20 LTER sites in Italy, Switzerland and Austria covering in most casesmore than two decades of observations. We analyzed a set of key climate parameters, such as temperature and snow cover duration, in relation to vascular plant species composition, plant traits, abundance patterns, pedoclimate, nutrient dynamics in soils and water, phenology and composition of freshwater biota.

The overall results highlight the rapid response of mountain ecosystems to climate change, with site-specific characteristics and rates. As temperatures increased, vegetation cover in alpine and subalpine summits increased as well. Years with limited snow cover duration caused an increase in soil temperature and microbial biomass during the growing season. Effects on freshwater ecosystemswere also observed, in terms of increases in solutes, decreases in nitrates and changes in plankton phenology and benthos communities. Thiswork highlights the importance of comparing and integrating long-term ecological data collected in different ecosystems for a more comprehensive overviewof the ecological effects of climate change. Nevertheless, there is a need for (i) adopting co-located monitoring site networks to improve our ability to obtain sound results from cross-site analysis, (ii) carrying out further studies, in particular short-term analyses with fine spatial and temporal resolutions to improve our understanding of responses to extreme events, and (iii) increasing comparability and standardizing protocols across networks to distinguish local patterns from global patterns. 


\title{
Dense image matching of terrestrial imagery for deriving high-resolution topographic properties of vegetation locations in alpine terrain
}

\author{
Niederheiser R., M. Rutzinger M., Bremer M., Wichmann V.
}

The investigation of changes in spatial patterns of vegetation and identification of potential micro-refugia requires detailed topographic and terrain information. However, mapping alpine topography at very detailed scales is challenging due to limited accessibility of sites. Close-range sensing by photogrammetric dense matching approaches based on terrestrial images captured with hand-held cameras offers a light-weight and lowcost solution to retrieve high-resolution measurements even in steep terrain and at locations, which are difficult to access. We propose a novel approach for rapid capturing of terrestrial images and a highly automated processing chain for retrieving detailed dense point clouds for topographic modelling. For this study, we modelled 249 plot locations. For the analysis of vegetation distribution and location properties, topographic parameters, such as slope, aspect, and potential solar irradiation were derived by applying a multi-scale approach utilizing voxel grids and spherical neighbourhoods. The result is a micro-topography archive of 249 alpine locations that includes topographic parameters at multiple scales ready for biogeomorphological analysis. Compared with regional elevation models at larger scales and traditional 2D gridding approaches to create elevation models, we employ analyses in a fully 3D environment that yield much more detailed insights into interrelations between topographic parameters, such as potential solar irradiation, surface area, aspect and roughness.

\section{Mapping alpine vegetation location properties by dense matching}

\author{
Niederheiser R., Rutzinger M., Lamprecht A., Steinbauer K., Winkler M., Pauli H.
}

Highly accurate 3D micro topographic mapping in mountain research demands for light equipment and low cost solutions. Recent developments in structure from motion and dense matching techniques provide promising tools for such applications. In the following, the feasibility of terrestrial photogrammetry for mapping topographic location properties of sparsely vegetated areas in selected European mountain regions is investigated. Changes in species composition at alpine vegetation locations are indicators of climate change consequences, such as the pronounced rise of average temperatures in mountains compared to the global average. Better understanding of climate change effects on plants demand for investigations on a micro-topographic scale. We use professional and consumer grade digital single-lens reflex cameras mapping 288 plots each $3 \times 3 \mathrm{~m}$ on 18 summits in the Alps and Mediterranean Mountains within the GLORIA (GLobal Observation Research Initiative in Alpine environments) network. Image matching tests result in accuracies that are in the order of millimetres in the XY-plane and below $0.5 \mathrm{~mm}$ in Z-direction at the second image pyramid level. Reconstructing vegetation proves to be a challenge due to its fine and small structured architecture and ist permanent movement by wind during image acquisition, which is omnipresent on mountain summits. The produced 3D point clouds are gridded to $6 \mathrm{~mm}$ resolution from which topographic parameters such as slope, aspect and roughness are derived. At a later project stage these parameters will be statistically linked to botanical reference data in order to conclude on relations between specific location properties and species compositions.

\section{Changes in composition, ecology and structure of high-mountain vegetation: a re-visitation study over 42 years}

\author{
Evangelista A., Frate L., Carranza M.L., Attorre F., Pelino G., Stanisci A.
}

High-mountain ecosystems are increasingly threatened by climate change, causing biodiversity loss, habitat degradation and landscape modifications. However, very few detailed studies have focussed on plant biodiversity in the high mountains of the Mediterranean. In this study, we investigated the long-term changes that have occurred in the composition, structure and ecology of high-mountain vegetation in the central Apennines (Majella) over the last 42 years. We performed a re-visitation study, using historical and newly collected vegetation data to explore which ecological and structural features have been the most successful in coping with climatic changes. Vegetation changes were analysed by comparing georeferenced phytosociological releve's collected in high-mountain habitats (dolines, gentle slopes and ridges) on the Majella massif in 1972 and in 2014. Composition analysis was performed by detrended correspondence analysis, followed by an analysis of similarities for statistical significance assessment and by similarity percentage procedure (SIMPER) for identifying which species indicate temporal changes. Changes in ecological and structural indicators were analysed by a permutational multivariate analysis of variance, followed by a post hoc comparison. Over the last 42 years, clear floristic changes and significant ecological and structural variations occurred.We observed a significant increase in the thermophilic and mesonitrophilic plant species and an increment in the frequencies of hemicryptophytes. This re-visitation study in the Apennines agrees with observations in other alpine ecosystems, providing new insights for a better understanding of the 
effects of global change on Mediterranean high-mountain biodiversity. The observed changes in floristic composition, the thermophilization process and the shift towards a more nutrient-demanding vegetation are likely attributable to the combined effect of higher temperatures and the increase in soil nutrients triggered by global change. The re-visitation approach adopted herein represents a powerful tool for studying climate-related changes in sensitive high-mountain habitats.

\title{
Hochgebirge als Hotspots der Diversität - durch den Klimawandel in Gefahr?
}

\author{
Erschbamer B., Mallaun M., Unterluggauer P.
}

With increasing altitude, species numbers decrease. Nevertheless, in comparison to lowlands, high altitude ecosystems often harbour more species and exhibit a higher number of endemics. Alpine species are considered to be particularly vulnerable to climate change. Due to global warming, cold-adapted species might disappear and lowland species with a broad ecological range invade the summits; competitive species may increase and, as consequence, new communities will develop. In order to observe the changes, long term projects are needed. In this paper, the results of two GLORIA sites, one in the Central Alps (Texelgruppe, South Tyrol, Italy) and one in the Dolomites (South Tyrol, Italy) are presented. The sites were monitored after 8 and 14 years, respectively. The following questions should be answered: (1) How does diversity change in the alpine belt of siliceous and calcareous mountains? (2) Do coldadapted species decrease and warm-adapted ones increase? (3) Which species are particularly spreading and which are shrinking? The monitoring was carried out at two scales: the summit area scale and the $1 \mathrm{~m}^{2}$ plot scale. In both study areas, the number of species increased with exception of the highest summit in the Central Alps. Diversity increase was highest at the uppermost summit in the Dolomites with 64 $\%$ increase after 14 years, the lowest changes occurred in the Central Alps with $3 \%$ increase after 8 years. In the Dolomites, the newly arriving species had significantly higher altitudinal ranks in contrast to the resident species, i.e. a thermophilization occurred. This was true also for the alpine belt in the Central Alps. Within the $1 \mathrm{~m}^{2}$ plots, the highest turnover was found at the treeline ecotone. Here, some tendencies of decreasing cold-adapted species were recognized.

In conclusion, the lower summits will experience a reforestation in the near future. According to the signs of thermophilization, the communities at the summits will change. However, due to the steepness and the scree sites at some expositions, changes will certainly be decelerated at the higher summits.

\section{Distribution of plant species and dispersal traits along environmental gradients in central mediterranean summits}

\author{
Di Musciano M., Carranza'M.L., Frate L., Di Cecco V., Di Martino L. , Frattaroli A.R., Stanisci A.
}

High-mountain ecosystems are spots of plant diversity in which species composition and traits depict a long evolutionary history of species adaptation to steep environmental gradients. We investigated the main trends in plant species composition and reproductive and dispersal traits (pollen vector, diaspore appendages, dispersal of diaspores and fruit type) in central Mediterranean summits in relation to environmental factors (altitude, aspect, debris cover and slope). Based on 114 plots, with floristic and environmental data collected in the year 2016 on alpine calcareous grasslands in the central Apennines, we explored how species composition varies in relation to environmental factors using CCA (canonical correspondence analysis). Then, we analyzed the relationships among species presence, the occurrence of reproductive and dispersal traits and environmental variables. We used for this analysis the fourth-corner model approach. Our results highlight a consistent response of floristic composition and of structural and ecological characteristics to environmental gradients, with elevation and debris cover being the most important ones. The environmental characteristics of the analyzed ecosystems (e.g., steep slopes and harsh environments) combined with the persistence of perennial plant species already present in each stand, the high precision of pollination and the prevalence of short-distance dissemination strategies should allow the calcareous endemic plant communities of the analyzed Mediterranean summits to be conserved at least for a mid-term period slowing down the expansion of the warm-adapted species, less adapted to the local environmental constrains. 


\title{
Climate and land use change impacts on Mediterranean high-mountain vegetation in the Apennines since the 1950s
}

\author{
Frate L., Carranza M. L., Evangelista A., Stinca A., Schaminée J. H., \& Stanisci A
}

Background: High-mountain ecosystems are centres of plant diversity that are particularly sensitive to land-use and climate change. Aims: We investigated the ecological trends associated with land use and climate change since the 1950s in different vegetation types in high-mountain habitats in the central Apennines. Methods: We analysed temporal changes in: Pinus mugo scrub, calcareous subalpine grasslands and alpine scree vegetation, comparing historical and recent vegetation records from vegetation plots from two periods (1955-1980 and 1990-2014) for their ecological indicator values (Landolt temperature and nutrient indicators) and structural traits (growth forms) over time using generalised linear models (GLMs). Results: We observed significant temporal differences in the ecology and structure of the analysed habitats. In the Pinus mugo scrub we detected a reduction of subalpine and herbaceous species and in calcareous alpine screes we observed an increment of the lower montane, montane and subalpine species and of dwarf shrubs. Conversely, subalpine grasslands were stable over time. Conclusions: Ecological changes that have occurred in the Central Apennines, following changes in type and intensity of land use and recent warming are consistent with those observed in other European mountains, for which climate and land-use changes are claimed as the main driving forces.

\section{Theses}

\author{
Analyse von Vegetationsstandorten im Hochgebirge mithilfe des Verfahrens des „dense matchings“ von \\ terrestrischen Schrägbildaufnahmen \\ den Outer J. \\ Supervisor: Rutzinger M., Geitner C.
}

Master's thesis examines whether fully automated "dense matching" software of close-range photogrammetry can generate sufficiently accurate 3D-models to classify and characterise vegetation areas. The study area is located at Schrankogel (Stubaier Alpen, Tirol, Austria). GLORIA (GLobal Observation Research Initiative in Alpine environments) placed square observation stations and recordings were obtained from four stations (two $3 \times 3 \mathrm{~m}, 3 \times 8 \mathrm{~m}$ and $3 \times 11 \mathrm{~m}$ ). The proper technique of image acquisition was tested by using surfaces with various vegetation covers. Two different open source software programs, Autodesk 123D Catch and VisualSfM, were used to generate 3D point clouds from terrestrial oblique images. The free software CloudCompare was used for post-processing, e.g. georeferencing the 3D point clouds. Quality and quantity assessments were performed to compare the software's results and to prove its geometrical accuracy. These analyses demonstrate that 123D Catch is characterized by a limited number of input data and geometrical errors are produced by automatic interpolation of gaps in the 3D point clouds. VisualSfM generates sufficiently accurate 3D point clouds; therefore, the 3D point clouds from VisualSfM were applied for further analysis. The Green-Red Vegetation Index (GRVI) was successfully used to classify green vegetation areas by using a calculated tolerance range of the GRVI. However, coloured vegetation (e.g. blossom) could not be identified and different vegetation types (e.g. vascular plants and mosses) could not be distinguished due to their similar GRVI values. Moreover, the comparison of the calculated vegetation cover and those which were recorded in 2014 by GLORIA, indicated that the smaller study areas $(3 \times 3 \mathrm{~m})$ showed very good matches. On the contrary, larger study areas obtained higher variations in total, but individual observation squares showed similar vegetation coverages. Topographical attributes (slope, aspect and roughness) and radiation properties (global radiation and insolation time) were calculated to characterise vegetation areas. These analyses show no significant correlation between the various parameters by using a scale of $1 \mathrm{~m}^{2}$ (one observation square). Thus, particular characteristics cannot be assigned to vegetation areas. Microscale analysis $\left(<1 \mathrm{~m}^{2}\right)$, where selected observation squares were divided into different classes (blocks, gravel, soil, vegetation and coloured vascular plants), confirmed that the study areas are homogeneous with uniformly increasing slope, approximately the same altitude, similar exposure, roughness and radiation value. Therefore, general statements about characteristics of vegetation areas at Schrankogel are not possible. So far, the "dense matching" methods have rarely been used in geosciences research. For this reason, the Master's thesis should be regarded as an experimental study. This study focuses on the traceability of the experiments by giving precise workflows from the photogrammetric image acquisition to the analysis of 3D models. 


\title{
Mapping surface types in high mountain environments of the Alps
}

\author{
Hofbauer $\mathrm{H}$. \\ Supervisor: Winkler, M.
}

Determining whether the surfaces of potential microrefugia for alpine vascular plants allow colonization requires a solid data basis. The visual estimation of surface types in permanent squares of the GLORIA network is com-pared with digital measurements in a GIS. Linear mixed-effects models are employed to examine (1) three re-gions of the Alps separately, (2) the three regions of the Alps together and (3) the Alpine regions pooled with three Mediterranean regions. The significance of the results differs depending on surface type. For example, while estimated and measured areas of the surface type vascular plants were significantly correlated in all anal-yses, none of the models for the class bryophytes were significant. The heterogeneous results can be explained by factors such as area size and frequent confusion of certain surface types. Due to the high expenses and the unreliability of the method, it is only suitable for supporting visual surface estimations.

\section{Vegetation detection in Structure-from-Motion derived 3D-models}

\author{
Kamphuis J.C. \\ Supervisor: Lindenbergh R.C., Rutzinger M.
}

A multispectral camera has been used to make NIR, RED, GRN images of GLORIA plots. These are modelled with Agisoft Photoscan (Agisoft, 2015) following a Structure from Motion approach to get orthophotos and texture atlases. Pixels of these images are classified on their NDVI response, classifying them as vegetation or rock. The resulting 3D models seem to have local errors in the order of centimetres. Global errors cannot be assessed because of a lack of reverence.

\section{Comparing two methods of recording the top cover of surface types in permanent plots on GLORIA summits in Mediterranean regions}

Klingraber $\mathrm{B}$.

Supervisor: Winkler M.

Anthropogenic greenhouse gases are likely responsible for global climate change. Especially alpine ecosystems react very sensitively to alterations and the temperature increase leads to upward shifting of alpine plants. Therefore, the research initiative GLORIA observes the surface cover types of alpine monitoring areas because they are indicators for the presence of potential microrefugia and of available space for colonization which are important factors for biodiversity. In this paper, the method of estimating the surface area of cover types in situ was compared to the method of measuring the area in geographical information systems in three Mediterranean mountain regions. In general, significant correlations between in situ and GIS areas were found in all regions for cover classes "vascular plants" and "scree" but not for cover classes "lichens" and "bryophytes". Within a region, data sets were sometimes too small to calculate linear mixed-effects models. Nevertheless, both methods are suitable to determine the size of the surface cover types in monitoring plots.

\section{Analyse des Landbedeckungswandels von Vegetationsstandorten im Hochgebirge mittels Satellitenfernerkundung}

Mayr S.

Supervisor: Geitner C., Rutzinger M.

A change in vegetation due to climate change and accompanying factors, especially in high altitude regions, has been acknowledged in recent studies. After outlining some of the prevailing drivers of this shift and the current state of research in this area, this work takes a remote sensing approach to quantify landcover-changes occurring in approximately 15 years on a regional level. Therefore Land-sat 7, Landsat 8 and Sentinel 2 satellite data aswell as corresponding auxiliary data is employed to investigate six study sites $(25 \times 25 \mathrm{~km})$ in European high altitude regions located in the Alps and the Mediterranean. After administering various pre-processing applications, the Random Forest machine learning algorithm and additional height data is utilized to classify the landcover of the six scenes into ten landcover classes. These classifications obtain accuracies exceeding $95 \%$. By executing a Change Detection on this classified data, the change in landcover is determined and can therefore be ana-lysed. Depending on location, results show versatile changes within classes. Discovered trends in the study regions indicate an expansion of alpine vegetation, most notably in more elevated and previ-ously rock-dominated areas. This is in accordance with observations of a general upward-shift of plant species under a warming climate (Pauli et al. 2012). 


\title{
Resilience and turnover in high-altitude ecosystems in Central Apennines
}

\author{
PhD thesis Dr. Alberto Evangelista
}

This P.h.D thesis investigated how and when the high-mountain vegetation in Central Apennines has changed during the last decades in relation with recent global climate and land use changes.

Multi-temporal vegetation analysis was performed based on a newly created floristic and ecological database. The database, called VIOLA (VegetatIOn of centraL Apennines), harmonizes a huge amount of published and new relevès of High Mountain Vegetation of Central Apennines. VIOLA was built with Turboveg and includes 1726 phytosociological relevés collected in the high mountains (1600 to $2900 \mathrm{~m}$ a.s.l.) of central Italy (Gran Sasso, Majella, Matese, Meta and Velino massif), during the last six decades (1955-2016) and referable to 7 habitats of European conservation concern. VIOLA is included and harmonized with other international and national vegetation databases as GIVD (Global Index of VegetationPlot Database, http://www.givd.info/ID/EU-IT-019), the European Vegetation Archive (EVA, www.euroveg.org) and the Italian national vegetation database (Vegltaly, www.vegitaly.it).

We also analyzed the data collected in permanent plots during the last 15 years (2000-2015) in central Apennines conforming with GLORIA international protocol. The results of the multi-temporal analysis underline the presence of significant changes in species composition, structure and ecology of high mountain plant communities. During the last decades, a consistent expansion of warmth demanding and nutrient demanding plant species and, a decrease of cold adapted taxa, coupled with the increase of hemicryptophytes and dwarf-shrubs occurred.

Global warming and land use change seem the major drivers of the observed structural and ecological changes in high elevation habitats. Our results confirm the usefulness of large vegetation database (such as VIOLA), for multi-temporal analysis of vegetation structure, ecology and dynamics. Vegetation databases would represent a good solution for future studies at the local, regional and European scale and would be a sound tool for monitoring vegetation and Habitats of European conservation concern in a rapidly changing world.

\section{Vegetation analysis in the permanent plots of GLORIA project in Majella National Park: a synchronic approach to identify the key species for monitoring climate change}

\author{
Dr. Michele Di Musciano - MSc Thesis. University of L'Aquila-University of Molise
}

The high mountain environments being exposed to low temperature conditions, they are generally considered particularly sensitive to climate warming, furthermore, this ecosystems gained increased scientific interest in climate change research as they allow to observe ecological effects of global warming with a minor interference of a direct human pressure (Guisan et al., 1995; Beniston et al., 1996; Grabherr et al., 1995; Gottfried et al., 2002; Pauli et al., 2003; Pauli et al., 2007). Since 2001, the highest peaks of the Majella National Park (central Apennines) are part of the biomonitoring network of GLORIA (Global Observation Research Initiative in Alpine Environments) project (Pauli et al., 2015; Stanisci et al., 2005; Stanisci et al., 2014). In the context of climate change, identifying the plant traits of newly appearing or disappearing species therefore helps us to understand these selection processes, which is important for predicting future species assemblages (Matteodo et al., 2013).

In this study, we investigated the effect of altitude and aspect in the composition, structure and ecology of high-mountain vegetation in the central Apennines, and furthermore we analyzed the dispersal traits of species, focusing especially on key species, which have been shown to be successful in a warmer world. The characterization of dispersal traits which are the principal traits that influence the upward movement capacity is still lacking on monitored plant species.

We performed this study using the data collected in 2015(Pauli et al., 2015) in three different summits in Majella National Park; we have analysed 140 plots of $1 \mathrm{~m}$ square along the vertical (elevation) and horizontal (different directions) gradient. Species composition analysis was performed by non-metric multidimensional scaling (nMDS), followed by an analysis of similarities (ANOSIM) for statistical significance assessment and by similarity percentage procedure (SIMPER) for identifying which species are more predictive for altitude and aspect changes. Changes in ecological and structural indicators were analysed by a permutational multivariate analysis of variance (PERMANOVA), followed by a post-hoc comparison.

To summarize, the aims of this work are: i) the floristic and vegetation characterization of permanent plots of summits of GLORIA project along the vertical (altitude) and horizontal (aspect) gradient. ii) the analysis of floristic similarities along the two gradients taken in account iii) the identification of key species that could play an important role facing global warming iv) the study of the dispersal ability and colonization of these key species. 


\section{Acknowledgements}

First and foremost we would like to thank the numerous persons who helped with the fieldwork in the six MediAlps regions: Agnes Dellinger, Michele Di Musciano, Veronika Fasching, Ludovico Frate, Thomas Gassner, Claudia Gstöttl, Christian Kuehs, Julia Lamprecht, Lena Nicklas, Giovanni Pelino, Norbert Sauberer, Adriano Stinca, Hermann Stockinger, Michael Suen, Peter Unterluggauer, David Wedenig, among others.

We are grateful to our interview partners for their time and for sharing their knowledge with us, to Rainer Schultheis and Peter Behofsics who undertook the longest hike of their life to interview us for a Ö1 radio program, and to the students who wrote their theses in the frame of the MediAlps project for their hard work and enthusiasm.

We thank the Majella National Park technicians and Forestry Service personnel that supported us for local displacements and the team of Schiestlhaus on Mt. Hochschwab for making us a home in the mountains.

The Austrian Academy of Sciences is acknowledged for funding in the frame of the Earth System Sciences Program and for the support throughout the project. 


\section{References}

Auer, I., Bohm, R., Jurkovic, A., Lipa, W., Orlik, A., Potzmann, R., Schoner, W., Ungersbock, M., Matulla, C., Briffa, K., Jones, P., Efthymiadis, D., Brunetti, M., Nanni, T., Maugeri, M., Mercalli, L., Mestre, O., Moisselin, J.M., Begert, M., MullerWestermeier, G., Kveton, V., Bochnicek, O., Stastny, P., Lapin, M., Szalai, S., Szentimrey, T., Cegnar, T., Dolinar, M., GajicCapka, M., Zaninovic, K., Majstorovic, Z. and Nieplova, E. (2007) HISTALP - historical instrumental climatological surface time series of the Greater Alpine Region. International Journal of Climatology 27(1), 17-46.

Barry, R.G. (1994) Mountain Environments in Changing Climates. Beniston, M. (ed), pp. 3-33, Routledge, London.

Bates, D., Maechler, M., Bolker, B., Walker, S. (2015) Ime4: Linear mixed-effects models using Eigen and S4. Journal of Statistical Software 67(1), 1-48.

Bätzing, W. (2005) Die Alpen: Geschichte und Zukunft einer europäischen Kulturlandschaft, Beck, C. H.

Beck, P.S.A., Atzberger, C., Hogda, K.A., Johansen, B. and Skidmore, A.K. (2006) Improved monitoring of vegetation dynamics at very high latitudes: A new method using MODIS NDVI. Remote Sensing of Environment 100(3), 321-334.

Becker, A., Korner, C., Brun, J.J., Guisan, A. and Tappeiner, U. (2007) Ecological and land use studies along elevational gradients. Mountain Research and Development 27(1), 58-65.

Bender, O., Borsdorf, A., Fischer, A. and Stötter, J. (2011) Climate Change - Gepphysical Foundations and Ecological Effects. Blanco, J. and Kheradmand, H. (eds), pp. 403-422, InTech.

Bobbink, R., Hicks, K., Galloway, J., Spranger, T., Alkemade, R., Ashmore, M., Bustamante, M., Cinderby, S., Davidson, E., Dentener, F., Emmett, B., Erisman, J.W., Fenn, M., Gilliam, F., Nordin, A., Pardo, L. and De Vries, W. (2010) Global assessment of nitrogen deposition effects on terrestrial plant diversity: a synthesis. Ecological Applications 20(1), 30-59.

Bobbink, R., Hornung, M. and Roelofs, J.G.M. (1998) The effects of air-borne nitrogen pollutants on species diversity in natural and semi-natural European vegetation. Journal of Ecology 86(5), 717-738.

Boutin, M., Corcket, E., Alard, D., Villar, L., Jimenez, J.J., Blaix, C., Lemaire, C., Corriol, G., Lamaze, T. and Pornon, A. (2017) Nitrogen deposition and climate change have increased vascular plant species richness and altered the composition of grazed subalpine grasslands. Journal of Ecology 105(5), 1199-1209.

Bowman, W.D., Gartner, J.R., Holland, K. and Wiedermann, M. (2006) Nitrogen critical loads for alpine vegetation and terrestrial ecosystem response: are we there yet? Ecological Applications 16(3), 1183-1193.

Bremer, M., Mayr, A., Wichmann, V., Schmidtner, K. and Rutzinger, M. (2016) A new multi-scale 3D-GIS-approach for the assessment and dissemination of solar income of digital city models. Computers Environment and Urban Systems 57, 144154.

Broll, G. and Keplin, B. (2005) Mountain ecosystems: Studies in treeline ecology, Springer, Berlin, Heidelberg.

Buhler, C. and Roth, T. (2011) Spread of common species results in local-scale floristic homogenization in grassland of Switzerland. Diversity and Distributions 17(6), 1089-1098.

Bunce, R.G.H., Pérez-Soba, M., Jongman, R.H.G., Gómez Sal, A., Herzog, F. and Austad, I. (eds) (2004) Transhumance and Biodiversity in European mountains, Report of the EU-FP5 project TRANSHUMOUNT (EVK2-CT-2002-80017). IALE publication series nr 1, pp 321.

Byg, A., Salick, J. and Law, W. (2010) Medicinal Plant Knowledge Among Lay People in Five Eastern Tibet Villages. Human Ecology 38(2), 177-191.

CH2018 (2018) Climate Scenarios for Switzerland: Technical Report, National Centre for Climate Services, Zurich.

Christensen, J.H., Hewitson, B., Busuioc, A., Chen, A., Gao, X., Held, I., Jones, R., Kolli, R.K., Kwon, W.-T., Laprise, R., Magaña Rueda, V., Mearns, L., Menéndez, C.G., Räisänen, J., Rinke, A., Sarr, A. and Whetton, P. (2007) Climate Change 2007: The Physical Science Basis. Contribution of Working Group I to the Fourth Assessment Report of the 
Intergovernmental Panel on Climate Change. Solomon, S., Qin, D., Manning, M., Chen, Z., Marquis, M., Averyt, K.B., Tignor, M. and Miller, H.L. (eds), pp. 847-940, Cambridge University Press, Cambridge.

Conrad, O., Bechtel, B., Bock, M., Dietrich, H., Fischer, E., Gerlitz, L., Wehberg, J., Wichmann, V. and Böhner, J. (2015) System for Automated Geoscientific Analyses (SAGA) v. 2.1.4.

Dirnböck, T., Dullinger, S., Gottfried, M. and Grabherr, G. (1999) Die Vegetation des Hochschwab (Steiermark) - Alpine und subalpine Stufe. Mitteilungen des naturwissenschaftlichen Vereins der Steiermark 129, 111-251.

Dullinger, S., Gattringer, A., Thuiller, W., Moser, D., Zimmermann, N.E., Guisan, A., Willner, W., Plutzar, C., Leitner, M., Mang, T., Caccianiga, M., Dirnböck, T., Ertl, S., Fischer, A., Lenoir, J., Svenning, J.-C., Psomas, A., Schmatz, D.R., Silc, U., Vittoz, P. and Hülber, K. (2012) Extinction debt of high-mountain plants under twenty-first-century climate change. Nature Climate Change 2(8), 619-622.

Earth Science Communications Team (2018) Global climate change. Vital signs of the plantet. Global temperature.

Engardt, M. and Langner, J. (2013) Simulations of future sulphur and nitrogen deposition over Europe using meteorological data from three regional climate projections. Tellus Series B-Chemical and Physical Meteorology 65, 14.

Erschbamer, B., Mallaun, M. and Unterluggauer, P. (2017) Hochgebirge als hotspots der Diversität - durch den Klimawandel in Gefahr? Ber. d. Reinh.-Tüxen-Ges. 29(53-64).

Erschbamer, B., Unterluggauer, P., Winkler, E. and Mallaun, M. (2011) Changes in plant species diversity revealed by long-term monitoring on mountain summits in the Dolomites (northern Italy). Preslia 83(3), 387-401.

Esri (2015) ARCMAP 10.3. 1.

Evangelista, A., Frate, L., Carranza, M.L., Attorre, F., Pelino, G. and Stanisci, A. (2016) Changes in composition, ecology and structure of high-mountain vegetation: a re-visitation study over 42 years. Aob Plants 8, 11 .

Frate, L., Carranza, M.L., Evangelista, A., Stinca, A., Schaminee, J.H.J. and Stanisci, A. (2018) Climate and land use change impacts on Mediterranean high-mountain vegetation in the Apennines since the 1950s. Plant Ecology \& Diversity 11(1), 8596.

Fronzek, S., Carter, T.R. and Jylha, K. (2012) Representing two centuries of past and future climate for assessing risks to biodiversity in Europe. Global Ecology and Biogeography 21(1), 19-35.

Garcia-Llorente, M., Harrison, P.A., Berry, P., Palomo, I., Gomez-Baggethun, E., Iniesta-Arandia, I., Montes, C., del Amo, D.G. and Martin-Lopez, B. (2018) What can conservation strategies learn from the ecosystem services approach? Insights from ecosystem assessments in two Spanish protected areas. Biodiversity and Conservation 27(7), 1575-1597.

Giménez-Benavides, L., Escudero, A., García-Camacho, R., García-Fernández, A., Iriondo, J.M., Lara-Romero, C. and Morente-López, J. (2018) How does climate change affect regeneration of Mediterranean high-mountain plants? An integration and synthesis of current knowledge. Plant Biology 20, 50-62.

Girardeau-Montaut, D. (2016) CloudCompare. Version 2.8

Gottfried, M., Pauli, H., Futschik, A., Akhalkatsi, M., Barancok, P., Benito Alonso, J.L., Coldea, G., Dick, J., Erschbamer, B., Fernández Calzado, M.R., Kazakis, G., Krajci, J., Larsson, P., Mallaun, M., Michelsen, O., Moiseev, D., Moiseev, P., Molau, U., Merzouki, A., Nagy, L., Nakhutsrishvili, G., Pedersen, B., Pelino, G., Puscas, M., Rossi, G., Stanisci, A., Theurillat, J.-P., Tomaselli, M., Villar, L., Vittoz, P., Vogiatzakis, I. and Grabherr, G. (2012) Continent-wide response of mountain vegetation to climate change. Nature Climate Change 2, 111-115.

Graae, B.J., Vandvik, V., Armbruster, W.S., Eiserhardt, W.L., Svenning, J.C., Hylander, K., Ehrlen, J., Speed, J.D.M., Klanderud, K., Brathen, K.A., Milbau, A., Opedal, O.H., Alsos, I.G., Ejrnaes, R., Bruun, H.H., Birks, H.J.B., Westergaard, K.B., Birks, H.H. and Lenoir, J. (2018) Stay or go - how topographic complexity influences alpine plant population and community responses to climate change. Perspectives in Plant Ecology Evolution and Systematics 30, 41-50.

Grace, J.B., Scheiner, S.M. and Schoolmaster Jr, D.R. (2015) Ecological statistics: contemporary theory and application, pp. 168 - 199, Oxford University Press, Oxford, UK. 
Grace, J.B., Schoolmaster, D.R., Guntenspergen, G.R., Little, A.M., Mitchell, B.R., Miller, K.M. and Schweiger, E.W. (2012) Guidelines for a graph-theoretic implementation of structural equation modeling. Ecosphere 3(8), 44.

Hautier, Y., Niklaus, P.A. and Hector, A. (2009) Competition for Light Causes Plant Biodiversity Loss After Eutrophication. Science 324(5927), 636-638.

Herzog, F. and Seidl, I. (2018) Swiss alpine summer farming: current status and future development under climate change. Rangeland Journal 40(5), 501-511.

Hofbauer, H. (2018) Mapping surface types in high mountain environments of the Alps. Bachelor Thesis, University of Natural Resources and Life Sciences Vienna (BOKU), Vienna, Austria.

Holman, I.P., Brown, C., Janes, V. and Sandars, D. (2017) Can we be certain about future land use change in Europe? A multi-scenario, integrated-assessment analysis. Agricultural Systems 151, 126-135.

Holtmeier, F.K. and Broll, G. (2005) Sensitivity and response of northern hemisphere altitudinal and polar treelines to environmental change at landscape and local scales. Global Ecology and Biogeography 14(5), 395-410.

Honnay, O., Verheyen, K., Butaye, J., Jacquemyn, H., Bossuyt, B. and Hermy, M. (2002) Possible effects of habitat fragmentation and climate change on the range of forest plant species. Ecology Letters 5(4), 525-530.

Isbell, F., Craven, D., Connolly, J., Loreau, M., Schmid, B., Beierkuhnlein, C., Bezemer, T.M., Bonin, C., Bruelheide, H., de Luca, E., Ebeling, A., Griffin, J.N., Guo, Q.F., Hautier, Y., Hector, A., Jentsch, A., Kreyling, J., Lanta, V., Manning, P., Meyer, S.T., Mori, A.S., Naeem, S., Niklaus, P.A., Polley, H.W., Reich, P.B., Roscher, C., Seabloom, E.W., Smith, M.D., Thakur, M.P., Tilman, D., Tracy, B.F., van der Putten, W.H., van Ruijven, J., Weigelt, A., Weisser, W.W., Wilsey, B. and Eisenhauer, N. (2015) Biodiversity increases the resistance of ecosystem productivity to climate extremes. Nature 526(7574), 574-U263.

Jacob, D., Petersen, J., Eggert, B., Alias, A., Christensen, O.B., Bouwer, L.M., Braun, A., Colette, A., Déqué, M., Georgievski, G., Georgopoulou, E., Gobiet, A., Menut, L., Nikulin, G., Haensler, A., Hempelmann, N., Jones, C., Keuler, K., Kovats, S., Kröner, N., Kotlarski, S., Kriegsmann, A., Martin, E., van Meijgaard, E., Moseley, C., Pfeifer, S., Preuschmann, S., Radermacher, C., Radtke, K., Rechid, D., Rounsevell, M., Samuelsson, P., Somot, S., Soussana, J.-F., Teichmann, C., Valentini, R., Vautard, R., Weber, B. and Yiou, P. (2014) EURO-CORDEX: new high-resolution climate change projections for European impact research. Regional Environmental Change 14(2), 563-578.

Jonsson, P., Cai, Z.Z., Melaas, E., Friedl, M.A. and Eklundh, L. (2018) A Method for Robust Estimation of Vegetation Seasonality from Landsat and Sentinel-2 Time Series Data. Remote Sensing 10(4), 13.

Kamphuis, J.C. (2015) Vegetation detection in Structure-from-Motion derived 3D-models. BSc Thesis, Delft University of Technology, Netherlands.

Karger, D.N., Conrad, O., Böhner, J., Kawohl, T., Kreft, H., Soria-Auza, R.W., Zimmermann, N.E., Linder, H.P. and Kessler, M. (2017) Climatologies at high resolution for the earth's land surface areas. Scientific Data 4, 170122.

Kirchner, M., Jakobi, G., Feicht, E., Bernhardt, M. and Fischer, A. (2005) Elevated NH3 and NO2 air concentrations and nitrogen deposition rates in the vicinity of a highway in Southern Bavaria. Atmospheric Environment 39(25), 4531-4542.

Klingraber, B. (2018) Comparing two methods of recording the top cover of surface types in permanent plots on GLORIA summits in Mediterranean regions. Bachelor Thesis, Natural Resources and Life Sciences Vienna (BOKU), Vienna, Austria.

Körner, C. (2000) The alpine life zone under global change. Gayana Botanica 57(1), 1-17.

Körner, C. (2003) Alpine plant life: functional plant ecology of high mountain ecosystems, Springer, Berlin, Heidelberg.

Körner, C. and Spehn, E.M. (eds) (2002) Mountain biodiversity: a global assessment, Parthenon Publishing, London, New York.

Lamprecht, A., Pauli, H., Fernández Calzado, M.R., Molero-Mesa, J., Bardy-Durchhalter, M., Gattringer, A., Moser, D., Steinbauer, K. and M., W. (in prep.) Climate driven changes of high mountain plant communities at the cold edge of southern Europe. 
Lamprecht, A., Semenchuk, P.R., Steinbauer, K., Winkler, M. and Pauli, H. (2018) Climate change leads to accelerated transformation of high-elevation vegetation in the central Alps. New Phytologist 220(2), 447-459.

Liechti, K. and Biber, J.P. (2016) Pastoralism in Europe: characteristics and challenges of highland-lowland transhumance. Revue Scientifique Et Technique-Office International Des Epizooties 35(2), 561-575.

Locatelli, B., Lavorel, S., Sloan, S., Tappeiner, U. and Geneletti, D. (2017) Characteristic trajectories of ecosystem services in mountains. Frontiers in Ecology and the Environment 15(3), 150-159.

MacDonald, D., Crabtree, J.R., Wiesinger, G., Dax, T., Stamou, N., Fleury, P., Lazpita, J.G. and Gibon, A. (2000) Agricultural abandonment in mountain areas of Europe: Environmental consequences and policy response. Journal of Environmental Management 59(1), 47-69.

Mace, G.M., Norris, K. and Fitter, A.H. (2012) Biodiversity and ecosystem services: a multilayered relationship. Trends in Ecology \& Evolution 27(1), 19-26.

Manzano Baena, P. and Casas, R. (2010) Past, present and future of Trashumancia in Spain: nomadism in a developed country. Pastoralism 1(1), 72-90.

Mayr, S. (2017) Analyse des Landbedeckungswandels von Vegetationsstandorten im Hochgebirge mittels Satellitenfernerkundung. Master Thesis, University of Innsbruck.

Mooney, H., Larigauderie, A., Cesario, M., Elmquist, T., Hoegh-Guldberg, O., Lavorel, S., Mace, G.M., Palmer, M., Scholes, R. and Yahara, T. (2009) Biodiversity, climate change, and ecosystem services. Current Opinion in Environmental Sustainability $1(1), 46-54$.

Mountain Research Initiative EDW Working Group (2015) Elevation-dependent warming in mountain regions of the world. Nature Climate Change 5, 424-430.

MSC-W \& CCC \& CEIP (2018) EMEP Status Report 1/2018. "Transboundary particulate matter, photo-oxidants, acidifying and eutrophying components", Norwegian Meteorological Institute.

Nagy, L. and Grabherr, G. (2009) The biology of alpine habitats, Oxford University Press, Oxford, New York.

Natura 2000 (2019) Standard data form. Lefka Ori Kai Paraktia Zoni.

Netting, R.M. (1981) Balancing on an Alp: Ecological Change and Continuity in a Swiss Mountain Community, Press Syndicate of the University of Cambridge, Cambridge, New York, Melbourne.

Netting, R.M. (1990) The Ecosystem Approach in Anthropology - From Concept to Practice. Moran, E.F. (ed), pp. 229-245, University of Michigan Press, Ann Arbor.

Niederheiser, R. (in prep.) Mapping alpine vegetation location properties. PhD Thesis, University of Innsbruck, Austria.

Niederheiser, R., Rutzinger, M., Bremer, M. and Wichmann, V. (2018) Dense image matching of terrestrial imagery for deriving high-resolution topographic properties of vegetation locations in alpine terrain. International Journal of Applied Earth Observation and Geoinformation 66, 146-158.

Niederheiser, R., Rutzinger, M., Lamprecht, A., Steinbauer, K., Winkler, M. and Pauli, H. (2016) Mapping alpine vegetation location properties by dense matching. Int. Arch. Photogramm. Remote Sens. Spatial Inf. Sci. XLI-B5, 881-886.

Niu, Y.J., Yang, S.W., Zhou, J.W., Chu, B., Ma, S.J., Zhu, H.M. and Hua, L.M. (2019) Vegetation distribution along mountain environmental gradient predicts shifts in plant community response to climate change in alpine meadow on the Tibetan Plateau. Science of the Total Environment 650, 505-514.

Nogues-Bravo, D., Araujo, M.B., Errea, M.P. and Martinez-Rica, J.P. (2007) Exposure of global mountain systems to climate warming during the 21st Century. Global Environmental Change-Human and Policy Dimensions 17(3-4), 420-428.

Ohmura, A. (2012) Enhanced temperature variability in high-altitude climate change. Theoretical and Applied Climatology 110, 499-508. 
Olden, J.D. (2006) Biotic homogenization: a new research agenda for conservation biogeography. Journal of Biogeography 33(12), 2027-2039.

Oliver, T.H. and Morecroft, M.D. (2014) Interactions between climate change and land use change on biodiversity: attribution problems, risks, and opportunities. Wiley Interdisciplinary Reviews: Climate Change, n/a-n/a.

Patty, L., Halloy, S.R.P., Hiltbrunner, E. and Körner, C. (2010) Biomass allocation in herbaceous plants under grazing impact in the high semi-arid Andes. Flora (Jena) 205(10), 695-703.

Pauli, H., Gottfried, M., Dullinger, S., Abdaladze, O., Akhalkatsi, M., Benito Alonso, J.L., Coldea, G., Dick, J., Erschbamer, B., Fernández Calzado, R., Ghosn, D., Holten, J.I., Kanka, R., Kazakis, G., Kollár, J., Larsson, P., Moiseev, P., Moiseev, D., Molau, U., Molero Mesa, J., Nagy, L., Pelino, G., Puşcaş, M., Rossi, G., Stanisci, A., Syverhuset, A.O., Theurillat, J.-P., Tomaselli, M., Unterluggauer, P., Villar, L., Vittoz, P. and Grabherr, G. (2012) Recent plant diversity changes on Europe's mountain summits. Science 336(353), 353-355.

Pauli, H., Gottfried, M., Lamprecht, A., Niessner, S., Rumpf, S., Winkler, M., Steinbauer, K. and Grabherr, G. (2015) The GLORIA field manual - standard Multi-Summit approach, supplementary methods and extra approaches, GLORIACoordination, Austrian Academy of Sciences \& University of Natural Resources and Life Sciences, Vienna.

Phoenix, G.K., Hicks, W.K., Cinderby, S., Kuylenstierna, J.C.I., Stock, W.D., Dentener, F.J., Giller, K.E., Austin, A.T., Lefroy, R.D.B., Gimeno, B.S., Ashmore, M.R. and Ineson, P. (2006) Atmospheric nitrogen deposition in world biodiversity hotspots: the need for a greater global perspective in assessing $\mathrm{N}$ deposition impacts. Global Change Biology 12(3), 470-476.

Porter, E.M., Bowman, W.D., Clark, C.M., Compton, J.E., Pardo, L.H. and Soong, J.L. (2013) Interactive effects of anthropogenic nitrogen enrichment and climate change on terrestrial and aquatic biodiversity. Biogeochemistry 114(1-3), 93-120.

Powers, R.F. (1990) Nitrogen mineralization along an altitudinal gradient - interactions of soil-temperature, moisture, and substrate quality. Forest Ecology and Management 30(1-4), 19-29.

R Core Team (2015) R: A language and environment for statistical computing, R Foundation for Statistical Computing, Vienna.

Ramirez-Villegas, J. and Jarvis, A. (2010) Downscaling Global Circulation Model Outputs: The Delta Method Decision and Policy Analysis Working Paper No. 1, p. 18, International Center for Tropical Agriculture (CIAT), Cali, Colombia.

Rieg, L., Wichmann, V., Rutzinger, M., Sailer, R., Geist, T. and Stotter, J. (2014) Data infrastructure for multitemporal airborne LiDAR point cloud analysis - Examples from physical geography in high mountain environments. Computers Environment and Urban Systems 45, 137-146.

Rodríguez-Rodríguez, D. and Bomhard, B. (2012) Mapping direct human influence on the world's mountain areas. Mountain Research and Development 32(2), 197-202.

Rogora, M., Frate, L., Carranza, M.L., Freppaz, M., Stanisci, A., Bertani, I., Bottarin, R., Brambilla, A., Canullo, R., Carbognani, M., Cerrato, C., Chelli, S., Cremonese, E., Cutini, M., Di Musciano, M., Erschbamer, B., Godone, D., locchi, M., Isabellon, M., Magnani, A., Mazzola, L., di Cella, U.M., Pauli, H., Petey, M., Petriccione, B., Porro, F., Psenner, R., Rossetti, G., Scotti, A., Sommaruga, R., Tappeiner, U., Theurillat, J.P., Tomaselli, M., Viglietti, D., Viterbi, R., Vittoz, P., Winkler, M. and Matteucci, G. (2018) Assessment of climate change effects on mountain ecosystems through a cross-site analysis in the Alps and Apennines. Science of the Total Environment 624, 1429-1442.

Rosenzweig, C., G. Casassa, D.J. Karoly, A. Imeson, C. Liu, A. Menzel, S. Rawlins, T.L. Root, B. Seguin, P. Tryjanowski, (2007) Climate Change 2007: Impacts, Adaptation and Vulnerability. Contribution of Working Group II to the Fourth Assessment Report of the Intergovernmental Panel on Climate Change. Parry, M.L., Canziani, O.F., Palutikof, J.P., van der Linden, P.J. and Hanson, C.E. (eds), pp. 79-131, Cambridge University Press, Cambridge, UK.

Ross, L.C., Woodin, S.J., Hester, A.J., Thompson, D.B.A. and Birks, H.J.B. (2012) Biotic homogenization of upland vegetation: patterns and drivers at multiple spatial scales over five decades. Journal of Vegetation Science 23(4), 755-770.

Rosseel, Y. (2012) lavaan: An R Package for Structural Equation Modeling. Journal of Statistical Software 48(2), 36. 
Rumpf, S.B., Huelber, K., Klonner, G., Moser, D., Schuetz, M., Wessely, J., Willner, W., Zimmermann, N.E. and Dullinger, S. (2018) Range dynamics of mountain plants decrease with elevation. Proceedings of the National Academy of Sciences of the USA 115(8), 1848-1853.

Rupnik, E., Daakir, M. and Deseilligny, M.P. (2017) MicMac-a free, open-source solution for photogrammetry. Open Geospatial Data, Software and Standards 2(1), 14.

Sala, O.E., Chapin III, F.S., Armesto, J.J., Berlow, E., Bloomfield, J., Dirzo, R., Huber-Sannwald, E., Huenneke, L.F., Jackson, R.B., Kinzig, A., Leemans, R., Lodge, D.M., Mooney, H.A., Oesterheld, M., Poff, N.L., Sykes, M.T., Walker, B.H., Walker, M. and Wall, D.H. (2000) Global biodiversity scenarios for the year 2100. Science 287, 1770-1774.

Salick, J., Biun, A., Martin, G., Apin, L. and Beaman, R. (1999) Whence useful plants? A direct relationship between biodiversity and useful plants among the Dusun of Mt. Kinabalu. Biodiversity and Conservation 8(6), 797-818.

Salick, J., Fang, Z. and Byg, A. (2009) Eastern Himalayan alpine plant ecology, Tibetan ethnobotany, and climate change. Global Environmental Change-Human and Policy Dimensions 19(2), 147-155.

Salick, J. and Ross, N. (2009) Introduction: Traditional peoples and climate change. Global Environmental Change-Human and Policy Dimensions 19(2), 137-139.

Scherrer, D. and Körner, C. (2010) Infra-red thermometry of alpine landscapes challenges climatic warming projections. Global Change Biology 16(9), 2602-2613.

Simkin, S.M., Allen, E.B., Bowman, W.D., Clark, C.M., Belnap, J., Brooks, M.L., Cade, B.S., Collins, S.L., Geiser, L.H., Gilliam, F.S., Jovan, S.E., Pardo, L.H., Schulz, B.K., Stevens, C.J., Suding, K.N., Throop, H.L. and Waller, D.M. (2016) Conditional vulnerability of plant diversity to atmospheric nitrogen deposition across the United States. Proceedings of the National Academy of Sciences of the United States of America 113(15), 4086-4091.

Stackelberg, M. (in prep. ) Modellierung und Analyse phänologischer Zeitreihen im Gebirge mit Landsat und Sentinel-2. Master Thesis, University of Innsbruck, Austria.

Steinbauer, M.J., Grytnes, J.A., Jurasinski, G., Kulonen, A., Lenoir, J., Pauli, H., Rixen, C., Winkler, M., Bardy-Durchhalter, M., Barni, E., Bjorkman, A.D., Breiner, F.T., Burg, S., Czortek, P., Dawes, M.A., Delimat, A., Dullinger, S., Erschbamer, B., Felde, V.A., Fernandez-Arberas, O., Fossheim, K.F., Gomez-Garcia, D., Georges, D., Grindrud, E.T., Haider, S., Haugum, S.V., Henriksen, H., Herreros, M.J., Jaroszewicz, B., Jaroszynska, F., Kanka, R., Kapfer, J., Klanderud, K., Kuhn, I., Lamprecht, A., Matteodo, M., di Cella, U.M., Normand, S., Odland, A., Olsen, S.L., Palacio, S., Petey, M., Piscova, V., Sedlakova, B., Steinbauer, K., Stockli, V., Svenning, J.C., Teppa, G., Theurillat, J.P., Vittoz, P., Woodin, S.J., Zimmermann, N.E. and Wipf, S. (2018) Accelerated increase in plant species richness on mountain summits is linked to warming. Nature 556(7700), 231234.

Stevens, C.J., Dise, N.B., Mountford, J.O. and Gowing, D.J. (2004) Impact of nitrogen deposition on the species richness of grasslands. Science 303(5665), 1876-1879.

Stocker, T.F., Qin, D., Plattner, G.K., Tignor, M.M.B., Allen, S.K., Boschung, J., Nauels, A., Xia, Y., Bex, V. and Midgley, P.M. (2013) IPCC 2013: Summary for Policy Makers. Climate Change 2013: The Physical Science Basis. Contribution of Working Group I to the Fourth Assessment Report of the Intergovernmental Panel on Climate Change, p. 1535, Cambridge, UK and New York.

Suttie, J.M. and Reynolds, S.G. (2003) Transhumant grazing systems in temperate Asia. Rome, F. (ed), FAO: Rome.

Tabor, K. and Williams, J.W. (2010) Globally downscaled climate projections for assessing the conservation impacts of climate change. Ecological Applications 20(2), 554-565.

Theurillat, J.-P. and Guisan, A. (2001) Potential impact of climate change on vegetation in the European Alps: A review. Climatic Change 50(1-2), 77-109.

Theurillat, J.P. (2016) Changements climatiques et évolution des écosystèmes subalpin et alpin. Mémoires de la Société Botanique de Genève 4, 23-34.

Turalioglu, F.S., Nuhoglu, A. and Bayraktar, H. (2005) Impacts of some meteorological parameters on SO2 and TSP concentrations in Erzurum, Turkey. Chemosphere 59(11), 1633-1642. 
Unterluggauer, P., Mallaun, M. and Erschbamer, B. (2016) The higher the summit, the higher the diversity changesresults of a long-term monitoring project in the Dolomites. Gredleriana 16, 5-34.

Venables, W. N., Ripley, B. D. (2002) Modern Applied Statistics with S. Fourth Edition. Springer, New York.

Wang, J., Luo, P., Yang, H., Mou, C.X. and Mo, L. (2016a) Different responses of alpine plants to nitrogen addition: effects on plant-plant interactions. Scientific Reports 6, 11.

Wang, Q., Fan, X. and Wang, M. (2016b) Evidence of high-elevation amplification versus Arctic amplification. Scientific Reports 6, 19219.

Winkler, M. et al. (in prep.) Climate change effects on species richness and composition of European mountain summits revisited.

Wood, S.N., Pya, N., Saefken, B. (2016) Smoothing parameter and model selection for general smooth models (with discussion). Journal of the American Statistical Association 111, 1548-1575.

Yager, K., Resnikowski, H. and Halloy, S. (2008) Grazing and climatic variability in Sajama national park, Bolivia. Pirineos 163, 97-109.

Zhao, Q., Li, J., Liu, J., Cuan, Y. and Zhang, C. (2019) Integrating supply and demand in cultural ecosystem services assessment: a case study of Cuihua Mountain (China). Environmental science and pollution research international.

Zimmermann, N.E., Yoccoz, N.G., Edwards, T.C., Jr., Meier, E.S., Thuiller, W., Guisan, A., Schmatz, D.R. and Pearman, P.B. (2009) Climatic extremes improve predictions of spatial patterns of tree species. Proceedings of the National Academy of Sciences of the United States of America 106, 19723-19728. 